Roberta Gonçalves Pereira Ikeda

\title{
Idade, crescimento e aspectos reprodutivos de Macrodon ancylodon (Bloch \& Schneider, 1801) na Costa Norte do Brasil
}

Dissertação apresentada ao Instituto Oceanográfico da Universidade de São Paulo, como parte dos requisitos para a obtenção do título de Mestre em Ciências, área de Oceanografia Biológica.

Orientadora:

Prof $^{\mathrm{a}}$. Dr ${ }^{\mathrm{a}}$ June Ferraz Dias

São Paulo

2003 


\title{
Universidade de São Paulo \\ Instituto Oceanográfico
}

\section{Idade, crescimento e aspectos reprodutivos de Macrodon ancylodon (Bloch \& Schneider, 1801) na Costa Norte do Brasil}

\author{
Roberta Gonçalves Pereira Ikeda
}

Dissertação apresentada ao Instituto Oceanográfico da Universidade de São Paulo, como parte dos requisitos para obtenção do título de Mestre em Ciências, área de Oceanografia Biológica.

Aprovada em 25/08/2003

Comissão Julgadora:

Prof $^{a}$. Dr ${ }^{\mathrm{a}}$. June Ferraz Dias

Prof $^{a}$. Dr ${ }^{a}$. no Instituto Oceanográfico da Universidade de São Paulo

Dr. Antônio Olinto Ávila da Silva

Dr. no Instituto de Pesca

Dra $^{\mathrm{a}}$. Eloci Peres Rios

Dr $^{\text {a }}$. pelo Instituto Oceanográfico da Universidade de São Paulo 
À memória do Prof. Dr. Yasunobu Matsuura (20/02/1942 - 19/05/2003) 
"Podemos subtrair-nos à ignorância, podemos encontrar-nos como criaturas excelentes, inteligentes e hábeis. Podemos ser livres! Podemos aprender...!".

"Só quero partilhar o que descobri mostrar a todos esses horizontes que estão à nossa frente".

"Nunca deixe de aprender, de treinar e de lutar por compreender cada vez melhor o perfeito e invisível princípio de toda a vida."

"Não creia no que seus olhos dizem. Tudo que mostram é limitação. Olhe com o entendimento, descubra o que já sabe e verá como...". 


\section{ÍNDICE}

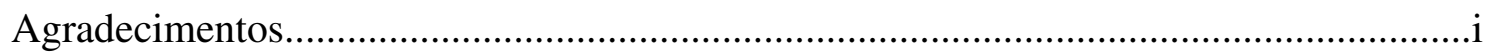

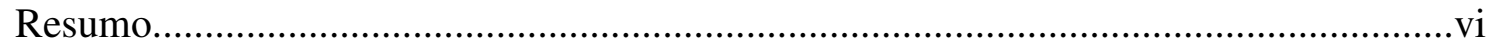

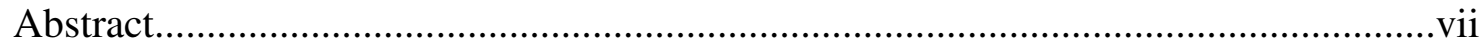

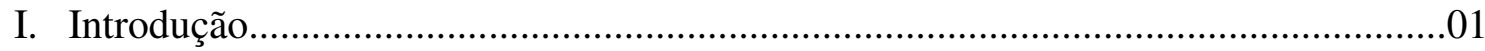

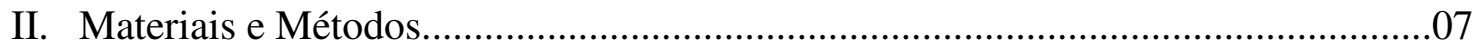

1. Dados sobre precipitação e temperatura da superfície do mar (TSM).................07

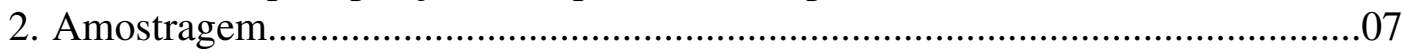

3. Tratamento das amostras.................................................................................... 10

4. Idade e crescimento da Macrodon ancylodon da costa Norte do Brasil..............12

4.1 Estimativa dos parâmetros de crescimento e da idade pelo método

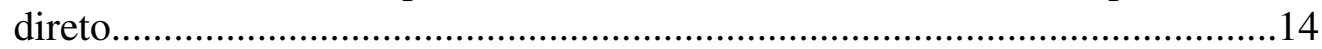

4.2 Estimativa dos parâmetros de crescimento e da idade pelo método indireto ..............................................................................................17

5. Aspectos da dinâmica reprodutiva da Macrodon ancylodon da costa Norte do

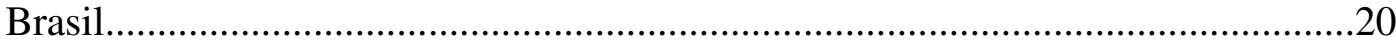

5.1 Caracterização da dinâmica reprodutiva a partir de aspectos macroscópicos ......................................................................................... 20

5.2 Aspectos microscópicos................................................................ 25

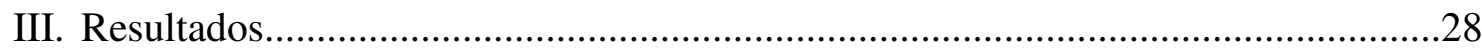

1. A precipitação na desembocadura dos rios Amazonas e Tocantins na costa Norte do Brasil e temperatura da superfície do mar (TSM) ............................................28

2. Descrição das amostras.........................................................................................29

3. Idade e crescimento da Macrodon ancylodon da costa Norte do Brasil..............32

3.1 Estimativa dos parâmetros de crescimento e da idade pelo método direto

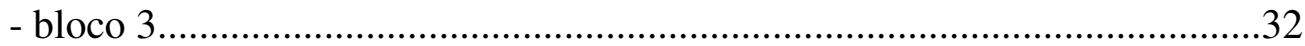

3.2 Estimativa dos parâmetros de crescimento e da idade pelo método indireto - bloco 1 ...........................................................................................

4. Aspectos da dinâmica reprodutiva da Macrodon ancylodon da costa Norte do

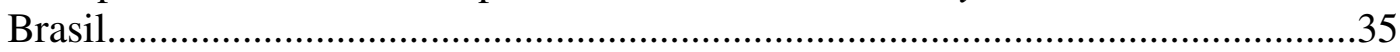

4.1 Caracterização da dinâmica reprodutiva a partir de aspectos

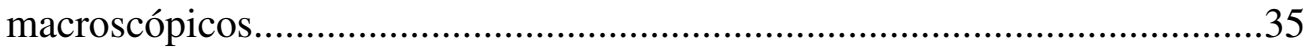

4.2 Aspectos microscópicos........................................................................38

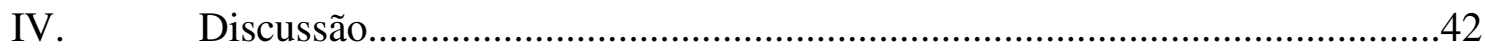

V. Síntese dos resultados e recomendações........................................................60

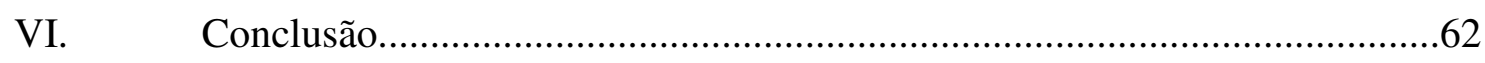

VII. Referências Bibliográficas...........................................................................63

Tabelas

Figuras 


\section{LISTA DE TABELAS}

Tabela 1: Descrição dos blocos amostrais para Macrodon ancylodon da costa Norte do Brasil. $\mathrm{N}^{\mathrm{o}}$ - número de indivíduos amostrados. .74

Tabela 2: Parâmetros da equação potencial da relação peso-comprimento de M. ancylodon da costa Norte brasileira, por sexo e período, para as amostras do bloco 2 .

Tabela 3: Parâmetros da equação potencial da relação peso-comprimento de Macrodon ancylodon da costa Norte brasileira, por período amostrado, para as amostras do bloco 2

Tabela 4: Equações das relações dos comprimentos e pesos do otólito com o comprimento e peso dos indivíduos de Macrodon ancylodon da costa Norte do Brasil. $\mathrm{L}_{\mathrm{oe}}$, comprimento do otólito esquerdo; $\mathrm{L}_{\mathrm{od}}$, comprimento do otólito direito; $\mathrm{H}_{\mathrm{oe}}$, altura do otólito esquerdo; $\mathrm{H}_{\mathrm{od}}$, altura do otólito direito; $\mathrm{W}_{\mathrm{oe}}$, peso do otólito esquerdo; $\mathrm{W}_{\mathrm{od}}$, peso do otólito direito; $\mathrm{L}_{\mathrm{t}}$, comprimento total do peixe; e $\mathrm{W}_{\mathrm{t}}$, peso total do peixe......46

Tabela 5: Classificação microscópica para gônadas de $M$. ancylodon avaliadas macroscopicamente como "B", a partir da presença de fases ovocitárias. .77

Tabela 6: Ocorrência das estruturas derivadas dos folículos ovarianos de M. ancylodon da costa Norte do Brasil por período, para gônadas avaliadas macroscopicamente como "B" .78 
Tabela 7: Resumo de alguns dos parâmetros de crescimento para diferentes populações de Macrodon ancylodon na costa brasileira...........................................78

Tabela 8: Épocas de desova de Macrodon ancylodon. As marcas maiores (X) correspondem a épocas de pico de desova, enquanto as menores (x) indicam que está ocorrendo desova de alguns indivíduos da população....................................................79

Tabela 9: Descrição de alguns parâmetros reprodutivos para diferentes populações de M. ancylodon para a costa brasileira. 80 


\section{LISTA DE FIGURAS}

Figura 1: Macrodon ancylodon (Bloch \& Schneider, 1801) da costa Norte do Brasil. .81

Figura 2: Mapa da área de estudo (costa Norte do Brasil), com a indicação dos locais de desembarques pesqueiros onde foram realizadas as amostragens para este trabalho. .82

Figura 3: Média mensal da precipitação de chuvas no período de 1966 a 2001, nas estações localizadas próximas às desembocaduras dos rios Amazonas e Tocantins. Fonte: INMET. 82

Figura 4: Temperatura da superfície do mar (TSM) referente a: A) junho de 1998; B) setembro de 1998; C) dezembro de 1999 e. Dados fornecidos pelo PODAAC/JPL .83

Figura 5: Distribuição da freqüência de classes de comprimento total $(\mathrm{cm})$ para indivíduos de M. ancylodon da costa Norte do Brasil provenientes da atividade artesanal (emalhe) do bloco amostral 1 84

Figura 6: Distribuição de frequiência de classes de comprimento total $(\mathrm{cm})$ para indivíduos de M.ancylodon da costa Norte do Brasil provenientes da atividade artesanal (curral - cerco fixo) do bloco amostral 1

Figura 7: Descrição das capturas em número de indivíduos por classe de comprimento e por arte de pesca das amostras do bloco 1, para $M$. ancylodon da costa Norte brasileira. .90 
Figura 8: Distribuição de freqüência de classes de comprimento (Lt) para indivíduos de M. ancylodon da costa Norte do Brasil provenientes das amostras do bloco 2 91

Figura 9: Relação peso-comprimento de Macrodon ancylodon para as amostras do bloco 2 .

Figura 10: Distribuição de frequiência de comprimento total $(\mathrm{cm})$ para indivíduos de M.ancylodon da costa Norte do Brasil provenientes das amostras do bloco 3. .94

Figura 11: Relação peso-comprimento para sexos grupados de Macrodon ancylodon da costa Norte do Brasil para as amostras do bloco 3. .95

Figura 12: Otólito sagita esquerdo inteiro de Macrodon ancylodon (Bloch \& Schineider, 1801) da costa Norte do Brasil. Lo = comprimento total do otólito $(\sim 12,25 \mathrm{~mm})$, Ho = altura do otólito $(\sim 5,00 \mathrm{~mm})$ e $\mathrm{A}=$ denticulações .96

Figura 13: Equações matemáticas que descrevem o crescimento em peso e comprimento de Macrodon ancylodon da costa Norte do Brasil. Loe - comprimento do otólito esquerdo; Lod - comprimento do otólito direito; Hoe - altura do otólito esquerdo; Hod altura do otólito direito; Woe - peso do otólito esquerdo; Wod - peso do otólito direito; $\mathrm{Lt}$ - comprimento total do peixe; $\mathrm{Wt}$ - peso total do peixe. .97

Figura 14: Gráficos dos resíduos da regressão linear das medidas dos otólitos de M. ancylodon da costa Norte do Brasil. .98

Figura 15: A) Diagrama de dispersão dos dados de comprimento total e os valores de anéis em secções de otólitos para indivíduos com o primeiro raio na amplitude de 0,75 0,85 mm em relação ao núcleo. B) Diagrama de dispersão dos dados de comprimento 
total e os valores dos raios de anéis em secções de otólitos para indivíduos com o primeiro raio na amplitude de 0,65 - 0,70 mm em relação ao núcleo

Figura 16: Incremento marginal médio dos otólitos de Macrodon ancylodon da costa Norte do Brasil, por grupo de anéis e por período de ocorrência. Os números representam o número de otólitos analisados 100

Figura 17: Porcentagem do tipo de bordo por período amostrado para Macrodon ancylodon da costa Norte do Brasil. TR - translúcido; O - opaco. 101

Figura 18: Curvas de crescimento das coortes calculadas através do sistema ELEFAN I (pacote computacional FISAT) para Macrodon ancylodon da costa Norte do Brasil. 102

Figura 19: Ajuste da equação de crescimento de von Bertalanffy para Macrodon ancylodon na costa Norte do Brasil a partir dos dados estimados pelo método indireto para sexos grupados. Coorte $01 \quad-\quad$ junho e coorte 02 dezembro 103

Figura 20: Proporção sexual de $M$. ancylodon da costa Norte do Brasil no período de 1998 a 1999 104

Figura 21: Proporção sexual mensal de M. ancylodon da costa Norte do Brasil para o período de 1998 a 1999. * significamente diferente ao nível de 5\% 104

Figura 22: Proporção sexual de $M$. ancylodon da costa Norte do Brasil por classe de comprimento para o período de 1998-1999. * significamente diferente ao nível de $5 \%$ 104 
Figura 23: Freqüência de ocorrência dos estádios de maturidade para fêmeas de $M$. ancylodon da costa Norte do Brasil, para o período de 1998 a 1999. 105

Figura 24: Distribuição da freqüência relativa de fêmeas adultas da espécie Macrodon ancylodon da costa Norte do Brasil segundo comprimento total. A curva sigmóide representa o ajuste do modelo logístico para estimativa de $\mathrm{L}_{50}$ e $\mathrm{L}_{100}$ 105

Figura 25: Variação temporal da relação gonadossomática das fêmeas de Macrodon ancylodon da costa Norte do Brasil 106

Figura 26: Variação temporal da diferença entre as relações gonadossomáticas RGS 1 e RGS2 para fêmeas de Macrodon ancylodon da costa Norte do Brasil. 106

Figura 27: Variação temporal da relação gonadossomática das fêmeas de Macrodon ancylodon da costa Norte do Brasil utilizando os valores dos indivíduos maiores que o comprimento médio de início de primeira maturação gonadal. 107

Figura 28: Variação temporal da diferença entre as relação gonadossomática das fêmeas Variação temporal da diferença entre as relação gonadossomática das fêmeas de Macrodon ancylodon da costa Norte do Brasil, utilizando os valores dos indivíduos maiores que o comprimento médio de início de primeira maturação gonadal .107

Figura 29: Variação temporal do fator de condição das fêmeas de Macrodon ancylodon da costa Norte do Brasil 108

Figura 30: Variação temporal da diferença entre os valores do fator de condição para fêmeas de Macrodon ancylodon da costa Norte do Brasil 108 
Figura 31: Distribuição do diâmetro dos ovócitos da M. ancylodon da costa Norte do Brasil. tomados a partir da leitura em preparações permanentes sobre microscopia de luz (micro) e de ovócitos dissociados sob estereomicroscópio (macro). 109

Figura 32: Corte de ovário $\mathrm{B}_{1}$ de Macrodon ancylodon da costa Norte do Brasil, onde se observam ovócitos nas fases 2, 3, 4 e 5, com ausência de folículos pós-ovulatórios e folículos atrésicos. Aumento $4 \mathrm{x}$ 110

Figura 33: Corte de ovário $\mathrm{B}_{1}$ de Macrodon ancylodon da costa Norte do Brasil, onde se observam ovócitos nas fases 2, 3, 4 e 5, com ausência de folículos pós-ovulatórios e folículos atrésicos. Aumento $4 \mathrm{x}$ 110

Figura 34: Corte de ovário $\mathrm{B}_{\mathrm{n}}$ de Macrodon ancylodon da costa Norte do Brasil, onde se observam folículos pós-ovulatórios e folículos atrésicos. Aumento 10x 111

Figura 35: Corte de ovário $\mathrm{B}_{\mathrm{n}}$ de Macrodon ancylodon da costa Norte do Brasil, onde se observam folículos pós-ovulatórios e folículos atrésicos. Aumento 10x 111

Figura 36: Corte de ovário $\mathrm{B}_{\mathrm{n}}$ de Macrodon ancylodon da costa Norte do Brasil, onde se observam folículos pós-ovulatórios e folículos atrésicos. Aumento 10x 112 


\section{Agradecimentos}

Agradeço ao magnífico Criador de todas as coisas do mundo, por ter me dado vida, saúde, discernimento, paciência, alegria, disposição e, principalmente, por ter me colocado no meio de pessoas tão maravilhosas, para que desta forma pudesse me tornar um ser humano mais digno.

À ilustre pessoa que depositou confiança em mim no início desta trajetória, mas que, por um infortúnio da vida, terminou sua jornada sem ver este fim. Prof. Yasunobu Matsuura, agradecimentos são poucos para expressar a saudade, o carinho e a admiração que tenho por ti. Muito ficou sem dizer ... Muitos ficaram sem aprender ... Meu grande e eterno obrigada.

À Prof ${ }^{a}$. Dra June Ferraz Dias, por ter-me acolhido no momento tão difícil e ter-me contagiado com sua empolgação, mostrando que o aprendizado é contagiante e inovador. Obrigada pela mão constantemente estendida.

Agradeço aos meus pais que, durante toda minha jornada, acreditaram $e$ incentivaram meu caminhar, em especial minha mãe, que mostrou, através de suas atitudes, que podemos chegar lá, basta apenas acreditar.

Ao meu esposo Hilton, meu maior incentivador, que, por inúmeras vezes e como ninguém, soube compreender minha ausência física e espiritual. Obrigada por tudo.

À minha adorada irmã, Flávia, que, do seu modo, deu-me forças nos momentos de angústia, mesmo sem saber. 
À minha mais amada criança, meu sobrinho e afilhado Victor, por me mostrar, mesmo sendo tão pequenininho, que devemos fazer do ato de aprender algo constante e excitante... que cada descoberta é um mundo mágico e novo.

À Suzuki, pela sabedoria com que me ensinou, pela mão amiga no tratamento das amostras, pelo senso científico e estético, por tão sabiamente me fez ver e compreender os dois lados da vida. Obrigada.

Ao Programa REVIZEE/NO, na pessoa do Dr. Maâmar El-Robrini, pela confiança de ter-me cedido tão gentilmente as amostras deste trabalho.

Ao CEPNOR/IBAMA, nas pessoas de seu chefe Ítalo Araruna Vieira e da Rosália Cutrim Souza, pela gentileza e confiança de ter me cedido a maior parte das amostras deste trabalho através do Programa REVIZEE/N, assim como o uso das instalações físicas e, principalmente, da amizade.

Ao CNPq, pelo auxílio financeiro durante este trabalho.

Ao Instituto Brasileiro de Meteorologia, pelo fornecimento dos dados de precipitação.

Aos meus colegas de sala, Michael e Venâncio, pelos grandes momentos de descontração.

À minha mais solidária e companheira amiga, Lidiane de Almeida Teixeira (Lidi), que soube como ninguém compreender minhas angústias, meus medos, meus questionamentos da ciência e da existência. Aprender que dividir 
alegrias e tristezas nos faz sentirmos muito melhor. Obrigada simplesmente por ser minha amiga. Ah! Vale lembrar também da hospedagem que não tinha fim. Que paciência!

À minha doce e desesperada amiga Carolina Pacheco Bertozzi, cuja garra e destemor mostrou-me que podemos rever sempre o que somos capazes. Obrigada pela unipresença. Mesmo morando distante, sua amizade $e$ companheirismo me ajudou muito, principalmente nos meses finais desta dissertação.

Ao Márcio, "Bãrcio", pelo seu carinho e por estar sempre pronto para ajudar, esquecendo muitas vezes de si mesmo.

$\grave{A}$ D. Francisca e ao Sr. Ikeda pela grande força e torcida.

Ao meus amigos Andréa Tascheto Sardinha e Marlos Pereira Góes, pela companhia em diversos momentos e pela tão preciosa mão amiga nos momentos críticos. Meus agradecimentos.

Ao meu socorro mor, Tuca, pelo grande auxílio na análise dos dados, na discussão dos resultados, pela sua eterna preocupação, que ultrapassou a razão de querer apenas ajudar. Meu eterno obrigado à minha informalmente co-orientadora.

A todos os funcionáros da biblioteca, em especial a Cris, Cida, Cido, Maria, Glorinha, Claudinha, Raimunda, pela simpatia e amizade que nos tratam, e pela 
grande torcida, parecendo mais pais de alunos que funcionários desta instituição.

Às meninas da secretaria da pós (Silvana, Ana Paula e mais recentemente a pequena Geovana), que sempre estiveram prontas a nos atender com espirito de alegria e dedicação. Não posso deixar de mencionar aqui o Jorge, a primeira pessoa que conversei e conheci no IO. Valeu! Cheguei aqui!

A todos do laboratório da Profa. Carmem, que tão gentilmente cederam o espaço e equipamentos necessários a este trabalho, e por terem me recebido com alegria e cordialidade.

A todos que indiretamente ou diretamente ajudaram este trabalho a ser concluído: Rita, Paula Gênova, Janine, Edilson, Cristina, Ricardo Nonaka, Lurdes, Kika, Gabriel, Sr. Amaro, Cacá, Didi e cia.

À Adriana Figueiredo Fonseca, pela preocupação na aquisição das amostras e tudo o mais que fosse preciso. Você foi e é preciosa, amiga.

Ao meu eterno amigo do peito e irmão camarada, Marcelo Cunha Bahia, que sempre me faz retornar ao início da nossa jornada na qual tudo é possível, onde os sonhos podem ser realizados.

Aos amigos Andréa Crocetti, Débora Noleto e Carlos que sempre incentivaram a caminhar nesta direção. 
Um agradecimento especial faço aos meus maravilhosos amigos do Coral Mokiti Okada São Paulo A. Vocês se tornaram parte da minha vida e sem seus carinhos, sem vocês, com certeza não teria conseguido ir tão longe. Em especial quero agradecer à Isabel Abdala, à Maria Raimunda, ao Roberto Carlos e à Lenir pela eterna força e amizade.

O medo é imenso de deixar de citar pessoas que são muito queridas e que, de alguma forma, contribuiu para que este trabalho se tornasse realidade. Minhas desculpas e meus sinceros agradecimentos. 


\section{RESUMO}

Macrodon ancylodon é um cienídeo demersal distribuído desde a Venezuela até a costa Nordeste do Brasil, sendo um dos principais recursos pesqueiros da costa Norte brasileira. Este trabalho estimou os parâmetros de crescimento, através de métodos diretos e indiretos, assim como descreveu os aspectos reprodutivos utilizando análises macro- e microscópicas dos ovários. As amostras foram obtidas no período de 1998 a 2001, provenientes de atividades pesqueiras industriais e artesanais na costa Norte. Para o estudo do crescimento, pelo método direto, foram realizados cortes transversais dos otólitos sagittae, e, para o método indireto, distribuições modais da frequiência de comprimento. Os parâmetros de crescimento para duas coortes encontradas foram: coorte 1) $\mathrm{L}_{\infty}=47,4 \mathrm{~cm}, \mathrm{k}=0,42$ e $\mathrm{t}_{\mathrm{o}}=-0,3442$; coorte 2) $\mathrm{L}_{\infty}=46,8 \mathrm{~cm}, \mathrm{k}=0,44$ e $\mathrm{t}_{\mathrm{o}}=-$ 0,3302, nascidas em junho e dezembro, respectivamente. As avaliações qualitativas e quantitativas das gônadas indicaram que o período de desova é prolongado, com picos em julho-agosto e dezembro-fevereiro, coincidindo com o final do período de transição do regime de pluviosidade. As fêmeas atingem o comprimento médio de início de primeira maturação gonadal $\left(\mathrm{L}_{50}\right)$ aos $25,08 \mathrm{~cm}$, com 1,5 anos de idade, e todas estão participando do processo reprodutivo ao atingir $34,00 \mathrm{~cm}\left(\mathrm{~L}_{100}\right)$. O estudo histológico indicou existência de estádios maturacionais intermediários aos da classificação macroscópica bem como erros na identificação macroscópica do estádio "B", da ordem de $40 \%$.

Palavras-chaves: Macrodon ancylodon, crescimento, idade, reprodução, histologia. 


\begin{abstract}
Macrodon ancylodon is a demersal marine Sciaenidae largely distributed along the Brazilian coast. It is one of the major fisheries resources, mainly in the Northern and Southern regions of the Brazil. This work aims to estimate the growth parameters trough direct and indirect methods as well as estimate the reproductive aspects trough macroscopic and microscopic analyses of the gonads. The samples were obtained in the 1998-2001 period, derived from industrial and artisanal fishing activities that work along the Northern Brazilian coast. In order to conduct the growth study by the direct method, transversal sections were employed over the otolith sagitta. By the indirect method the length frequency modal distribution were observed during the period. The histological study was conducted on macroscopically classified females "semi-mature". It was verified the variation of the gonadosomatic relationship, the variation of the condition factor and the frequencies of the maturation stages. The growth parameters couldn't be estimated due to the absence of modal distribution in the length frequency and because the otolith sections were unreadable. The macroscopic valuation indicate a prolonged spawning season and has peaks in June-July and November-December, which coincide with the transition of the pluviometric period. The histological study indicate that the female enter this stages "semi-mature" more than once per cycle. The female reach the first maturation mean length $\left(\mathrm{L}_{50}\right)$ of $25,08 \mathrm{~cm}$ and all of them participate in the reproductable process when reach $34,00 \mathrm{~cm}\left(\mathrm{~L}_{100}\right)$.
\end{abstract}

Key words: growth, otolith, age, reproduction, gonad, histology 


\section{INTRODUÇÃO}

Os recursos pesqueiros são considerados recursos naturais renováveis e seu uso racional é fundamental para garantir seu aproveitamento futuro. Nos últimos 20 anos, a produção mundial de pescados marinhos cresceu a uma taxa anual de 2,3\%, chegando a 86 milhões de toneladas em 1997. Esse volume, porém, indica apenas o pescado aproveitado. Na verdade, a pesca comercial tira do mar - e descarta - uma enorme quantidade de peixes sem valor comercial: em 1994, esse descarte atingiu 27 milhões de toneladas. Os dois números permitem estimar que a produção total de pescados dos oceanos (ou a retirada de biomassa) ultrapassa 100 milhões de toneladas ao ano (Matsuura, 2001). Com este grande volume de produção, torna-se necessário um gerenciamento adequado desses recursos.

Nesse sentido, a pesquisa pesqueira fornece subsídios que contribuem para o melhor desenvolvimento desta atividade. Atualmente, pode-se observar um aumento de estudos referentes à biologia pesqueira de espécies com valor comercial, principalmente nas regiões tropicais e subtropicais, e sua relação com os fatores bióticos e ambientais (Matsuura, 1981; Jablonski \& Matsuura, 1985; Matsuura, 1986; Franks et al., 1999; Castro, 2000; Powell et al., 2000; Campana, 2001).

É atribuída à pesquisa pesqueira a função de estimar o rendimento máximo sustentável (MSY - maximum sustainable yield) de espécies de interesse comercial. Segundo Lowe-McConnell (1987), isto envolve o conhecimento das espécies de peixes presentes numa dada área e de suas dinâmicas populacionais; de quão rápido os peixes crescem e se reproduzem; do tamanho e em que idade desovam; de suas taxas e causas de mortalidade; de seus movimentos migratórios e outras variáveis. 
Informações sobre idade estão dentre as mais importantes variáveis biológicas, formando a base para cálculos de taxas de crescimento e de mortalidade, produtividade e até mesmo para as abordagens mais complexas, como a análise da população virtual (VPA - virtual population analysis) (Campana, 2001).

Para a avaliação de um estoque são necessárias, além das informações sobre idade, aquelas informações sobre a dinâmica reprodutiva. Segundo Isaac-Nahum (1981), as particularidades sobre a reprodução, assim como o número de ovócitos depositados pela população "desovante", determinarão o número de indivíduos que ingressarão na população a cada ano e influenciarão a dinâmica populacional como um todo.

Um período de particular interesse no ciclo reprodutivo de uma espécie é a época de desova, na qual todos os gametas estão aptos a serem liberados pelas gônadas (King, 1995). Além disso, essa liberação pode ser desencadeada por estímulos, ou uma combinação destes, os quais induzem gônadas imaturas ou em repouso a se tornarem ativas. Estes estímulos podem ser provocados tanto por fatores endógenos, como eventos internos relacionados ao crescimento e maturidade, quanto por fatores exógenos, como luz, salinidade, disponibilidade de alimento, fases lunares, precipitação e, mais comumente, temperatura.

Em função da importância de conhecer a dinâmica dos estoques de interesse econômico, Macrodon ancylodon surge no cenário regional da costa Norte do Brasil como uma espécie de relativa importância, tanto pelo volume capturado quanto pelo consumo humano da população local.

A espécie Macrodon ancylodon (Fig. 1) é um cienídeo demersal marinho com ampla distribuição geográfica, ocorrendo desde as águas tropicais da Venezuela até as águas subtropicais da Argentina (Lowe-McConnell, 1966; Martins-Juras, 1980; 
Menezes \& Figueiredo, 1980), podendo as larvas e jovens serem encontrados em águas estuarinas (Sinque, 1977; Lowe-McConnell, 1999; Zorro, 1999). Os locais de maior abundância dessa espécie encontram-se em duas regiões: norte do continente sulamericano e região Sul do Brasil (Yamaguti, 1979).

Por ser um peixe com uma ampla distribuição, diversas denominações vulgares são encontradas para $M$. ancylodon tais como: pescadinha-gó, pescada-gó e corvina de boca-mole na região Norte; e pescadinha, pescada-foguete e pescadinha-real na região Sudeste/Sul.

Dados sobre estatística pesqueira marítima do Estado do Pará indicam que a pesca costeira da região Norte é de natureza eminentemente artesanal, perfazendo $88 \%$ de todas as atividades pesqueiras (MMA-IBAMA-CEPNOR-SECTAM, 2001). As espécies mais importantes não só pelo volume de captura, mas também pelo seu alto valor comercial, desta área, são: a pescada-amarela (Cynoscion acoupa), a serra (Scomberomus brasiliensis), a cavala (Scomberomus cavalla), o pargo (Lutjanus purpureus), a gurijuba (Arius parkeri), a pescada-gó (Macrodon ancylodon) e os tubarões (Carcharrhinus sp.). Em relação à pesca da pescada-gó, Santana (1998) relata que este recurso é capturado principalmente pela pesca artesanal através de currais (cerco fixo) e redes de emalhar. Na pesca industrial esse recurso é capturado pela frota camaroneira, compondo a fauna acompanhante.

Em oposição à pesca na região Norte brasileira, que está baseada na atividade pesqueira artesanal, as regiões Sudeste/Sul apresentam uma pesca bastante desenvolvida, com operações pesqueiras especializadas e direcionadas aos mais diferentes recursos. Castro (2000) relata que M. ancylodon é um importante recurso para a pesca comercial das regiões Sudeste/Sul do Brasil, onde é capturada principalmente por barcos de parelha. 
Estudos sobre alimentação, crescimento, reprodução e diferenciação geográfica foram realizados com a espécie, principalmente nas regiões Sudeste/Sul do Brasil, como pode ser verificado em Magro et al. (2000), que realizaram uma abrangente síntese sobre os principais trabalhos existentes acerca da biologia de $M$. ancylodon.

Na costa Norte do país, os principais trabalhos sobre a espécie iniciaram-se na década de 1980: Fernandes (1982), tratando a alimentação na Ilha de São Luis-MA; Santana (1998), realizando um minucioso levantamento bibliográfico para a espécie, estudou a biologia e pesca para o litoral do município de Salinópolis, nordeste do Estado do Pará; JICA-MPEG-IBAMA (1998), realizando análises das estruturas rígidas para estudos de crescimento; Zorro (1999), estudando a biologia e distribuição de alguns cienídeos no estuário do rio Caeté, nordeste do Estado do Pará, através das análises de crescimento pelo método indireto, reprodução e alimentação; e Santos (2002), caracterizando geneticamente a taxonomia molecular e a biogeografia da espécie para toda a costa brasileira, tendo encontrado dois grupos geneticamente distintos, um abrigando as populações da Venezuela e costas Norte e Nordeste brasileiras (grupo tropical) e outro compreendendo populações das regiões Sul e Sudeste do Brasil e da Argentina (grupo subtropical).

Tendo em vista que os trabalhos existentes sobre Macrodon ancylodon na costa Norte do Brasil foram realizados utilizando somente dados de frequiência de comprimento para estimar os parâmetros de crescimento, e observações macroscópicas das gônadas para descrever a biologia reprodutiva, este trabalho tem por objetivo estudar aspectos básicos da dinâmica populacional sobre a idade, o crescimento e a reprodução de Macrodon ancylodon da costa Norte do Brasil. Utilizando como ferramentas os métodos direto e indireto para estimar os parâmetros de crescimento e a 
histologia para estudar com detalhamento a dinâmica reprodutiva, o presente trabalho pretende fornecer subsídios para estudos posteriores sobre avaliação de estoque e para manejo apropriado deste recurso pesqueiro.

\section{Área de Estudo}

A região de estudo está situada na costa Norte do Brasil, entre a foz do rio Oiapoque $\left(52^{\circ} \mathrm{W}\right)$ e a foz do rio Parnaíba $\left(40^{\circ} \mathrm{W}\right)$ (Fig. 2). Esta região é caracterizada por uma dinâmica oceanográfica singular em relação às outras regiões do planeta (Castro \& Miranda, 1998). Ela apresenta uma ampla plataforma continental, que pode chegar a $300 \mathrm{~km}$ de extensão, uma intensa descarga de rios e um padrão de ventos e correntes oceânicas com intensa variação sazonal.

O sistema de correntes na região é caracterizado pela presença da Corrente Norte do Brasil (CNB), fluindo ao longo da quebra de plataforma. Esta corrente pode atingir uma velocidade superior a $120 \mathrm{~cm} \mathrm{~s}^{-1}$, e um transporte acima de $30 \times 10^{6} \mathrm{~m}^{3} \mathrm{~s}^{-1}$. Devido à mudança de sinal da força de Coriolis na região do Equador, a CNB sofre retroflexões em vários níveis ao atravessá-la, formando diferentes correntes que fluem para o leste da bacia. A retroflexão da CNB também é controlada pelo regime de ventos (Góes, 2001), sendo responsável pelo transporte da massa de água costeira para a região adjacente à desembocadura do rio Pará, cujo transporte provoca uma eutrofização e, consequientemente, um aumento da biomassa e produção primária de toda a porção oeste desta área (Paiva, 2001). O mesmo autor afirma que a retroflexão da Corrente Norte do Brasil é o principal fator responsável pelo processo de transporte e dispersão de nutrientes na costa do Estado do Amapá.

$\mathrm{Na}$ região equatorial, os ventos alísios de sudeste e nordeste se encontram numa região conhecida como Zona de Convergência Intertropical (ZCIT). Esta região é caracterizada por forte precipitação devido à convecção provocada pelo encontro dessas 
frentes. A ZCIT tem uma forte variação sazonal, e se encontra mais ao norte nos meses de agosto-setembro, e mais próxima ao equador nos meses de março-abril (Molinari et al., 1986).

A hidrografia da plataforma continental é dominada pela intrusão de água doce vinda da descarga do rio Amazonas $\left(1 \times 10^{5}\right.$ a $\left.2 \times 10^{5} \mathrm{~m}^{3} \mathrm{~s}^{-1}\right)$, que se mistura com as águas salinas provenientes do oceano (Geyer et al., 1991). Esta intrusão de água doce, que é fortemente influenciada pelas marés e ventos locais, transporta enorme quantidade de sedimentos e nutrientes. Estes, por sua vez, enriquecem as águas costeiras, influenciando a distribuição espacial dos organismos na região. Segundo Figueiredo $e t$ al. (1991), a descarga do rio Amazonas na plataforma continental atinge uma média de $1,8 \times 10^{5} \mathrm{~m}^{3} \mathrm{~s}^{-1}$ de água doce, variando sazonalmente com máximo de $2,5 \times 10^{5} \mathrm{~m}^{3} \mathrm{~s}^{-1} \mathrm{em}$ maio e mínima de $1,2 \times 10^{5} \mathrm{~m}^{3} \mathrm{~s}^{-1}$ em novembro. Esta água costeira, enriquecida de nutrientes e resultante do encontro das águas do rio Amazonas com as águas tropicais, exerce uma pequena influência sobre a costa do Amapá e uma grande influência sobre a área adjacente à desembocadura do rio Pará (Paiva, 2001). 


\section{II - MATERIAIS E MÉTODOS}

\section{1- Dados sobre precipitação e temperatura da superfície do $\operatorname{mar}(\mathrm{TSM})$}

Os dados de precipitação média mensal foram obtidos de oito estações meteorológicas localizadas nas proximidades das desembocaduras dos rios Amazonas e Tocantins no período de 1966 a 2001 (fonte: Instituto Nacional de Meteorologia INMET). A partir destes dados foi realizada a climatologia anual conforme Silva (1989), utilizando os valores médios de precipitação mensal (mm) para todo o período, entre 1966 e 2001.

Os dados de temperatura da superfície do mar, gerados a partir de informações coletadas pelo sensor AVHRR (Advanced Very-High Resolution Radiometer), foram produzidos e distribuídos pelo Physical Oceanography Distributed Active Archive Center do Jet Propulsion Laboratory / NASA (National Aeronautics and Space Administration), no formato HDF (Hierarchical Data Format).

\section{2 - Amostragem}

As operações pesqueiras realizadas comercialmente na região estudada podem ser separadas em duas categorias: (1) local, ou pequena-escala, ou pesca artesanal, e (2) de larga-escala ou pesca industrial. A pesca artesanal é caracterizada por operações pesqueiras que utilizam diversos tipos de artes de pesca, como o arrasto, o cerco fixo ou curral e a rede de emalhe, explorando uma grande diversidade de espécies nas regiões mais costeiras, enquanto a pesca industrial, com mais autonomia e com barcos mais potentes, opera basicamente com arrasto de fundo, concentrando suas capturas nos 
estoques de piramutaba (Brachyplatystoma vaillantii) e camarão em áreas sobre a plataforma continental (JICA-MPEG-IBAMA, 1998).

As atividade de arrasto de camarão é desenvolvida junto à superfície de fundo. Geralmente, neste tipo de atividade, o bordo inferior da rede é constituído por um cabo de aço forte, forrado ou não, lastrado com correntes de ferro e muitas vezes munido com rodelas de borracha, roletes, esferas etc. (Nédélec, 1982). Regionalmente, este tipo de operação, é realizada por uma embarcação armada com tangones, que sustentam as redes lateralmente no momento do arrasto.

Diferentemente do arrasto, o curral e a rede de emalhe não utilizam embarcação para realizar suas operações, mas para recolher o produto capturado. O curral é um tipo de armadilha constituída por estacas, ramos de árvore, panos de redes etc., que são geralmente construídos em zonas de maré, permitindo a passagem de pequenos peixes pelos espaços existentes entre as estruturas. Em oposição ao curral, a rede de emalhe utiliza vários tipos de redes que podem ser combinadas e que podem ser usadas isoladamente ou em conjunto, podendo ser armada em qualquer área. Nesta arte os peixes ficam enroscados (Nédélec, 1982).

Dados específicos, como malhagem, comprimento da rede, tamanho dos currais, capacidade dos barcos, entre outros, não estiveram disponíveis para este estudo.

As amostras deste estudo, em sua maioria, são provenientes do Programa de Avaliação do Potencial Sustentável dos Recursos Vivos da Zona Econômica Exclusiva (REVIZEE) no litoral da costa Norte do Brasil, que tem por objetivo central proceder ao levantamento dos recursos vivos da ZEE (Zona Econômica Exclusiva), levantando sua distribuição, sua abundância, sua dinâmica em função das condicionantes ambientais, estabelecendo os potenciais sustentáveis e perspectivas de exploração dos mesmos (Figueiredo et al., 2002). 
Os dados biológicos e merísticos da pescada-gó foram obtidos através de espécimes amostrados em locais de desembarques das frotas artesanal e industrial no Estado do Pará. Os dados obtidos destas amostras foram divididos em três blocos, em função da época de amostragem e tipo de análise:

Bloco 1 - Capturas comerciais da frota artesanal e industrial (Belém, Vigia, Bragança e São João de Pirabas).

A partir destas capturas, realizadas pelas atividades de pesca industrial (arrasto) e artesanal (curral e emalhe), foram tomados os dados utilizados para a estimativa da distribuição de freqüência relativa por classe de comprimento total $\left(\mathrm{L}_{\mathrm{t}}\right)$ no período de maio de 1998 a novembro de 2000. Estas informações foram obtidas no contexto do Programa REVIZEE no litoral da costa Norte do Brasil.

Bloco 2 - Capturas comerciais da frota artesanal do município de Bragança e da frota industrial do município de Belém.

Dos exemplares coletados, a partir das atividades comerciais pesqueiras (arrasto, emalhe e curral), foram tomados dados biológicos e merísticos destinados ao estudo sobre os aspectos reprodutivos dos indivíduos coletados, entre junho de 1998 e setembro de 1999. Assim como as amostras do bloco 1, as amostras deste bloco foram obtidas no contexto do Programa REVIZEE no litoral da costa Norte do Brasil.

Bloco 3 - Capturas comerciais da frota artesanal e industrial dos municípios de Bragança e Belém.

As amostras foram obtidas, na sua maioria, pelas operações de arrasto de camarões, no período de junho de 2000 a maio de 2001, exceto para os meses de dezembro de 2000 e janeiro de 2001, cujas amostras foram provenientes da pesca artesanal em área de estuário. 
Este terceiro bloco refere-se às amostras de cujos exemplares foram retirados os otólitos sagittae (sagita) e tomados os dados para estudos sobre o crescimento.

\section{3 - Tratamento das amostras}

Bloco 1 - As amostras relativas a este bloco foram obtidas nos desembarques das frotas por coletores residentes nos municípios citados. As medidas de comprimento total $\left(\mathrm{L}_{\mathrm{t}}\right)$ em centímetros, que é o comprimento da ponta do focinho até o término da nadadeira caudal, foram obtidas pelo método "measuring-card punching" (JICAMPEG-IBAMA, 1998), no qual o peixe é deitado sobre seu flanco direito em cima de uma ficha milimetrada e, com o auxílio de um objeto perfurante, é feito um furo na ficha ao final da nadadeira caudal.

Os dados de comprimento total destas amostras foram separados por arte de pesca (curral, emalhe e arrasto) e plotados em histogramas, verificando-se a distribuição de freqüência de comprimento dos indivíduos para o período amostrado.

Bloco 2 - As amostras deste bloco, destinadas ao estudo dos aspectos reprodutivos da espécie, foram examinadas logo em seguida à aquisição dos exemplares nos locais de desembarque. Após a identificação, os espécimes eram medidos em ictiômetro, sendo tomadas as medidas de comprimento total $\left(\mathrm{L}_{\mathrm{t}}\right)$ em centímetros com precisão de milímetros, e obtendo-se também o peso total $\left(\mathrm{W}_{\mathrm{t}}\right)$ em gramas.

As gônadas amostradas neste bloco foram expostas e identificado macroscopicamente o sexo e classificado o estádio de desenvolvimento gonadal, seguindo-se as descrições e a escala de maturidade gonadal elaborada por Vazzoler (1996). Após a identificação e a classificação, as gônadas foram retiradas e pesadas em 
balanças, com precisão de gramas $\left(\mathrm{W}_{\mathrm{g}}\right)$, sendo posteriormente fixadas em solução de Bouin ou Dawidson.

Foi calculada a equação potencial da relação peso-comprimento, a partir da curva elaborada com os dados obtidos dos indivíduos. Testou-se a hipótese de significância da diferença entre os parâmetros "b" e "a" resultantes da equação da relação peso-comprimento linearizada de machos e fêmeas para o período total e para cada mês, utilizando-se o teste "t" (Zar, 1999), e pacote computacional GraphPad Prism ${ }^{1}$.

Bloco 3 - Após a confirmação da identificação dos exemplares, foram medidos o comprimento total $\left(\mathrm{L}_{\mathrm{t}}\right)$ com precisão em milímetros e o peso total $\left(\mathrm{W}_{\mathrm{t}}\right)$ em gramas, sendo retirado o par de otólitos sagita.

Os otólitos sagita foram retirados da cápsula auditiva, lavados, secos e acondicionados em sacos plásticos, para posterior processamento. Neste bloco amostral não foi possível realizar a identificação do sexo e do estádio de maturação gonadal dos indivíduos, pois as amostras encontravam-se congeladas por, no mínimo, cinco meses, o que danificou completamente o conteúdo abdominal dos peixes. Qualquer tentativa de identificação poderia incorrer em classificação errônea. Portanto, todas as análises referentes a este terceiro bloco foram realizadas para sexos agrupados.

Como não foi possível identificar o sexo dos indivíduos deste bloco amostral, testou-se a hipótese de significância da diferença entre os parâmetros "b" e "a" resultantes da equação da relação peso-comprimento linearizada dos sexos agrupados das amostras dos blocos 2 e 3, utilizando-se o teste "t" (Zar, 1999), para identificar diferenças entre os exemplares capturados por artes e regiões diferentes.

\footnotetext{
${ }^{1}$ A menção da marca ou produto não implica sugestão de uso.
} 


\section{4 - Idade e crescimento de Macrodon ancylodon da costa Norte}

\section{do Brasil.}

Se a taxa de ingestão de alimento for suficientemente alta, o peixe pode, em adição ao custo energético de suas atividades metabólicas de manutenção, sintetizar novos tecidos. Este tecido pode ser mantido dentro do corpo sob a forma de crescimento somático, incluindo alguns produtos de armazenagem, ou disseminado como gametas. O crescimento e a reprodução podem ser tratados como processos complementares, que dependem de recursos limitados de energia e de nutrientes, provenientes de sua dieta alimentar (Wootton, 1990).

O crescimento pode ser definido basicamente como o ganho em peso ou aumento no comprimento do peixe ou outra dimensão linear. O crescimento é dito isométrico quando o peixe está crescendo a uma mesma taxa em todas as dimensões lineares, ou seja, quando o comprimento, a altura e a largura são proporcionais.

Registros de crescimento são encontrados em estruturas calcificadas do corpo dos peixes como escamas, otólitos, ossos ou espinhos. Para estimar o crescimento de um peixe ou de uma população de peixes são necessárias informações sobre a idade que o peixe ou a população apresentam. Nos otólitos a deposição de matriz proteica e de carbonato de cálcio sob a forma de aragonita se faz diária e sazonalmente; porém, a medida que os indivíduos crescem, a deposição se torna cada vez mais fina com conseqüente queda no limite de resolução das marcas diárias e sazonais. Ao longo do tempo, períodos de crescimento mais lento, onde a deposição é menor, ou mais rápido podem ser identificados nos otólitos através de conjuntos de marcas diárias ou sazonais, denominadas anéis de crescimento. Assim a idade pode ser avaliada pela estimativa temporal da deposição de anéis de crescimento. Outro modo de estimar a idade é através do acompanhamento das progressões modais das freqüências de comprimento de uma 
coorte. A coorte pode ser definida como um grupo de peixes de um estoque nascidos no mesmo ano (Cadima, 2000).

Segundo Lux (1971), o crescimento pode ser estudado através de três meios: pelo método direto, o qual utiliza dados de leituras de anéis de crescimento; pelo método indireto, que utiliza dados de freqüência de comprimento da população; e pela observação do crescimento de peixes com idades conhecidas.

Os estudos sobre idade e crescimento da pescada-gó realizados neste trabalho enfocaram as metodologias utilizadas pelos métodos direto e indireto para estimar os parâmetros da curva de crescimento de von Bertalanffy:

$$
\begin{aligned}
& \mathrm{L}_{\mathrm{i}}=\mathrm{L}_{\infty}\left(1-\mathrm{e}^{-\mathrm{k}(\mathrm{t} \mathrm{i}-\mathrm{to})}\right) \\
& \text { onde, } \\
& \mathrm{L}_{\mathrm{i}}=\text { comprimento na idade " } \mathrm{t}_{\mathrm{i}} \text { "; } \\
& \mathrm{L}_{\infty}=\text { comprimento assintótico, que é o comprimento médio que o peixe }
\end{aligned}
$$
alcança se ele crescer indefinidamente (Gayanilo \& Pauly, 1997);

$$
\mathrm{k}=\text { constante de crescimento ou "parâmetro de curvatura", que exprime a }
$$
velocidade com que o peixe se aproxima do seu $\mathrm{L}_{\infty}$ (Sparre \& Venema, 1997);

$\mathrm{t}_{\mathrm{o}}=$ idade hipotética na qual o tamanho do peixe é zero. Biologicamente, este parâmetro não tem significado, porque o crescimento começa a partir da eclosão, quando a larva já tem um certo comprimento, que pode ser chamado L (0), quando atribuímos t=0 no dia do nascimento (Sparre \& Venema, 1997);

$$
\mathrm{t}_{\mathrm{i}}=\text { idade no comprimento " } \mathrm{L}_{\mathrm{i}} \text { ". }
$$




\section{1) Estimativa dos parâmetros de crescimento e da idade pelo}

\section{método direto}

Estudos precedentes (Martins-Juras, 1980; JICA-MPEG-IBAMA， 1998; Castro, 2000) verificaram que, para a estimativa da idade de M. ancylodon, o otólito sagita é a estrutura rígida que melhor indica seu crescimento.

Otólitos são concreções calcáreas do ouvido interno dos peixes ósseos, que fazem parte de um sistema que controla o equilíbrio e a audição (Bastos, 1990). Embora existam três pares de otólitos (sagitta, lapillus e asteriscus), nem sempre é possível utilizar mais de um par para estudos de estimativa da idade (Lux, 1971). O crescimento do otólito se dá normalmente ao redor do núcleo de forma concêntrica (Lux, 1971). Geralmente eles são constituídos por aragonita, com um teor orgânico entre 0,2 e $10,0 \%$, formado por uma proteína fibrosa semelhante à queratina, chamada otolina (Bastos, 1990).

Fatores como a temperatura da água, disponibilidade de alimento ou reprodução, que afetam o metabolismo, alterando o crescimento do peixe, causam mudanças sazonais na densidade e espessura das camadas que estão sendo depositadas nos otólitos e, em alguns casos, é possível estimar a idade do peixe a partir da contagem destas camadas (anéis) resultantes dos processos fisiológicos envolvidos na deposição.

Dentre as amostras do bloco 3, realizou-se uma subamostragem, a qual procurou contemplar um total de 20 indivíduos (pares de otólitos) por classe de comprimento de 20 milímetros para cada mês de coleta.

Os otólitos foram medidos sob estereomicroscópio, com uma régua micrometrada acoplada, sendo anotados os dados de comprimento total $\left(\mathrm{L}_{\mathrm{o}}\right)$ e altura $\left(\mathrm{H}_{\mathrm{o}}\right)$ em milímetros com precisão de duas casas decimais, e o peso $\left(\mathrm{W}_{\mathrm{o}}\right)$ em gramas, com precisão de quatro casas decimais. Estas medidas foram submetidas ao teste "t" de 
Student pareado (Zar, 1999) para verificar a existência ou não de diferenças significativas entre os otólitos direito e esquerdo de cada indivíduo. Como não houve diferença entre os otólitos, optou-se por manusear o otólito esquerdo nas análises.

Quando observado inteiro, o otólito de M. ancylodon da costa Norte brasileira apresenta sua porção central muito opaca, impossibilitando identificar, com segurança, os primeiros anéis, sendo que esta dificuldade também foi observada para as populações Sudeste/Sul por Martins-Juras (1980) e Castro (2000). Por este motivo, decidiu-se realizar cortes transversais, os quais possibilitam visualizar os anéis que estão mais próximos ao núcleo, pois reduzem a interferência da opacidade na região central do otólito inteiro.

Para realizar os cortes transversais, os otólitos inteiros foram emblocados em resina náutica ou acrílica. As secções transversais foram cortadas em serra metalográfica de baixa velocidade, obtendo-se de duas a três secções de 0,3 mm de espessura, aumentando desta forma a probabilidade de atingir o núcleo da estrutura (JICA-MPEG-IBAMA, 1998). A secção que contivesse ou em que melhor se visualizasse o núcleo foi desgastada com lixas de diferentes granulações, que variaram de 280 a $1400 \mu \mathrm{m}$. Em seguida, a secção era embebida em bálsamo do Canadá para realçar os anéis e, por fim, montada entre lâminas de vidro e lamínulas para posterior observação (Chilton \& Beamish, 1982).

Uma vez preparados, os cortes foram analisados sob estereomicroscópio com luz transmitida, utilizando régua micrometrada acoplada. As tomadas de medidas do raio do otólito $\left(\mathrm{R}_{\mathrm{o}}\right)$ e do raio dos anéis $\left(\mathrm{R}_{\mathrm{i}}\right)$, em milímetros foram realizadas no plano ventral do otólito. Foi também observado o tipo de bordo, se translúcido (TR) ou opaco (OP) para cada exemplar. 
Após uma leitura preliminar, cada secção de otólito foi lida duas vezes, independentemente. Os cortes que tiveram leituras discordantes foram reexaminados e, no caso de dúvida, não considerados neste estudo. Foram consideradas legíveis as secções em que a posição e o número dos anéis, e o tipo de bordo estivessem concordantes.

Foram considerados como anéis que indicam o crescimento as zonas translúcidas (TR), regiões de pouca deposição de carbonato de cálcio, que estão relacionadas à época em que o organismo apresenta seu menor crescimento (Chilton \& Beamish, 1982), seguida pelas zonas opacas (OP), que estão relacionadas à época em que o organismo apresenta seu maior crescimento. Marcas translúcidas que não acompanhavam o contorno nuclear da secção foram consideradas como anéis falsos.

\section{a) Relação entre as medidas do peixe e as medidas dos otólitos}

As relações existentes entre as medidas de comprimento total do otólito $\left(\mathrm{L}_{\mathrm{o}}\right)$, altura (largura) do otólito $\left(\mathrm{H}_{\mathrm{o}}\right)$ e o comprimento total do peixe $\left(\mathrm{L}_{\mathrm{t}}\right)$, em milímetros, assim como o peso total do otólito $\left(\mathrm{W}_{\mathrm{o}}\right)$ e peso total do peixe $\left(\mathrm{W}_{\mathrm{t}}\right)$, em gramas, foram plotadas e tiveram seus ajustes descritos por equações matemáticas.

\section{b) Validação}

A confiabilidade da leitura dos anéis dos otólitos pode ser comprovada através da plotagem dos dados de comprimento total dos indivíduos $\left(\mathrm{L}_{\mathrm{t}}-\mathrm{mm}\right)$ contra os raios dos anéis $\left(\mathrm{R}_{\mathrm{i}}-\mathrm{mm}\right)$, sendo o resultado comumente denominado gráfico de constância, uma vez que se espera que a posição de cada anel corresponda a um determinado comprimento (Campana, 2001; Vaz-dos-Santos, 2002). 
A periodicidade de formação dos anéis foi verificada a partir da variação mensal do incremento marginal médio (IM) para cada grupo de anéis separadamente, e pelo cálculo das porcentagens mensais de bordas opacas (OP) e translúcidas (TR).

O incremento marginal representa a intensidade de deposição de carbonato de cálcio no otólito para cada grupo de anéis. O IM foi calculado, para cada exemplar nas amostras, de acordo com a fórmula de Mio (1961), utilizando-se o pacote estatístico $\operatorname{MINITAB}^{2}$ :

$$
\begin{aligned}
& \mathrm{IM}=\underline{\mathrm{R}}_{\underline{0}} \frac{-\mathrm{R}_{\mathrm{n}}}{\mathrm{R}_{\mathrm{O}}} \\
& \text { onde: } \\
& \mathrm{IM}=\text { incremento marginal }(\mathrm{mm}) ; \\
& \mathrm{R}_{\mathrm{O}}=\text { raio do otólito }(\mathrm{mm}) ; \\
& \mathrm{R}_{\mathrm{n}}=\text { raio do último anel etário }(\mathrm{mm}) .
\end{aligned}
$$

\section{2) Estimativa dos parâmetros de crescimento e da idade pelo}

\section{método indireto}

Populações de peixes que se reproduzem sazonalmente podem ser caracterizadas pela entrada regular de novos recrutas, ou seja, de indivíduos de uma coorte que entram pela primeira vez na área de pesca (Cadima, 2000). Quando adequadamente amostrados, esses recrutas revelam entradas regulares de indivíduos, especialmente nos primeiros poucos anos de vida, compondo uma estruturação característica de modas nas distribuições de frequiências de comprimento, indicando a presença de vários grupos de idade na área (Weatherley, 1972).

\footnotetext{
${ }^{2}$ A menção da marca ou produto não implica sugestão de uso.
} 
O método indireto para avaliar a idade e o crescimento dos indivíduos consiste em separar uma distribuição de freqüência de comprimento em coortes, e atribuir idades arbitrárias a cada uma delas.

Inicialmente o estudo de dados de freqüência de comprimento para estimativas de idade e crescimento foi introduzido por Petersen (1892) apud Gayanilo \& Pauly (1997), dando origem a duas técnicas básicas: a primeira, o "Método de Petersen" e a segunda, a "Análise da Progressão Modal". O Método de Petersen atribui idade relativa aos picos de freqüência de comprimento na amostra; porém esta atribuição se torna difícil em organismos que podem ou não desovar várias vezes no ano, enquanto a Análise da Progressão Modal consiste em ligar os picos das amostras de freqüência de comprimento a idades conhecidas pela média do incremento de crescimento, sendo que seu maior problema é a identificação dos picos que serão conectados. Ambos os métodos são subjetivos (Gayanilo \& Pauly, 1997).

Por ser uma das ferramentas eletrônicas mais utilizadas para estimar o crescimento em populações de peixes tropicais, optou-se por utilizar a rotina ELEFAN I (Eletronic Length Frequency Analysis) do pacote computacional FISAT (Gayanilo \& Sparre, 1997) para as amostras do bloco 1 de dados, que estima os parâmetros de crescimento a partir de dados seqüenciais de freqüência de comprimento. Este programa combina a lógica do Método de Petersen com a Análise da Progressão Modal, com o mínimo de subjetividade (Gayanilo \& Pauly, 1997), reestruturando os dados de comprimento pelo método de média corrida. A principal premissa deste método é que as amostras sejam representativas da população, e que exista uma progressão das modas ao longo do tempo. Ao final da análise, têm-se os valores dos parâmetros "k" e "L $\mathrm{L}_{\infty}$ da expressão de crescimento de von Bertalanffy. 
O programa ELEFAN I não estima o parâmetro " $\mathrm{t}_{\mathrm{o}}$ " da expressão de crescimento de von Bertalanffy, sendo que neste trabalho estimou-se o " $t_{0}$ " através da equação de Pauly (1980):

$\log \left(-\mathrm{t}_{\mathrm{o}}\right)=-0,3922-0,2752 \log \mathrm{L} \infty-1,038 \log \mathrm{k}$

Outros dois parâmetros de crescimento são utilizados pelo ELEFAN I: "C" amplitude da variação de crescimento, que pode estar correlacionada com a diferença entre as temperaturas mínima e máxima anuais da massa de água em que a espécie habita, e "ts" - summer point, que corresponde à época do ano em que a taxa de crescimento é mais alta. Adicionando-se 0,5 ao parâmetro "ts" (ts $+0,5)$, obtém-se o winter point (WP), isto é, época do ano em que ocorre o menor crescimento (Gayanilo \& Pauly, 1997).

No presente trabalho tanto valores de "WP" quanto valores de "C" não foram utilizados na rotina do ELEFAN I, pois todos os valores utilizados entre 0 a 1 dentre os quais eles variam, não mostraram melhora nos resultados de "Rn", que é a razão entre a soma dos picos explicados (ESP) pela soma dos picos disponíveis (ASP) nas amostras.

A soma dos picos explicados (ESP- explained sum of peaks) consiste em uma pontuação que mede o quanto uma curva pode se aproximar do seu melhor ajuste. Sempre que uma curva atingir uma barra dos dados reestruturados, que pode ser positiva ou negativa, ela conta pontos. A pontuação total de uma curva de crescimento é a soma dos pontos contados de cada amostra. A soma dos picos disponíveis (ASP - available sum of peaks) é a pontuação máxima que uma curva pode alcançar, isto é, a soma dos picos positivos. A razão ESP/ASP (Rn) torna-se, assim, uma medida de quanto uma curva está próxima do melhor ajuste possível (Sparre \& Venema, 1997). 


\section{5 - Aspectos da dinâmica reprodutiva da Macrodon ancylodon da costa Norte do Brasil}

Para caracterizar a dinâmica reprodutiva de M. ancylodon na região da costa Norte do Brasil, as análises foram realizadas com base nas observações sobre as gônadas dos peixes das amostras do segundo bloco, seguindo metodologia apresentada por Vazzoler (1982; 1996).

Entendem-se por gônadas de peixes os ovários e testículos nos quais os gametas (ovócitos e espermatozóides) se desenvolvem e são armazenados.

As gônadas femininas são os órgãos mais apropriados para estudos sobre reprodução por serem potencialmente capazes de fornecer informações sobre o grau de maturação, e por conseguinte da(s) época(s) e do(s) local(is) de desova, bem como sobre o número possível de descendentes (Chaves, 1985; West, 1990). Os machos são normalmente excluídos deste tipo de análise porque é mais difícil avaliar o estágio maturacional, de forma mais caracterizada e precisa, fornecendo, portanto, poucas evidências definidas sobre épocas de desova. Além disso, as gônadas masculinas (testículos) não apresentam grandes variações em seu peso (West, 1990). Nesse sentido, optou-se por estudar os ovários, para que fosse possível utilizar alguns indicadores dos processos reprodutivos da espécie em estudo.

\section{1) Caracterização da dinâmica reprodutiva a partir de}

\section{aspectos macroscópicos}

\section{a) Proporções sexuais}

A partir da identificação do sexo dos exemplares e assumido que as proporções de machos e fêmeas sejam de 1:1 como produto da meiose e segregação de cromossomas, genes ou interações que determinam o sexo, aplicou-se aos resultados o 
teste do $\chi^{2}$ (chi-quadrado) para se identificar as diferenças estatisticamente significativas: primeiro, nas proporções sexuais para o período como um todo; segundo, para a variação mensal da proporção entre fêmeas e machos; e terceiro, para as proporções sexuais por classes de comprimento total.

\section{b) Maturidade e período reprodutivo}

\section{- Método Qualitativo (variação temporal da frequiência dos estádios de maturidade gonadal)}

Este método baseia-se na verificação temporal dos diferentes estádios de maturidade gonadal, observando-se em que fase de desenvolvimento a gônada se apresenta durante um período que corresponda a um ciclo completo de reprodução.

A identificação do período de desova, então, é decorrente das maiores frequiências mensais de indivíduos nos estádios maduro e/ou hidratado, reforçados por períodos subseqüentes do aparecimento estádio desovado. A escala de maturidade adotada inicialmente compôs-se de quatro estádios: A - imaturo, B - em maturação, C maduro e D - desovado.

Analisando-se detalhadamente os indivíduos amostrados, percebeu-se que gônadas classificadas em estádio "C", de peixes com o mesmo comprimento, apresentavam seus pesos $\left(\mathrm{W}_{\mathrm{g}}\right)$ muito acima da média de peso gonadal desse estádio. Nestes casos, as gônadas com pesos muito superiores foram consideradas em processo de hidratação. Optou-se, portanto, por assumir uma nova escala macroscópica de estádios maturacionais, que incluísse esses indivíduos. Assim, a nova escala seria: Aimaturo, caracterizado por apresentar os ovários filamentosos, translúcidos, sem sinal de vascularização ou de ovócitos a olho nu; B- em maturação, os ovários são maiores e intensamente vascularizados, observando-se poucos ovócitos ao olho nu; C- maduro, os ovários apresentam-se túrgidos, com grande visibilidade de ovócitos grandes e opacos; 
D- hidratado, são os ovários maduros que apresentam ovócitos translúcidos e grande peso gonadal; e E- desovado, os ovários apresentam-se flácidos, com tamanho relativamente grande mas não volumosos, observando-se poucos ovócitos e a presença de zonas hemorrágicas. Desta forma, as análises referentes aos estádios de maturidade seguem esta nova escala e, os indivíduos classificados previamente como "D" (esvaziado "em recuperação") referentes à escala de Vazzoler (1996), foram incluídos no estádio "E" (desovado).

\section{- Métodos Quantitativos (Relação gonadossomática)}

Para estimar o período reprodutivo de uma espécie e diminuir a subjetividade das classificações baseadas em escalas macroscópicas, utiliza-se concomitantemente mais de um método, associando-se a análise da variação temporal da freqüência de ovários nos distintos estádios de maturidade, classificados macroscopicamente, à análise de indicadores quantitativos da fase em que a gônada se encontra dentro do processo de maturação (Vazzoler, 1996).

Este método quantitativo baseia-se em observações que utilizam dados de peso total de cada indivíduo $\left(\mathrm{W}_{\mathrm{t}}\right)$ e de peso das gônadas $\left(\mathrm{W}_{\mathrm{c}}\right)$, sendo a variação temporal da relação gonadossomática $1\left(\mathrm{RGS}_{1}\right)$, a relação que utiliza o peso total do indivíduo, e a relação gonadossomática $2\left(\mathrm{RGS}_{2}\right)$, a que utiliza dados de peso total do indivíduo sem o peso das gônadas.

A estimativa dos valores da relação gonadossomática individual e média para as amostras do bloco 2 foi realizada a partir dos dados de peso individuais por estádio de maturação dos indivíduos adultos, excluindo-se, portanto, os exemplares no estádio "A", e para cada período segundo as equações: 
$\mathrm{RGS}_{1}=\frac{\mathrm{W}_{\mathrm{g}}}{\mathrm{W}_{\mathrm{t}}} * 100 \quad \mathrm{RGS}_{2}=\frac{\mathrm{W}_{\mathrm{g}}}{\mathrm{W}_{\mathrm{c}}} * 100$

$\Delta \mathrm{RGS}=\mathrm{RGS}_{1}-\mathrm{RGS}_{2}$

onde,

$\mathrm{W}_{\mathrm{t}}=$ peso total do indivíduo $(\mathrm{g})$

$\mathrm{W}_{\mathrm{g}}=$ peso da gônada de cada indivíduo $(\mathrm{g})$;

$\mathrm{W}_{\mathrm{c}}=\mathrm{W}_{\mathrm{t}}-\mathrm{W}_{\mathrm{g}}=$ peso do corpo com vísceras, mas sem gônadas $(\mathrm{g})$.

É importante ressaltar que, neste estudo, os valores de RGS foram calculados sem considerar os indivíduos imaturos (estádio "A") porque estes não apresentam pesos gonadais significativos, uma vez que não estão participando do processo reprodutivo.

O período delimitado pelos valores mais elevados de $\Delta$ RGS corresponde ao período em que as gônadas estão com maior grau de maturidade, sendo que as quedas seguidas aos picos correspondem aos períodos de desova.

Para a estimativa do comprimento médio de início de primeira maturação gonadal $\left(\mathrm{L}_{50}\right)$, comprimento no qual $50 \%$ das fêmeas da população está iniciando sua participação no processo reprodutivo, e do comprimento em que todas as fêmeas estão participando deste processo $\left(\mathrm{L}_{100}\right)$, foi empregado o modelo logístico descrito em King (1995):

$\mathrm{P}=1 /\left(1+\exp \left(-\mathrm{r}\left(\mathrm{L}-\mathrm{L}_{\mathrm{m}}\right)\right)\right)$

onde,

$\mathrm{P}=$ proporção de indivíduos com gônadas maduras;

r = elevação da curva;

$\mathrm{L}=$ comprimento do indivíduo maduro $(\mathrm{mm})$;

$\mathrm{L}_{\mathrm{m}}=$ comprimento médio da maturidade gonadal $\left(\mathrm{L}_{50}-\mathrm{mm}\right)$. 
Os parâmetros deste modelo foram ajustados sobre os dados de número relativo de indivíduos maduros através do método interativo de mínimos quadrados.

\section{c) Fator de condição}

O fator de condição é um indicador do grau de higidez de um indivíduo, e seu valor reflete as condições nutricionais recentes e/ou o gasto de reservas em atividades metabólicas, possibilitando relações com condições ambientais e aspectos comportamentais das espécies (Vazzoler, 1996). Ele é usado para indicar variações na densidade populacional e nas condições alimentares (LeCren, 1951; Ricker, 1975 e Braga, 1986). O fator de condição é também utilizado como indicador do período de desova, pois reflete as alterações que ocorrem individualmente.

Como método quantitativo, o fator de condição alométrico utiliza o índice "b" resultante da equação que descreve a relação peso-comprimento, os dados de peso total do indivíduo e seu comprimento para $\mathrm{K}_{1}$ e dados de peso total dos exemplares sem o peso da gônada e seu comprimento para $K_{2}$. O fator de condição alométrico foi calculado para cada exemplar, e suas médias obtidas para cada período, segundo as equações:

$$
\begin{aligned}
& \mathrm{K}_{1}=\frac{\mathrm{W}_{\mathrm{t}}}{\mathrm{L}_{\mathrm{t}}^{\mathrm{b}}} * 100 \quad \mathrm{~K}_{2}=\frac{\mathrm{W}_{\mathrm{c}}}{\mathrm{L}_{\mathrm{t}}^{\mathrm{b}}} * 100 \\
& \Delta \mathrm{K}=\mathrm{K}_{2}-\mathrm{K}_{1} \\
& \text { onde, } \\
& \mathrm{L}_{\mathrm{t}}=\text { comprimento total do indivíduo }(\mathrm{cm}) ; \\
& \mathrm{b}=\text { parâmetro da equação da relação peso-comprimento } \\
& \mathrm{W}_{\mathrm{t}}=\text { peso total do indivíduo (g); } \\
& \mathrm{W}_{\mathrm{g}}=\text { peso da gônada de cada indivíduo }(\mathrm{g}) ;
\end{aligned}
$$


$\mathrm{W}_{\mathrm{c}}=\mathrm{W}_{\mathrm{t}}-\mathrm{W}_{\mathrm{g}}=$ peso do corpo com vísceras, mas sem gônadas $(\mathrm{g})$.

O período delimitado pelos valores mais elevados de $\Delta \mathrm{K}$ seguidos de quedas pode corresponder ao período reprodutivo, uma vez que reflete o peso das gônadas e que grande parte da energia acumulada pelo indivíduo deve ter sido canalizada para o desenvolvimento das gônadas e/ou para migrações ou outros comportamentos reprodutivos (Vazzoler, 1996).

\section{2) Aspectos microscópicos}

Para a obtenção de informações sobre a época, a área e o tipo de desova, sobre a fecundidade e o entendimento do ciclo reprodutivo de indivíduos de diferentes espécies, faz-se necessária uma classificação do desenvolvimento gonadal (Dias et al., 1998).

Normalmente as classificações são realizadas pelo método macroscópico, e são de caráter subjetivo, podendo muitas vezes subestimar ou superestimar os estádios de maturação gonadal.

Uma forma de minimizar este caráter subjetivo é realizar observações microscópicas, que se baseiam nos caracteres citológicos das diferentes fases do desenvolvimento das células germinativas. Este tipo de abordagem é mais precisa, pois reflete a dinâmica reprodutiva, considerando fases específicas pelas quais passam os ovócitos durante sua maturação (Dias et al., 1998).

Aceitando que a desova da referida espécie seja parcelada (Yamaguti, 1967; Juras, 1979; Moraes, 1980), considerando a sugestão de Dias et al. (1998) - que ressaltam a utilização simultânea de classificação microscópica de uma parcela significativa de ovários classificados macroscopicamente como "B" (em maturação), 
nas espécies com desova parcelada, tendo como objetivo detectar uma possível ocorrência de folículos pós-ovulatórios em indivíduos pré-classificados como em maturação (B) ou já maduros (C) -, foram montadas preparações permanentes com cortes de ovários classificados macroscopicamente como "B", representando $20 \%$ da amostra do bloco 2 de dados.

As gônadas permaneceram conservadas durante aproximadamente dois anos nas soluções de Bouin e Dawidson. Para amenizar os problemas decorrentes da ação dos fixadores, estes foram removidos com água destilada. Em seguida, as gônadas foram colocadas em solução aquosa tamponada de formol a $10 \%$ por aproximadamente um mês. Logo após este período, o formol foi trocado por álcool a 70\%. Os cortes foram realizados com técnicas rotineiras utilizadas em histologia, sendo o material fixado submetido ao processo de desidratação em série progressiva de alcoóis, diafanização por xilol e inclusão em parafina. O material emblocado foi, então, cortado em micrótomo, tendo cada corte $5 \mu \mathrm{m}$ de espessura, corado com hematoxilina-eosina e observado sob microscópio de luz.

As gônadas do estádio "B" foram então reclassificadas de acordo com a frequiência de ocorrência dos folículos pós-ovulatórios conforme Dias et al., (1998). As fases ovocitárias e as estruturas citológicas consideradas basearam-se naquelas descritas por Isaac-Nahum (1981), Hibiya (1982), Chaves (1988), Silva (1996) e Vazzoler (1996).

Ainda com a finalidade de estudar a dinâmica reprodutiva da espécie, tomaram-se os dados de diâmetro dos ovócitos de gonâdas no estádio de maturidade "B”. Cerca de 2000 ovócitos, provenientes de cinco indivíduos, foram medidos diretamente das gônadas e de suas preparações permanentes correspondentes, sendo os 
diâmetros tomados ao acaso no eixo central no qual o núcleo estivesse presente. Ambas as medidas foram realizadas sob estereomicroscópio com luz transmitida, utilizando régua micrometrada acoplada.

Para tomada dos dados de diâmetro, pequenas alíquotas do ovário foram seccionadas e mantidas em uma solução de Gilson modificada, contendo ácido nítrico a $80 \%$, álcool a 70\%, e água destilada, durante aproximadamente $12 \mathrm{~h}$, sendo periodicamente agitadas para que os ovócitos se desprendessem das paredes (lamelas) do ovário. 


\section{III - RESULTADOS}

\section{1 - A precipitação na desembocadura dos rios Amazonas e Tocantins na costa Norte do Brasil e temperatura da superfície do mar (TSM)}

Com base nos dados mensais sobre pluviosidade obtidos pelo INMET, no período de 1966 a 2001, puderam ser identificadas duas estações anuais e dois períodos transicionais de acordo com a intensidade da precipitação (Fig. 3):

a) Estação das chuvas, descrita como o período de alto índice pluviométrico $(<320 \mathrm{~mm})$, de fevereiro a abril;

b) Período de transição I, correspondente ao período intermediário entre o período das chuvas e o período "seco", ocorrendo de maio a julho;

c) Estação da "seca", em relação aos outros períodos, este é o que apresenta o mais baixo índice pluviométrico (> $80 \mathrm{~mm}$ ), ocorrendo de agosto a outubro; e,

d) Período de transição II, correspondente ao período intermediário entre o período "seco" e o período das chuvas, ocorrendo de novembro a janeiro.

Estas estações/períodos correspondem aproximadamente ao fim do verão e início de outono; outono e início de inverno; fim do inverno e início da primavera e fim da primavera e início do verão no hemisfério sul.

A região equatorial normalmente apresenta pequenas variações nos fatores ambientais, sendo caracterizada principalmente pela intensidade pluviométrica regional. As águas provenientes das precipitações das chuvas levam aos rios nutrientes terrestres que, juntamente com a matéria orgânica dos manguezais, fertilizam as águas costeiras destas regiões. 
O Jet Propulsion Laboratory (JPL) forneceu os dados no formato de grade regular, de abrangência global, representando uma projeção cilíndrica eqüidistante da distribuição da temperatura da superfície do mar. As referidas grades apresentam resolução espacial de $9 \mathrm{~km}$ por $9 \mathrm{~km}$ (Fig. 4). As figuras resultantes indicaram não haver diferenças na temperatura superficial do mar para as diferentes épocas relativas a intensidade pluviométrica, mantendo-se praticamente constante durante todo o ano.

\section{2 - Descrição das amostras}

Bloco 1 - O bloco 1 é formado por 31 amostragens realizadas mensalmente, entre 1998 e 2000, obtendo-se um total de 453.411 indivíduos de $M$. ancylodon, abrangendo comprimentos totais de 5,0 a 43,0 cm (Tab. 1 e Figs. 5 e 6). Para o período total verificou-se que tanto as maiores capturas em número de indivíduos como os maiores comprimentos totais de $M$. ancylodon foram obtidos pela pesca artesanal por meio de redes de emalhe. Já os menores indivíduos foram capturados pelas operações de arrasto de camarão realizados pela atividade industrial.

A maior quantidade de indivíduos capturados veio dos emalhes (405.462). Apesar de um número menor de meses de amostragem, a segunda forma de captura que mais forneceu indivíduos foi o arrasto (36.971). Nas três artes de pesca, o mês de julho apresentou, em anos diferentes, o menor comprimento total registrado mensalmente. $\mathrm{O}$ comprimento total máximo foi registrado no mês de março de 2000 para o arrasto, em setembro de 1998 para o curral e para os meses de julho a novembro de 1998 e setembro de 1999 para o emalhe. O comprimento médio máximo encontrado foi registrado no mês de março de 2000 para as artes de arrasto e curral, e junho de 1998 para o emalhe, enquanto seu mínimo foi registrado em outubro de 2000 para o arrasto, 
julho de 1998 para o curral e dezembro de 1998, abril, julho, agosto de 1999 e agosto de 2000 para o emalhe.

As amostras provenientes do arrasto direcionado à pesca do camarão tiveram número e amplitude de comprimento menor, estando a moda em torno dos 25,0 cm, enquanto o comportamento dos outros petrechos foi semelhante nas modas (em torno de 28,0 e $32,0 \mathrm{~cm}$ ) e queda nos $30,0 \mathrm{~cm}$, sendo que o emalhe capturou mais (Fig. 7).

Bloco 2 - As amostras deste bloco foram agrupadas, já que sua finalidade foi o estudo de aspectos biológicos da espécie, não sendo necessário diferenciá-las por petrechos.

A amostra do bloco 2 é composta por 2.274 indivíduos, os quais apresentaram uma amplitude de comprimento que abrangeu valores entre 13,5 e 43,7 cm e pesos entre 20,9 a 744,6 g para todos os indivíduos (Tab. 1 e Fig. 8). O maior comprimento total seguido pelo maior peso total encontrado nesta amostra ocorreu no mês de junho de 1998, enquanto que o menor comprimento total foi registrado em abril de 1999 e o menor peso total em março de 1999. Os comprimentos médio mínimo e máximo foram verificados em março de 1999 e setembro de 1998, respectivamente, e os pesos médios mínimos e máximos foram registrados em março de 1999 e outubro de 1998, respectivamente.

Para a relação peso-comprimento deste bloco amostral, foram calculadas as equações:

$$
\begin{aligned}
& y=0,0032 x^{3,3109}, \operatorname{com~}^{2}=0,97 \text { para sexos agrupados; } \\
& y=0,0027 x^{3,3652}, \operatorname{com~r}^{2}=0,97 \text { para fêmeas; e, } \\
& y=0,0034 x^{3,2979}, \operatorname{com~}^{2}=0,97 \text { para machos (Fig. 9). }
\end{aligned}
$$


O resultado do teste "t" realizado para as equações linearizadas para todo o conjunto de amostras deste bloco encontrou diferenças significativas entre machos e

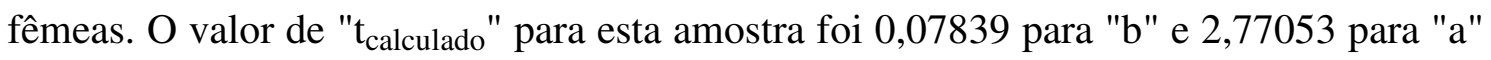
com " $\alpha$ " 0,05 e 1561 gl ("t crítico $=1,9600)$.

Verificou-se que, para as amostras de junho de 1998 a junho de 1999, não houve diferenças significativas para os parâmetros "b" e "a" da equação linearizada de peso-comprimento para machos e fêmeas. Contudo, diferenças significativas foram observadas nos meses de julho a setembro de 1999 (Tab. 2).

Calculou-se a relação peso-comprimento por período amostrado, sendo os resultados descritos na tabela 3. Como o valor do expoente "b" resultante da equação peso-comprimento pode indicar o grau de bem estar do animal, estes resultados sugerem que a pescadinha-gó apresentou uma melhor condição nos meses de agosto de 1998 e setembro de 1999, e uma menor condição em dezembro de 1998, quando a descarga do rio Amazonas está no período de seu menor volume. Outros valores maiores de "b" podem ser encontrados nos meses de junho de 1998 e fevereiro, março, abril e junho de 1999, sendo que os meses de fevereiro e março de 1999 correspondem à estação das chuvas.

Bloco 3 - Assim como as amostras do bloco 2, as amostras deste bloco foram grupadas, já que visavam o estudo de aspectos biológicos da espécie, não sendo necessário diferenciá-las por petrechos.

Considerando as amostras do bloco 3, foram medidos e pesados 549 indivíduos, cujas amplitudes de comprimento e peso abrangeram entre 15,7 e 45,0 cm, e 10,7 e 548,8 g, respectivamente (Tab. 1 e Fig. 10). O maior valor encontrado para o comprimento total e peso total desta amostra e de todos os comprimentos totais dos blocos amostrais ocorreu no mês de dezembro de 2000. O comprimento e peso mínimo 
foram verificados nos meses de março de 2001 e setembro de 2000, respectivamente. $\mathrm{O}$ comprimento e peso médio mínimo foram registrados no mês de março, enquanto o comprimento e peso médio máximo foram registrados no mês de agosto de 2000.

Como não foi possível a identificação do sexo dos indivíduos deste bloco e, também, da maturidade gonadal, a análise da relação peso-comprimento para essa amostra foi realizada para sexos agrupados, tendo sido encontrados os valores 3,3833 para "b", 0,0024 para "a" e 0,96 para r $^{2}$ (Fig.11).

$\mathrm{O}$ teste " $t$ " realizado para as equações de peso-comprimento linearizadas do bloco 2, para sexos grupados, e bloco 3 mostrou não existir diferença significativa entre "b" e "a" destas amostras, sendo o "t $\mathrm{t}_{\text {crítico }}$ igual a 1,9600, com " $\alpha$ " 0,05 e 2135 gl, o

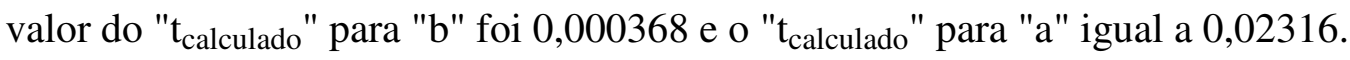

\section{3 - Idade e crescimento de Macrodon ancylodon da costa Norte do Brasil.}

\section{1) Estimativa dos parâmetros de crescimento e da idade pelo método direto - bloco 3}

a) Relação entre as medidas dos indivíduos e as medidas dos otólitos

Os otólitos sagita de Macrodon ancylodon da região Norte do Brasil são muito opacos, principalmente na porção central, e seu bordo ventral é caracterizado por denticulações que variam em tamanho e número (Fig. 12). Quando mergulhados em meio clareador (álcool, água, xilol, nujol), os anéis translúcidos podem ser observados próximos ao bordo, mas dificilmente na região central do otólito.

O teste "t" pareado realizado para as medidas tomadas do par de otólitos indicou não haver diferença significativa entre o otólito direito e o otólito esquerdo.

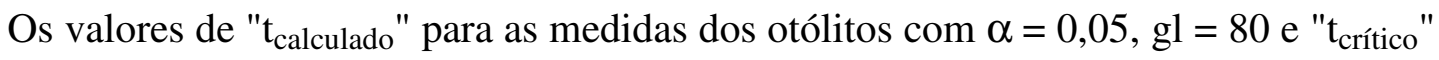


$=1,9901$ para duas caudas foi 0,7543 para o comprimento total dos otólitos; 0,6554 para a altura dos otólitos, e 0,9902 para o peso dos otólitos.

As equações que descreveram as relações entre as medidas dos otólitos e as medidas dos indivíduos estão descritas na tabela 4 e figuras 13 e 14. Estas relações demonstram como o crescimento dos otólitos é influenciado pelo crescimento do indivíduo. As figuras 13 a) a 13 c) e 14 a) a 14 c) mostram que as variações do comprimento, da altura e do peso dos otólitos direito e esquerdo são grandemente proporcionais, enquanto que as figuras $13 \mathrm{~d}$ ) a $13 \mathrm{~h}$ ) indicam que o crescimento do otólito, em peso ou em comprimento, não segue proporcionalmente o crescimento do peixe em peso ou em comprimento.

\section{b) Validação}

Utilizando-se as medidas de todos os otólitos, observou-se que o gráfico de constância apresentou uma tendência crescente em seus valores. Posteriormente, verificando-se minuciosamente os dados, constatou-se que o primeiro anel translúcido apresentava uma grande variação na distância em relação ao núcleo, e optou-se por separar as distâncias do primeiro anel translúcido em dois grupos. O primeiro grupo estaria compreendido na faixa entre 0,65 e $0,70 \mathrm{~mm}$ de distância entre o $1^{\circ}$ anel e o núcleo, e o segundo grupo na faixa de 0,75 a $0,85 \mathrm{~mm}$ do $1^{\circ}$ anel em relação ao núcleo. Os gráficos resultantes desta separação (Fig. 15) mostraram-se coerentes com o modelo proposto de constância na posição dos anéis ao longo da vida do peixe, e sugerem a existência de duas coortes anuais.

Devido ao número de secções legíveis ter sido muito baixo, correspondendo a $45 \%$ ou 94 otólitos de um total de 209, não se pôde validar a formação dos anéis de crescimento, sendo que o comprimento total dos indivíduos, cujos otólitos apresentaram secções legíveis, esteve concentrado na faixa de 16,0 a $25,0 \mathrm{~cm}$, muito abaixo do comprimento total máximo encontrado nesta amostra, que foi $45,0 \mathrm{~cm}$. Leituras das 
secções de indivíduos maiores foram impossibilitadas devido ao reduzido número destes indivíduos nas amostras e, principalmente, pelas secções dos otólitos destes indivíduos serem ilegíveis, tornando reduzida a correspondência entre as leituras.

A análise da variação do incremento marginal não foi conclusiva, pois o número de secções legíveis por grupo-de-anel não permitiu um cálculo satisfatório do incremento mensal por número de anéis observados (Fig. 16).

A análise da variação mensal das porcentagens de bordas opacas e translúcidas indicou que, provavelmente, a formação dos anéis etários é bianual, com início de deposição da primeira banda opaca em setembro e da segunda em janeiro (Fig. 17).

Como a validação da periodicidade na formação dos anéis de crescimento mostrou-se inconsistente para a espécie M. ancylodon da costa Norte do Brasil, os parâmetros das variáveis de crescimento da equação de von Bertalaffy pelo método direto não puderam ser calculadas.

\section{2) Estimativa dos parâmetros de crescimento e da idade pelo método indireto - bloco 1}

Das amostras do bloco 1, somente os dados de frequiência de comprimento provenientes dos indivíduos capturados em currais (cerco-fixo) apresentaram um deslocamento de modas satisfatório. Constatada a progressão modal da frequiência de comprimento, aplicou-se a rotina ELEFAN I para este grupo de indivíduos.

Considerando WP $=0$ e $\mathrm{C}=0$, ou seja, ausência de oscilação sazonal associada às características biológicas da população encontradas neste trabalho, obtiveram-se duas coortes, a primeira iniciando-se em junho e a segunda em dezembro, como podem ser vistas na figura 18. 
Os valores encontrados para " $\mathrm{t}_{\mathrm{o}}$ " para as duas coortes foram: coorte 01 (junho) de $-0,3442$ e coorte 02 (dezembro) de $-0,3302$.

Estimados os parâmetros das variáveis da curva de crescimento de von Bertalaffy, foi plotada a curva de crescimento para a Macrodon ancylodon da costa Norte do Brasil (Fig.19).

\section{4 - Aspectos da dinâmica reprodutiva da Macrodon ancylodon da costa Norte do Brasil.}

4.1) Caracterização da dinâmica reprodutiva a partir de aspectos macroscópicos

\section{a) Proporções sexuais}

Quanto às proporções de indivíduos machos e fêmeas (Fig.20), observou-se que, de modo geral, para o período total, houve predominância não significativa dos machos sobre as fêmeas, apresentando um valor $\chi^{2}=0,79$. Contudo houve pequenos períodos em que ocorreu predominância de machos e outros de fêmeas, havendo entre eles um período sem tendência de variação. As fêmeas tiveram predominância significativa nos meses de julho e novembro de 1998 e setembro de 1999, enquanto os machos estiveram predominando nos meses de setembro, outubro e dezembro de 1998 e março e julho de 1999 (Fig. 21).

Quanto à diferença nas proporções sexuais por classes de comprimento, verificou-se que, na faixa entre 26 e $36 \mathrm{~cm}$, a proporção entre machos e fêmeas não mostrou diferença significativa. Porém, em comprimentos inferiores a $25 \mathrm{~cm}$, ocorreu a predominância significativa de machos, e acima de $37 \mathrm{~cm}$, a predominância significativa de fêmeas (Fig. 22). Estes resultados sugerem que a expressão macroscópica do sexo ocorre, primeiro, nos machos ou que os machos foram 
superestimados, já que morfologicamente gônadas de indivíduos não diferenciados assemelham-se a testículos imaturos, e sugerem também que as fêmeas podem apresentar uma expectativa de vida superior à dos machos ou que apresentam maiores taxas de crescimento.

\section{b) Maturidade e Período Reprodutivo}

A figura 23 evidencia as diferentes participações percentuais das fêmeas com diferentes estádios de maturidade gonadal ao longo do período estudado. Observa-se que as maiores proporções de fêmeas maduras, hidratadas e desovadas, ou seja, em reprodução, encontra-se nos meses de junho, julho, agosto e novembro de 1998, e fevereiro, março, abril e agosto de 1999.

Observa-se a presença do estádio "D”, hidratado, nos meses de junho e julho de 1998, e março e abril de 1999, indicando que houve desova; e o estádio "C" para 53,3 \% do período amostrado. O estádio desovado ou pós-desova, por sua vez, foi encontrado para, praticamente, toda a amostra, com exceção do mês de dezembro de 1998.

Pela observação da figura 24 , pode-se inferir que $50 \%$ das fêmeas iniciaram o processo de maturação gonadal quando atingiram um comprimento total em torno de $25,08 \mathrm{~cm}\left(\mathrm{~L}_{50}\right)$, e todas estavam aptas a participar do processo reprodutivo ao atingir $34,0 \mathrm{~cm}$ de comprimento total $\left(\mathrm{L}_{100}\right)$.

A análise da variação mensal da relação gonadossomática dos indivíduos adultos (Fig. 25) evidenciou quatro picos seguidos de quedas dos valores: o primeiro em julho-agosto de 1998 e o segundo em dezembro de 1998-fevereiro de 1999, coincidindo com o final do período de transição das chuvas, e outros dois picos com valores menores ocorrendo nos meses de abril-maio de 1999 e julho-agosto de 1999, sendo que 
a menor magnitude destes picos em relação aos de 1998 pode ser devido ao período em que ocorreu a coleta, que pode ter incidido nos indivíduos no início do período reprodutivo. A variação mensal de $\Delta$ RGS (Fig. 26) apresentou quatro picos, sendo que somente dois deles foram mais pronunciados, ocorrendo nos meses de julho e dezembro de 1998. Os picos menos pronunciados foram registrados nos meses de abril e julho de 1999.

As figuras 27 e 28 mostram os valores de RGS e $\Delta$ RGS utilizando os valores de RGS médio dos indivíduos com comprimentos acima do comprimento de início de primeira maturação gonadal $\left(\mathrm{L}_{50}\right)$. Desta forma, a redução do valor médio provocada pelos comprimentos dos indivíduos "B" que estão abaixo do valor de $\mathrm{L}_{50}$ calculado não está afetando os resultados. Estes novos valores para RGS e $\Delta$ RGS, embora muito próximos daqueles encontrados considerando-se todos os indivíduos em maturação, são mais realistas, porque consideram indivíduos adultos maiores que estão participando do processo reprodutivo.

\section{c) Fator de condição}

Os fatores de condição $\mathrm{K}_{1}$ e $\mathrm{K}_{2}$ apresentaram valores pronunciados durante os meses de julho, novembro de 1998, e de abril a junho de 1999, e menos pronunciados em outubro e dezembro de 1998 e agosto de 1999 (Fig. 29), como reflexo do peso das gônadas dos indivíduos. Por outro lado, os valores da variação mensal de $\Delta \mathrm{K}$ apresentaram quatro picos, sendo que os picos dos meses de julho e novembro de 1998 foram mais conspícuos do que os observados para os meses de abril e julho de 1999 (Fig. 30). A variação mensal de $\Delta \mathrm{K}$ apresentou um comportamento semelhante ao encontrado para $\Delta \mathrm{RGS}$, sugerindo pesos altos de gônadas como conseqüência da alocação de energia para o desenvolvimento dos ovócitos. 


\section{2) Aspectos microscópicos}

O estudo das distribuições de freqüência de diâmetro dos ovócitos permitiu distinguir as fases de seu desenvolvimento e, por conseguinte, a maturação gonadal. $\mathrm{O}$ desenvolvimento pôde ser caracterizado pelo número de modas e aumento do diâmetro dos ovócitos, tendo sido encontradas duas modas de freqüência para os ovários avaliados macroscopicamente em estádio "B" (Fig. 31). O tempo em que as gônadas permaneceram conservadas em soluções de Bouin e Dawidson e o processamento histológico provocaram uma retração no tecido ovariano. Mesmo havendo esta retração, pôde-se acompanhar a progressão do desenvolvimento dos ovócitos com $0,05 \mathrm{~mm}$ de defasagem entre as diferentes leituras. Os ovócitos com diâmetros inferiores a 0,2 mm fazem parte do grupo de ovócitos do estoque de reserva (fase 2), descritos na literatura, enquanto os ovócitos com diâmetros superiores a $0,2 \mathrm{~mm}$ estão iniciando ou já atingiram o grupo de ovócitos vitelogênicos (fases 4, 5 e 6). A presença destas duas modas sugere que os lotes de ovócitos maturam sincronicamente em dois grupos.

Apesar das preparações permanentes terem sido realizadas em ovários classificados macroscopicamente em apenas um estádio de maturidade ("B") foi possível identificar células em todas as fases de desenvolvimento. $\mathrm{Na}$ avaliação microscópica, foram encontradas as seguintes fases para as células germinativas femininas:

Fase 1 - Células germinativas jovens (ovogônias): são as menores normalmente formando grupos denominados ninhos. O citoplasma apresenta baixa afinidade pelos corantes e, por isso, são de difícil observação. Por este motivo, as ovogônias foram desconsideradas nas tomadas de medidas de diâmetro;

Fase 2 - Ovócitos do estoque de reserva: são considerados como banco de reserva de células germinativas. Cada lote de células que entra em processo de 
maturação se destaca e se diferencia das demais pelo aumento de seu diâmetro. O citoplasma apresenta seus limites bem definidos, com uma intensa afinidade pelo corante eosina. O núcleo apresenta vários nucléolos, também com afinidade pela eosina, que adquirem formas arredondadas para posteriormente migrar para a periferia nuclear (Figs. 32 e 33);

Fase 3 - Ovócitos com vacúolos periféricos: são as células nas quais o citoplasma acumula alvéolos corticais, responsáveis pela formação do espaço perivitelínico, e substâncias (inclusões) de reserva (lipídios) para futura utilização pelo embrião, como nutrição ou para flutuação. O método de coloração utilizado nas preparações permanentes não permitiu distinguir vacúolos dessas duas origens (Figs. 32 e 33$)$

Fase 4 - Ovócitos com granulações vitelínicas: são as células que já acumularam vitelo proteico como substância de reserva no citoplasma. O vitelo é formado por pequenos grânulos de natureza glicolipoproteica e que são facilmente visualizados (Figs. 32 e 33);

Fase 5 - Ovócitos com vitelogênese completa: são aqueles que aumentaram de tamanho devido ao acelerado surgimento de grânulos de vitelo que coalescem. Agora, estes grânulos são maiores e mais numerosos que na fase anterior (Figs. 32 e 33).

\section{Estruturas derivadas:}

Folículos atrésicos (FA): são folículos ovarianos que, em qualquer fase de seu desenvolvimento, entram em processo de absorção. Trata-se de uma estrutura derivada pois nem todo folículo passa por esta fase. Caracteristicamente seus núcleos estão desintegrados, os contornos celulares tornam-se irregulares, os grânulos de vitelo degeneram formando uma massa amorfa, a membrana pelúcida aparece fragmentada e macrófagos invadem o citoplasma ovocitário, destruindo seu conteúdo (Figs. 34 e 36). 
Folículos pós-ovulatórios (FPO): são constituídos por cordões de células foliculares, que não são expelidos com os ovócitos no processo de desova. Estas células hipertrofiam-se produzindo lamelas (dobras) (Figs. 34, 35 e 36).

Das estruturas encontradas, os folículos pós-ovulatórios são as únicas que indicam o processo de desova. Quando identificados, considera-se que houve desova recente.

Com base no arranjo celular, na predominância do tipo celular, na presença de folículos pós-ovulatórios e no diâmetro dos ovócitos, foi estabelecido um novo quadro sinótico para as gônadas classificadas macroscopicamente como "B" (Tab. 5). Esse quadro foi possível já que, em nível microscópio, foram verificadas características das etapas e processos envolvidos na reprodução da espécie para a região, modificando em parte a escala macroscópica aplicada inicialmente:

$\mathbf{B}_{1}$ - Em maturação (primeira fase): não apresenta evidências de desova (FPO), verificando-se uma grande variedade de tipos celulares, principalmente nas fases 2, 3, 4 e 5 (Fig. 32 e 33);

Bn - Desovado, e em um novo processo de maturação: apresenta as mesmas características da fase anterior incluindo as células da fase 5, porém com um alto grau de desorganização celular. O primordial, no entanto, é o aparecimento dos folículos pósovulatórios e ovócitos atrésicos (Figs. 34, 35 e 36).

Observando a tabela 6 pode-se verificar que ocorreu desova nos meses de julho, setembro e novembro de 1998, e fevereiro de 1999, quando ocorreram os FPO. Como as preparações permanentes foram realizadas em gônadas em estádio "B", este resultado indica que ocorreu uma pequena desova nos indivíduos "B", caracterizando uma desova em pequenos lotes e sugerindo desova parcelada, uma vez que simultaneamente ocorreram ovócitos maduros nas mesmas preparações permanentes. 
A porcentagem de acerto para as gônadas avaliadas macroscopicamente como "B", em maturação, foi $60 \%$, enquanto que os erros corresponderam a 5,7\% para "A", imaturo, e 34,3\% para "E", desovado.

Dentre as preparações permanentes examinadas, 35,71 \% continham ovócitos atrésicos, em pequenas quantidades, não tendo sido possível caracterizar, com clareza, o fim da estação de desova, a partir dessas estruturas.

Nesse sentido, quando comparamos os resultados obtidos pela variação mensal do fator de condição $\left(\mathrm{K}_{1}, \mathrm{~K}_{2}\right.$ e $\left.\Delta \mathrm{K}\right)$ com a variação mensal da relação gonadossomática $\left(\mathrm{RGS}_{1}, \mathrm{RGS}_{2}\right.$ e $\left.\Delta \mathrm{RGS}\right)$, com a frequiência mensal dos estádios gonadais, com a distribuição de freqüência dos diâmetros dos ovócitos, e finalmente com a avaliação microscópica dos estádios "B", verificamos que os resultados sugerem que a espécie $M$. ancylodon da costa Norte apresenta uma desova prolongada do tipo parcelada em pequenos lotes com picos nos meses de julho-agosto e dezembro-fevereiro.

O ciclo reprodutivo de Macrodon ancylodon da costa Norte brasileira pode ser esquematizado como se segue:

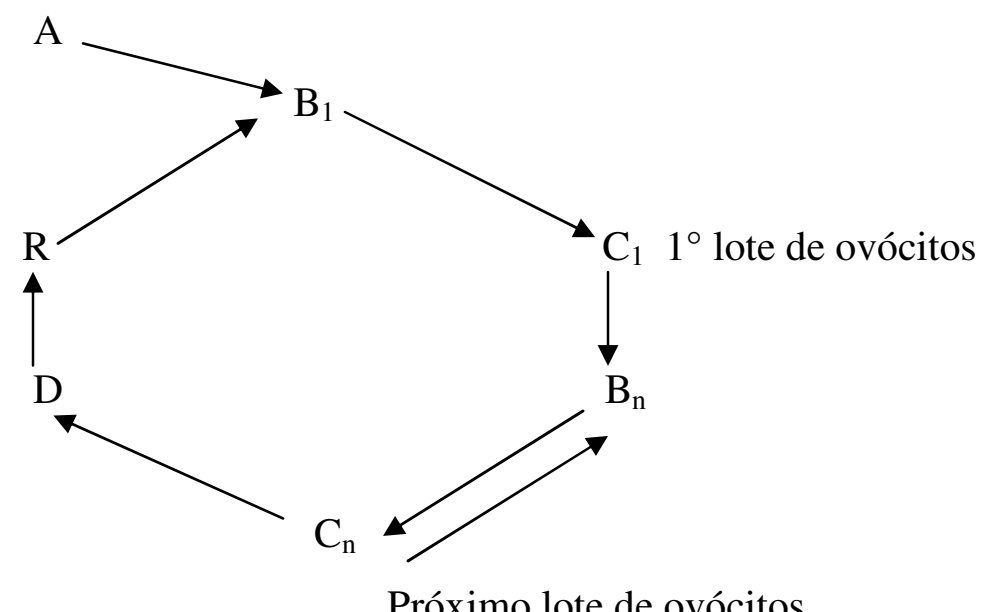

Próximo lote de ovócitos 


\section{V - DISCUSSÃO}

A costa Norte brasileira é cortada pela Linha do Equador, estando sujeita ao regime de intensidade dos ventos alísios, que deslocam a zona de convergência intertropical (ZCIT) para o norte ou para o sul do equador, dependendo da época do ano. Este deslocamento é um dos principais responsáveis pelo regime pluviométrico existente na região, ocorrendo um período de alta pluviosidade e outro de baixa pluviosidade, havendo entre eles períodos de transição. Apesar de as mudanças sazonais no fotoperíodo e temperatura serem pequenas dentro dos trópicos, comparadas às verificadas em regiões temperadas, essas mudanças sazonais podem ser observadas nos regimes de ventos e chuvas, os quais causam uma certa sazonalidade em muitos ecossistemas tropicais (Lowe-McConnell, 1999), sendo o caso da região estudada.

Além disso, vale ressaltar que a região é caracterizada por seus inúmeros rios e, principalmente, pela descarga de grandes rios como o Amazonas e o Tocantins. Por este motivo, as áreas costeiras são formadas, em sua grande maioria, por exuberantes e numerosos manguezais que, juntamente com os rios, são os responsáveis pela produtividade marinha na região. Este ponto de vista também foi observado por LoweMcConnell (1987), pois, segundo a autora, em geral os recursos demersais são distribuídos e localizados sobre a plataforma continental, onde a produtividade primária é maior do que em mar aberto e as profundidades são suficientemente rasas para serem acessíveis à ação das redes de arrasto. Essa maior produtividade em tais regiões é devida a uma maior disponibilidade de nutrientes vindos de fontes terrestres, resultantes do escoamento de terras durante as estações de chuva, e dos rios, que carreiam nutrientes do ecossistema terrestre para as regiões costeiras marinhas.

$\mathrm{Na}$ área de estudo, a distribuição desses nutrientes, nos domínios costeiro e oceânico, é realizada principalmente pela Corrente Norte do Brasil e sua retroflexão 
(Paiva, 2001). Por esta razão, na costa do Estado do Amapá são encontrados os maiores camarões, dentro de canyons submarinos (Aragão et al., 2001), onde ocorre o maior número de operações de arrasto para a captura deste recurso.

Segundo Lowe-McConnell (1999), os estuários tropicais são usualmente vastos e a imensa descarga de água doce espalha-se no mar por muitos quilômetros, enquanto que em estações ou anos secos a água do mar projeta-se por longas distâncias rio acima, onde as terras são baixas. Sendo mais densa, a água do mar tende a se deslocar por baixo das camadas de água doce, permitindo que peixes marinhos que habitam o fundo se desloquem rio acima mais facilmente do que aqueles que habitam a superfície. A interface água doce/água salgada desloca-se por grandes distâncias rio acima e rio abaixo, sazonalmente, alcançando mais de $200 \mathrm{~km}$ no rio Amazonas. Isso pode facilitar a migração de espécies de hábitos marinhos para a água doce.

O comportamento migratório de Macrodon ancylodon já havia sido descrito por Lowe-McConnell (1962, 1999), que relata uma tendência de os cienídeos da região da Guiana moverem-se para a costa em julho-agosto, meses em que cessam os ventos alísios locais bem como a principal estação chuvosa, quando os rios descarregam muita água doce para o mar; e para o largo, em águas mais fundas, em janeiro-março, quando os ventos alísios do nordeste sopram mais fortes, revolvendo o lodo do fundo, em águas costeiras. Yamaguti (1967) relatou que fêmeas da espécie da costa Sul brasileira migram da latitude $32^{\circ} \mathrm{S}$ para a $28^{\circ} 30^{\prime} \mathrm{S}$ e vice-versa, antes que os machos; Santana (1998) verificou a ocorrência da espécie durante todo o ano na faixa litorânea do Estado do Pará, destacando um deslocamento sazonal dos cardumes em função da forte influência das águas do rio Amazonas; e Zorro (1999) relatou que indivíduos adultos migram para o estuário para desovar, permanecendo lá até a fase juvenil, quando retornam para a área costeira. 
A influência da ZCIT no padrão de migração de espécies tropicais de peixes foi observado por Zagaglia (2003), que verificou uma maior abundância de albacora lage, Thunnus albacores, nas costas Norte e Nordeste brasileira em associação à presença da ZCIT, bem como da sua variabilidade sazonal, sendo que o período de maior concentração deste recurso na costa brasileira é entre março e abril, quando a ZCIT está mais próxima à latitude $5^{\circ} \mathrm{S}$. Ao contrário da albacora lage, a pescadinha-gó fica mais próxima à costa quando a ZCIT está mais ao norte da costa brasileira, que corresponde ao final do período de transição I, estação da seca e início do período de transição II (junho a dezembro), que são as épocas de menor precipitação, quando também ocorre o seu período de maior captura. Este fato pode estar relacionado à variação da salinidade da região costeira mais próxima aos estuários, já que a pescadinha-gó é um peixe marinho que utiliza o estuário como local de reprodução e para alimentação de larvas e juvenis.

Os dados de temperatura da superfície do mar (TSM) indicaram não haver uma relação direta na migração da pescadinha-gó, pois esta variável ambiental na região equatorial não sofre grandes flutuações sazonais, permanecendo praticamente inalterada por quase todo o ano. Cabe ressaltar que, apesar de se tratar de uma espécie demersal, a TSM foi usada como mais um indicador, embora indireto, de possíveis variações ambientais.

Tradicionalmente, a pesca na região Norte é caracterizada pela intensa atividade artesanal, atuante principalmente no Estado do Pará que, segundo Paiva (1997), é um dos maiores produtores de pescado artesanal do Brasil. Nesta atividade não existem espécies alvo, e sim um produto, composto por grande diversidade de espécies de peixes e crustáceos, que é todo comercializado localmente, e por um subproduto que é exportado: a bexiga natatória (grude). 
Paralelamente à atividade pesqueira artesanal, ocorre a atividade da pesca industrial que é impulsionada, principalmente, por dois recursos: o camarão, destacando-se o camarão-rosa, Farfantepenaeus subtilis, capturado na costa do Estado do Amapá, na foz do rio Amazonas, no nordeste do Estado do Pará e no Maranhão (JICA-MPEG-IBAMA, 1998; Aragão et al., 2001); e a piramutaba, Brachyplathystoma vaillantii, uma espécie de bagre estuarino-dulcícola (JICA-MPEG-IBAMA, 1998). Ambos recursos são direcionados ao mercado externo, já que praticamente toda a produção é exportada. Juntamente com as operações de arrasto para o camarão, outros recursos pesqueiros, de hábitos demersais, são capturados e, dentre eles, a pescada-gó.

Segundo Asano Filho et al. (2001), apenas 1,15\% das pescadas-gó capturadas pela frota camaroneira na região Norte brasileira, em 1997, foi desembarcado nas indústrias e aproveitado para consumo humano, sendo que, aproximadamente, $8.011 \mathrm{t}$ foi o desperdício estimado para a espécie nesse ano. MMA-IBAMA-CEPNOR (2001) estimou em 225,5 t a produção industrial desembarcada da pescada-gó no Estado do Pará para o ano de 1998, contra 1.921,0 t da pesca artesanal.

Em geral, as redes de arrasto são seletivas para tamanhos maiores, enquanto que outras artes, como redes de emalhe, são seletivas somente para um certo intervalo de comprimento, excluindo assim a captura de indivíduos muito pequenos e muito grandes (Sparre \& Venema, 1997). De modo contrário, mesmo com poucas e esparsas amostragens, as amostras das pescadinhas-gó provenientes das operações de arrasto para camarão mostraram-se seletivas para os indivíduos menores, enquanto que as outras artes foram menos seletivas, capturando indivíduos com uma grande amplitude de comprimento.

As maiores freqüências encontradas para os indivíduos menores ocorreram nos meses de junho e julho de 1998 para o apetrecho curral, enquanto que o surgimento 
destes indivíduos no restante das amostras, ou seja, para os outros meses, nesta arte de pesca bem como para a arte de emalhe, permaneceram constantes ao longo do período amostrado, sugerindo que o recrutamento para estas artes ocorre ao longo de todo o ano. Infelizmente, as amostras da atividade de arrasto foram esparsas, o que inviabilizou a observação do período de maior entrada destes indivíduos.

A entrada constante de peixes pequenos ocasionou uma diluição das modas de freqüências de comprimento nas amostras, o que dificultou o estudo para estimar a idade e o crescimento, tanto pelo método direto quanto pelo método indireto.

A relação peso-comprimento para todo o conjunto amostral do bloco 2, calculada em todo o período para sexos separados, mostrou haver diferenças significativas. No entanto, quando segregadas mensalmente, essas diferenças, entre machos e fêmeas ocorreram em poucos meses amostrados, ocasionando a diferença para o período total. A razão desta variação pode ser a condição nutricional sazonal da população. A diferença na relação peso-comprimento entre os sexos para todo o período divergiu daquela relatada para as populações do rio Caeté, região costeira do Norte do Brasil (Zorro, 1999), e da Guiana (Lowe McConnell, 1966), nos quais não ocorreram diferenças significativas. Conforme Ricker (1975), o motivo de tais variações pode ser a existência de diferenças entre as populações da mesma espécie, ou entre a mesma população em diferentes anos, estando presumivelmente associadas com sua condição nutricional.

\section{Idade e crescimento de Macrodon ancylodon da costa} Norte do Brasil

Como já foi mencionado, estudos sobre crescimento e avaliação da idade são essenciais para as estimativas de produção, do tamanho de estoques, do recrutamento e 
da mortalidade, de modo que muito esforço tem sido feito para que estes sejam realizados (Lowe-McConnell, 1999), principalmente em regiões tropicais (Manickchand-Heileman \& Phillip, 2000; Pilling et al., 2000; Rivera, 2000).

Segundo Sparre \& Venema (1997), o estudo do crescimento significa, basicamente, a estimativa do tamanho do corpo dos indivíduos em função da idade e, por consequiência, todos os métodos de avaliação de estoques pesqueiros trabalham essencialmente com dados de composição etária. Em águas temperadas, tais dados podem ser geralmente obtidos através da contagem de anéis anuais em partes rígidas, tais como escamas e otólitos. Esses anéis são formados devido às diferenças ambientais, bióticas e abióticas, do verão e do inverno. Porém, em áreas tropicais, não ocorrem mudanças drásticas nas características ambientais tornando muito difícil, senão impossível, usar a contagem de anéis sazonais para a avaliação de idades.

Existem métodos numéricos que permitem converter dados de freqüência de comprimento em composição por idades (Sparre \& Venema, 1997). Embora estes métodos não requeiram a leitura de anéis em partes rígidas, a interpretação final dos resultados torna-se mais confiável se estiverem disponíveis algumas leituras diretas de idade. A melhor resolução na avaliação de estoques pesqueiros de espécies tropicais é, portanto, a análise de um grande número de dados de freqüência de comprimento, combinada com um pequeno número de leituras de idade com base em anéis diários (Sparre \& Venema, 1997; Ahrenholz et al., 2000; Powell et al., 2000). Este método direto é dispendioso e tecnicamente mais difícil de ser executado e, por esta razão, é pouco utilizado, sendo os dados de frequiência de comprimento e estudos de idade com base em marcas anuais os mais freqüentemente utilizados.

Sparre \& Venema (1997) ressaltam que, quando se estudam os parâmetros de crescimento e os aspectos reprodutivos de uma espécie, deve-se sempre ter em mente que eles, logicamente, diferem de espécie para espécie, mas que também podem variar 
de estoque para estoque e entre machos e fêmeas de uma mesma espécie. Coortes sucessivas também podem crescer diferentemente, dependendo das condições ambientais.

Por estas razões, deve-se ter cautela ao se relacionar resultados sobre $M$. ancylodon da região Norte com aqueles da região Sudeste/Sul brasileira pois, em seu estudo, Santos (2002) sugere a existência de mais de uma espécie para o gênero Macrodon na costa brasileira, sendo este constituído por duas espécies crípticas, uma ocorrendo na região tropical (Venezuela, costas Norte e Nordeste brasileiras) e outra na região subtropical (costas Sudeste e Sul do Brasil, e costa da Argentina).

Vale relembrar que as análises das estimativas de crescimento realizadas neste estudo foram feitas para sexos grupados, já que não foi possível identificar o sexo dos indivíduos devido ao mau estado de conservação dos mesmos. Nesse sentido não se pôde verificar se há um crescimento diferencial entre machos e fêmeas.

O estudo de idade e crescimento, através da leitura de anéis sazonais em otólitos sagita inteiros de M. ancylodon, já havia sido realizado por Yamaguti (1966) Martins-Juras (1980) e Castro (2000) para as populações sudeste e sul do Brasil. Para essas populações, os referidos autores concluíram que a formação de anéis é anual.

Para a população tropical de $M$. ancylodon, localizada na região Norte brasileira, foram realizados testes em estruturas rígidas para a seleção daquelas que mais adequadamente revelassem a idade, verificando-se que dentre as vértebras, as escamas, os otólitos e os opérculos, a secção transversal do otólito foi a estrutura que melhor indicou o padrão de anéis (JICA-MPEG-IBAMA, 1998). Esse estudo concluiu que, durante a estação de chuvas, não houve correspondência na formação dos anéis entre os indivíduos, ou seja, a maioria dos anéis não estavam sendo formados na mesma época, e 
que os valores encontrados pelo método de incremento marginal foram largamente dispersos. Este fato, também, foi observado para outros cienídeos da região.

No presente estudo, tanto o método do incremento marginal (IM) quanto do tipo de bordo não validaram a formação dos anéis de crescimento. Contudo o método do tipo de bordo sugere a formação de dois anéis anuais, um em setembro e o outro em janeiro. Ávila-da-Silva (2002) também encontrou dificuldades em validar anéis de crescimento pelo método do IM, devido ao número amostral de indivíduos de Lopholatilus villarii por anéis observados não permitir o cálculo do IM mensal, e ao pequeno aumento do raio total dos otólitos nos indivíduos maiores.

A não-validação dos anéis de crescimento sazonal para $M$. ancylodon da costa Norte do Brasil corrobora o estudo preliminar realizado pela JICA-MPEG-IBAMA (1998), no sentido de que os anéis da espécie M. ancylodon da costa Norte do Brasil sofrem uma grande variação individual no período de sua formação e que, por esta razão, os anéis sazonais não expressariam o crescimento e a idade da referida espécie. Entretanto novos esforços devem ser direcionados ao estudo do crescimento com base em anéis diários para a pescada-gó, os quais poderiam elucidar seu crescimento e idade.

A validação dos anéis de crescimento foi impossibilitada pela baixa correspondência entre as leituras, dificultada, principalmente: pela seletividade da amostra, composta por indivíduos em uma restrita faixa de comprimento total; pela fraca marcação dos anéis; pela sua baixa legibilidade; pelas deformações morfológicas encontradas nas secções, resultando em um reduzidíssimo número de indivíduos por grupo de anel; e pela entrada constante de novos indivíduos na população, que ocasiona a marcação dos anéis sazonais em posições diferentes nos otólitos.

Como já foi ressaltado anteriormente, em regiões tropicais, as marcas de anéis de crescimento em estruturas rígidas são dificilmente validadas, pois estas regiões não 
sofrem fortes variações ambientais sazonalmente, como ocorrem nas regiões temperadas, onde grandes diferenças sazonais ambientais são evidenciadas.

O crescimento de um peixe é dito isométrico quando o comprimento, a altura e a largura crescem proporcionalmente, sendo que, geralmente, todas as estruturas do peixe acompanham esta regra. A partir das equações que descreveram a relação das medidas do peixe e das medidas dos otólitos, verifica-se que esta afirmação é verdadeira para o otólito até um certo ponto de seu crescimento pois, diferentemente do peixe, que tem todo o ambiente circundante para crescer, cada par de otólito é envolvido por uma cápsula (sacculus para o par sagitta, utriculus para o par lapillus e lagena para o par asteriscus (Lagler et al., 1962)) que restringe seu crescimento ao atingir um determinado comprimento, ou seja, o peixe e o otólito crescem em uma mesma proporção mas, a partir de um determinado comprimento, este crescimento deixa de ser proporcional. Por esta razão, geralmente se encontram dificuldades em ler anéis nas bordas de otólitos dos indivíduos maiores, pois os anéis de crescimento ficam tão próximos entre si que o limite de sua resolução dificulta a leitura.

Mesmo não expressando o crescimento da espécie para a região Norte brasileira, foi possível, através dos anéis translúcidos, verificar uma constância na posição de cada anel em relação ao núcleo, indicando a ocorrência de duas coortes anuais. Portanto, a confirmação dessas coortes corrobora os estudos realizados por Zorro (1999), que encontrou duas coortes, a primeira nascendo em julho-agosto e a segunda em outubro-novembro; e Santana (1998), que também encontrou duas coortes, a primeira nascendo em janeiro e a segunda em agosto, ambos realizados para a espécie na costa Norte brasileira (Tab. 7). Resultados semelhantes foram achados para a população da região Sul do Brasil, onde Martins-Juras (1980) encontrou uma bimodalidade da distribuição de freqüência de comprimento para o primeiro anel do 
otólito, sendo esta bimodalidade explicada pela presença de dois picos de desova; e Isaac-Nahum (1989), utilizando dados de freqüência de comprimento, verificou duas coortes, a primeira em março e a segunda em dezembro. Para a população da região Sudeste do Brasil, Castro (2000) encontrou duas coortes, a primeira surgindo em abril e a segunda surgindo em novembro.

A formação de anéis de crescimento, em algumas espécies de peixes tropicais ou mesmo para $M$. ancylodon da população sudeste, foi atribuída à desova e relacionada aos processos fisiológicos (Castro, 2000; Manickchand-Heileman \& Phillip, 2000). Para a população sul, tanto Yamaguti \& Santos (1966) quanto Martins-Juras (1980) concluíram que a formação dos anéis pode ser decorrente da influência da Corrente das Malvinas ou da migração que a população realiza ao longo da costa. Falsos anéis podem ser encontrados para a espécie sul (Martins-Juras, 1980), os quais são formados no período que corresponde à época de desova (Juras, 1979).

De uma forma geral, a formação dos anéis de crescimento em peixes é atribuída às variações intrínsecas da fisiologia do organismo, da sua dinâmica trófica, das migrações realizadas pela espécie e do tipo de desova. No caso de Macrodon ancylodon da costa Norte brasileira, a formação dos anéis de crescimento pode ser atribuída aos mesmos fatores individuais ou até mesmo a todos estes fatores em conjunto, já que os mesmos não apresentam um padrão comum de formação.

Devido à dificuldade encontrada para validar os anéis que expressam o crescimento, os parâmetros da curva de crescimento de von Bertalanffy não puderam ser calculados pelo método direto, sendo estes estimados a partir das freqüências de comprimento provenientes das atividades de pesca artesanal que utilizam o curral como arte de pesca. Este tipo de armadilha é menos seletiva que redes de emalhe e redes de 
arrasto. Por este motivo pôde-se acompanhar uma suave progressão modal da frequiência de comprimento total dos indivíduos para o período estudado.

Vale ressaltar que, de maneira geral, a desova ocorre durante o ano inteiro em regiões tropicais e mesmo tendo apresentado duas coortes, existe um recrutamento contínuo durante todo ano. Neste caso, a progressão sazonal de modas é extremamente sutil nos dados de freqüência de comprimento.

Os valores encontrados para os parâmetros da curva de crescimento de von Bertalanffy foram diferentes dos relatados para a espécie na região por Santana (1998) e por Zorro (1999). Este fato foi ocasionado pelo comprimento total máximo encontrado neste trabalho, que foi $45,0 \mathrm{~cm}$, superior aos comprimentos totais descritos por Santana (1998), com 42,0 cm, e Zorro (1999), com 41,0 cm, elevando o valor de $\mathrm{L}_{\infty}$ e, conseqüentemente, reduzindo o valor de "k". Mesmo diferindo nos valores dos parâmetros de crescimento, a idade estimada de seis anos para a $M$. ancylodon neste estudo foi similar àquela estimada por Zorro (1999), que foi de seis a sete anos.

Segundo Sparre \& Venema (1997), a principal fonte de erro que incide sobre estudos de crescimento está relacionada à amostragem obtida de capturas comerciais, que não capturam amostras aleatórias do estoque, tendo em vista tamanhos comercializáveis e áreas onde há maior concentração de pescados. Isto pôde ser verificado nas amostras provenientes das atividades de arrasto para camarão.

\section{Estrutura e dinâmica da reprodução de Macrodon ancylodon}

\section{da costa Norte do Brasil}

Segundo Isaac-Nahum (1983), as modalidades de reprodução, e em particular o ritmo de desova, representam respostas do organismo ao meio ambiente. 
Em águas tropicais, onde as temperaturas não seriam limitantes para a desova dos peixes, a sazonalidade é imposta principalmente por outros fatores ambientais, relacionados ao: a) aporte de nutrientes, embora alguns outros fatores possam influenciar diretamente as espécies; e b) pressões bióticas, que podem impor sazonalidade em ambientes relativamente não-sazonais, com suas comunidades de peixes muito diversas (Lowe-McConnell, 1987).

Para Micropogonias furnieri, outro cienídeo, as diferenças na periodicidade no ciclo reprodutivo ao longo de sua área de ocorrência estão provavelmente associadas às características oceanográficas de cada uma das regiões de ocorrência da espécie (IsaacNahum, 1983). Ao que tudo indica, o mesmo ocorre com M. ancylodon da costa Norte do Brasil, já que a mesma apresenta uma grande distribuição geográfica, pois ocorre desde a Venezuela às costas Norte e Nordeste brasileira.

Relativamente às proporções sexuais, os dados mostraram não haver predominância entre os sexos para o período total. Porém estas proporções sofreram alterações ao longo do período, não revelando nenhum padrão anual definido que pudesse indicar alguma relação de predomínio de um dos sexos com eventos ligados com a reprodução. Segundo Peres-Rios (2001), de um modo geral, as proporções de machos e fêmeas favorecendo um dos sexos pode significar fenômenos biológicos como segregação, migração ou sobrevivência diferencial, relacionados ou não com a reprodução. Peres-Rios (op. cit.) também observou que, para algumas espécies estuarinas, as diferenças observadas na razão 1:1 não estão relacionadas com o comportamento reprodutivo destas espécies, pois não obedecem a um padrão definido ao longo do ano.

O fato de ocorrer predominância de machos nos comprimentos inferiores a 25,0 cm pode ser devido a uma superestimativa dos indivíduos imaturos, já que o 
aspecto macroscópico de machos e de imaturos é semelhante. Predominância significativa de fêmeas de $M$. ancylodon das costas Sudeste e Sul nos comprimentos maiores já havia sido observada por Castro (2000), que reforçou a hipótese de Yamaguti \& Santos (1966) e Martins-Juras (1980) de que as fêmeas crescem mais que os machos. Silva (1996), Almeida (2001) e Dias et al. (2002) também encontraram predominância de fêmeas sobre os machos em comprimentos maiores para outras espécies. Eles atribuíram o fato a uma possível maior taxa de mortalidade dos machos, que também podem apresentar padrões de crescimento diferentes das fêmeas. Portanto, como não foi possível estimar o crescimento diferencial entre machos e fêmeas de M. ancylodon da costa Norte por meio das amostras do bloco 3 e com base nos dados da literatura, sugere-se que a predominância das fêmeas sobre os machos nos comprimentos superiores a 37,0 cm é, também, decorrência de crescimento diferencial entre os sexos.

Através das análises de distribuição de freqüência de indivíduos em cada estádio ao longo do ano, observou-se que o estádio "B” (em maturação) apareceu praticamente durante todo o ano, sendo que seu máximo de freqüência não foi seguido cronologicamente pelo estádio "C" (maduro), mas sim pelo "E" (desovado), sugerindo que a fecundidade parcial é baixa e que a desova é do tipo parcelada. Porém o surgimento de "B" ao longo de todo o ano pode ser devido a outros fatores: a) a não identificação correta de "E" (desovado) devido a uma baixa fecundidade parcial, fato comprovado neste trabalho; e b) que o estádio "B" é aquele para o qual os indivíduos retornam ao final de toda a desova. Além disso, o fato de "B" ser seguido por "E" pode indicar que o estádio "C" seja de curta duração, ou seja, que a maturação seja rápida.

As diferenças entre os valores dos fatores de condição $(\Delta \mathrm{K})$ e das relações gonadossomáticas $(\triangle \mathrm{RGS})$ indicaram haver picos de reprodução nos meses de julhoagosto/1998 e dezembro/1998-fevereiro/1999. Contudo observou-se que a atividade 
reprodutiva se faz por quase todo o ano, pois a freqüência de gônadas em atividade reprodutiva e de outros valores não tão baixos de $\Delta \mathrm{RGS}$ e $\Delta \mathrm{K}$ foram observados durante quase todo o ciclo reprodutivo.

A desova da pescada-gó ocorre, praticamente, o ano todo, com duas épocas mais intensas: a primeira em julho-agosto e a segunda em dezembro-fevereiro, que foram identificadas pela freqüência dos estádios gonadais, mas, principalmente, reforçadas pelas variações do fator de condição e pelas variações da relação gonadossomática. A análise da freqüência dos estádios gonadais indicou haver um pico de desova em março-abril, porém os resultados do fator de condição e da relação gonadossomática não indicaram haver ocorrido um pico expressivo para este período, e sim a desova de alguns indivíduos. Comparando-se estes dados com os de outras regiões, verificou-se que ocorre uma concordância para o pico reprodutivo para a espécie norte no período entre julho e agosto e entre dezembro e fevereiro (Santana, 1998; Zorro, 1999) (Tab. 8). Cabe lembrar que o mês de janeiro não foi referenciado, pois não houve amostragem neste mês.

Outro cienídeo de região equatorial que apresenta uma desova durante todo o ano é a corvina, Cynoscion maracaibaensis, da Venezuela, que apresenta um período principal, de janeiro a maio, e períodos secundários, em junho e setembro (AlmeidaPerez, 1972).

Ao que parece, os picos da desova da pescada-gó estão intimamente ligados ao regime pluviométrico. O gatilho ambiental destes picos de atividade reprodutiva está, provavelmente, no desbalanço pluviométrico existente na região, ou seja, os picos de desova ocorrem nas épocas que correspondem ao final do período de transição dos regimes. 
Os valores estimados para o comprimento médio da primeira maturação gonadal de $M$. ancylodon foram relativamente superiores àqueles estimados para as regiões costeiras de Salinópolis e do rio Caeté no Estado do Pará, e similares aos encontrados na Guiana (Lowe-McConnell, 1966; Santana, 1998; Zorro, 1999) (Tab. 9). Este fato pode ser devido às variações ambientais, e mesmo a diferenças entre as coortes. Comparando-se estes resultados com os encontrados para as populações Sudeste/Sul, parece não haver grandes diferenças entre as espécies, exceto os valores encontrados por Lara (1951) e Castro (2000), fato que pode ser atribuído às condições oceanográficas na região, à metodologia empregada, e, principalmente, ao fato de se tratar de populações e mesmo de espécies diferentes.

Correlacionando-se os dados de crescimento obtidos neste trabalho com os do L50, verificou-se que a idade média em que $50 \%$ dos indivíduos adultos estão participando do processo reprodutivo corresponde a aproximadamente 1,5 ano.

A partir do $\mathrm{L}_{50}$, verificou-se que em todos os blocos amostrais houve uma grande incidência de indivíduos que ainda não estão participando do processo reprodutivo, sendo estes capturados principalmente pela atividade de arrasto, pois proporcionalmente foi a atividade que mais concentrou indivíduos jovens.

Considerando, ainda, o valor do $\mathrm{L}_{50}$ e o valor percentual citado no início deste item, de que somente $1,15 \%$ das pescadas-gó provenientes da atividade industrial foram desembarcadas no ano de 1997, podemos inferir que praticamente todas as pescadas-gó descartadas no mar pela frota camaroneira eram indivíduos jovens, já que somente os indivíduos com os maiores comprimentos são desembarcados por esta atividade, visando a relação "custo-benefício". Esta grande ocorrência de indivíduos jovens que são descartados no mar pela pesca industrial também foi verificada por Santana (1998). 
Dias et al. (1998) sugerem que, para o entendimento do ciclo reprodutivo de indivíduos de diferentes espécies, se fazem necessários métodos diferentes aplicados concomitantemente, para que os indicadores gerados sejam mais precisos. Assim, as informações geradas pelos métodos qualitativos e quantitativos, como a relação gonadossomática, a distribuição da freqüência do diâmetro dos ovócitos e as classificações macro- e microscópica dos ovários, capacitarão o pesquisador para a tomada de decisões e elaboração de respostas, que atendam as demandas do conhecimento. Destes métodos, a classificação microscópica, apesar das dificuldades, é a mais precisa, pois considera as fases específicas do desenvolvimento dos ovócitos. Além disto, Dias et al. (1998) indicam que as escalas de maturidade que utilizam somente a classificação macroscópica correm o risco da subjetividade, generalização, não-detecção de desova recente e não-identificação de desova iminente. Dentre todos os estádios de maturidade macroscópico, o estádio "B" foi considerado pelos autores o mais crítico, por não apresentar caracteres tão distintos e particulares, como os encontrados para outros estádios.

Dias et al. (1998) recomendam, ainda, que a classificação macroscópica pode ser adequada para a percepção de desova em espécies que liberam todos os seus ovócitos num curto período de tempo (desova total), pois o número de ovócitos já maduros na gônada é grande e, com sua liberação, o ovário toma uma aparência flácida, hemorrágica e simultaneamente, há pouca ou nenhuma visualização de ovócitos. No entanto, nas espécies com fecundidade parcial baixa, a liberação de um número menor de ovócitos por desova torna imperceptível macroscopicamente a identificação dos indivíduos desovados.

Isaac-Nahum (1981) confirmou, pelas evidências histológicas, que a desova de Micropogonias furnieri é do tipo parcelada, em pelo menos dois lotes. Além disso, 
pelas modificações anatômicas macro- e microscópicas que ocorrem nos ovários ao longo do ciclo reprodutivo, a escala que melhor refletiria a realidade deveria ser composta por sete estádios: A - $B_{1}-B_{2}-C_{1}-C_{2}-D-R$.

A avaliação microscópica de gônadas "B" de M. ancylodon mostrou a existência de estruturas citológicas indicadoras de desova recente, ou seja, folículos pós-ovulatórios. Assim como para M. furnieri, é sugerido que no ciclo reprodutivo de M. ancylodon ocorram estádios intermediários entre o inicio da maturação e as desovas sucessivas. Seguindo o mesmo critério utilizado por Vazzoler (1971) e por Isaac-Nahum (1981), o ciclo reprodutivo de M. ancylodon da costa Norte do Brasil pode ser descrito por estádios maturacionais com possíveis intermediários $\left(A-B_{1}-B_{n}-C_{1}-C_{n}-D-D_{n}-\right.$ $\left.E-E_{n}\right)$.

A análise da freqüência de diâmetro dos ovócitos, realizada em gônadas classificadas macroscopicamente como "B", sugeriu que o desenvolvimento ovocitário da pescadinha-gó é do tipo sincrônico em dois grupos e, como visto anteriormente, os dados sugerem que a desova é do tipo parcelada, com tendências à intermitência, uma vez que a liberação dos ovócitos maduros pode ocorrer continuamente durante o ciclo reprodutivo dos indivíduos.

A desova do tipo parcelada já havia sido atribuída à espécie $M$. ancylodon da costa Sul brasileira, através de observações que utilizaram dados macroscópicos (Vazzoler, 1963a; Yamaguti, 1967; Juras, 1979; Moraes, 1980). Desovas parceladas também foram descritas para outro cienídeo, Stellifer rastrifer, da baía de Guaratuba-PR (Chaves \& Vendel, 1997) e do complexo estuarino-lagunar de Cananéia-Iguape-SP (Peres-Rios, 2001).

Todos os resultados observados isoladamente não podem ser considerados como bons indicadores da atividade reprodutiva da pescadinha-gó. Peres-Rios (2001) 
verificou que a RGS isolada não é suficiente para indicar o período de desova para uma espécie com desova parcelada, onde vários lotes de ovócitos são eliminados sucessivamente ao longo do período de desova. A mesma autora considera que pequenas alterações no peso da gônada, decorrentes da desova de pequenas parcelas, não provocaram variações acentuadas, a ponto de se refletirem nos valores da RGS. Portanto, tomou-se por prudência, analisar todos os resultados em conjunto, constatando-se que a desova é parcelada, através da análise da freqüência dos estádios de maturidade gonadais e pela avaliação microscópica do estádio "B", que encontrou a ocorrência de folículos pós-ovulatórios associados a ovócitos maduros não hidratados. 


\section{V- SÍNTESE DOS RESULTADOS E RECOMENDAÇÕES}

1. Com base nos dados pluviométricos, a região Norte brasileira apresenta duas estações anuais e dois períodos transicionais de acordo com a intensidade da precipitação: estação das chuvas (fevereiro a abril), período de transição I (maio a julho), estação da seca (agosto-outubro) e período de transição II (novembro-janeiro).

2. A relação peso-comprimento para as amostras dos blocos 2 e 3 não mostrou diferenças significativas, enquanto na mesma análise para machos e fêmeas do bloco 2 de amostras houve diferenças significativas, indicando diferenças no crescimento em peso ou comprimento entre machos e fêmeas.

3. A análise da porcentagem do tipo de bordo e da constância na posição dos anéis nos otólitos indica a existência de duas coortes anuais.

4. Os parâmetros da curva de crescimento de von Bertalanffy estimados pelo método indireto através do pacote computacional ELEFAN I foram:

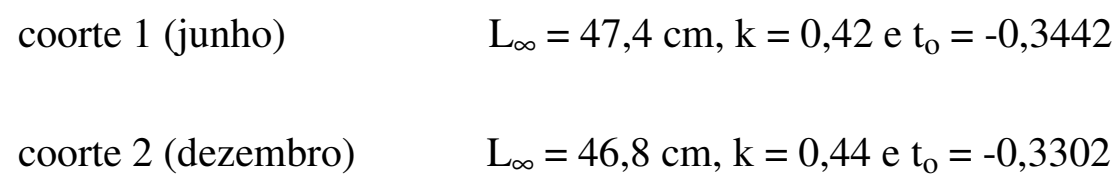

5. Para o ciclo reprodutivo total não houve predominância significativa de machos e fêmeas. Os machos predominaram significativamente nos comprimentos inferiores a 25,0 cm e as fêmeas em comprimentos superiores a 37,0 cm. Não houve indícios de predominância de um dos sexos relacionada à época de desova.

6. O período reprodutivo da espécie é prolongado, com desova do tipo parcelada tendendo a intermitência, apresentando picos nos meses de julho-agosto e dezembro-fevereiro, coincidindo com o final do período de transição das chuvas e reforçando o surgimento das coortes de crescimento. 
7. O comprimento no qual $50 \%$ das fêmeas está no processo reprodutivo $\left(\mathrm{L}_{50}\right)$ foi estimado em 25,08 cm, com 1,5 ano de vida. Este comprimento, aliado à freqüência de comprimentos, indica a grande captura de indivíduos jovens nas atividades pesqueiras, principalmente na atividade industrial. Todas as fêmeas estão aptas a participar do processo reprodutivo $\left(\mathrm{L}_{100}\right)$ a partir de $34,0 \mathrm{~cm}$.

8. A análise microscópica de gônadas avaliadas macroscopicamente como "B" mostrou a existência de folículos pós-ovulatórios em $34,3 \%$ dos indivíduos, evidenciando que a desova não foi detectada macroscopicamente em mais de 1/3 das gônadas avaliadas microscopicamente.

9. A escala macroscópica utilizada apresentou um nível de acerto do estádio "B" em apenas $60 \%$ das gônadas analisadas microscopicamente.

10. Devido ao aparecimento dos folículos pós-ovulatórios em gônadas avaliadas macroscopicamente como "B", o ciclo reprodutivo de M. ancylodon da costa Norte do Brasil pode ser descrito por estádios maturacionais com possíveis intermediários $\left(A-B_{1}-B_{n}-C_{1}-C_{n}-D-D_{n}-E-E_{n}\right)$.

11. Recomenda-se coleta de dados ambientais para caracterizar massas de água e situações oceanográficas relacionadas à precipitação e entrada de água doce no sistema mar-rio que possam subsidiar o entendimento do ciclo de vida da espécie estudada.

12. Devido à impossibilidade de avaliar a idade e crescimento através de marcas sazonais em otólitos sagita de Macrodon ancylodon da costa norte brasileira, recomenda-se a utilização de técnicas de contagem de anéis diários para a estimativa dos parâmetros de crescimento.

13. Recomenda-se realizar estudos sobre idade e crescimento em machos e fêmeas para verificar se há crescimento diferencial. 


\section{VI- CONCLUSÃO}

Neste estudo foram aplicados métodos diretos e indiretos para avaliação da idade e do crescimento da pescada-gó, além de métodos quantitativos e qualitativos para o detalhamento dos estudos sobre a reprodução da espécie. Na tentativa da aplicação de ferramentas metodológicas com maior resolução para o estudo de aspectos da dinâmica populacional de Macrodon ancylodon do norte do Brasil, relativos à idade, crescimento e reprodução, os resultados ora obtidos corroboram aqueles anteriormente relatados para a espécie e os amplia.

Apesar do elevado número de exemplares examinados neste estudo, a utilização de amostras de diversas procedências, bem como problemas com a conservação de algumas delas, não possibilitou a elucidação de alguns aspectos relativos à idade e à reprodução da espécie, que permanecem em aberto como perspectiva para trabalhos futuros. 


\section{V - REFERÊNCIAS BIBLIOGRÁFICAS}

Ahrenholz, D. W.; D. D. Squires; J. A. Rice; S. W. Nixon \& G. R. Fitzhugh. 2000. Periodicity of increment formation in otoliths of overwintering postlarval and prejuvenile atlantic menhaden, Brevoortia tyrannus. Fish. Bull, 98: 421-426.

Almeida, E. M. de . 2001. Estrutura da população, crescimento e reprodução de Maurolicus stehmanni Parin \& Kobyliansky, 1993 (Teleostei: Sternoptychidae) na Zona Econômica Exclusiva do Sul e Sudeste do Brasil. Dissertação de mestrado. Instituto Oceanográfico da Universidade de São Paulo, São Paulo, 118 p.

Almeida-Perez, P. 1972. Estudio preliminar de la histociologia de los ovários de la corvina Cynoscion maracaibaensis, Schultz, del lago de Maracaibo (Venezuela). (Perciformes, Sciaenidae). Mem Soc. cient. natur. "La Salle”, 32 (91): 20-46.

Aragão, J. A. N.; I. H. A. Cintra; K. C. de A. Silva \& I. J. A. Vieira. 2001. A explotação camaroneira na costa Norte do Brasil. Bol. Técnico-Científico do CEPNOR/Centro de Pesquisa e Extensão Pesqueira do Norte do Brasil, 1 (1): 11-44.

Asano Filho, M.; R. C. do Nascimento \& C. S. F. de Brito. 2001. Estimativa da participação da pescado-gó (Macrodon ancylodon, Bloch \& Schneider, 1801) nas pescarias do camarão na região Norte do Brasil. Bol. Técnico-Científico do CEPNOR/Centro de Pesquisa e Extensão Pesqueira do Norte do Brasil, 1 (1): 103-112.

Ávila-da-Silva, A. O. 2002. A evolução da pesca de linha-de-fundo e a dinâmica de população do peixe-batata, Lopholatilus villarii (Teleostei: Malacanthidae) na margem continental da costa brasileira entre os paralelos $22^{\circ}$ e $28^{\circ} \mathrm{S}$. Tese de doutorado. Instituto Oceanográfico da Universidade de São Paulo, São Paulo, $218 \mathrm{p}$. 
Bastos, G. C. C. 1990. Morfologia de otólitos de algumas espécies de perciformes (Teleostei) da Costa Sudeste-Sul do Brasil. Dissertação de Mestrado. Instituto Oceanográfico da Universidade de São Paulo, São Paulo, 180 p.

Bertozzi, C. P. 2002. Análise da pesca artesanal na região da Praia Grande (SP), no período 1999-2001. Dissertação de Mestrado. Instituto Oceanográfico da Universidade de São Paulo, São Paulo, 226 p.

Braga, F. M. de S. 1986. Estudo entre fator de condição e relação peso/comprimento para alguns peixes marinhos. Rev. brasil. Biol., 46 (2): 339-346.

Cadima, E. L. 2000. Manual de avaliação de recursos pesqueiros. FAO Doc. Técn. Pescas, 393, Roma, FAO: 162 p.

Campana, S. E. 2001. Acuracy, precision and quality control in age determination, including a review of the use and abuse of age validation methods. J. Fish Biol., 59: $197-242$.

Castro, B. M. \& L. B. de Miranda. 1998. Physical oceanography of the western atlantic continental shelf located between $4^{\circ} \mathrm{N}$ and $34^{\circ} \mathrm{S}$ coastal segment $(4, \mathrm{~W})$. In: Robinson, A. R. \& K. H. Brink. ed. The Sea, Oxford, John Wiley \& Jons, p. 209-251.

Castro, P. M. G. de. 2000. Estrutura e dinâmica da frota de parelhas do estado de São Paulo e aspectos biológicos dos principais recursos pesqueiros demersais costeiros da região Sudeste/Sul do Brasil $\left(23^{\circ}-2^{\circ}\right)$. Tese de doutorado. Instituto Oceanográfico da Universidade de São Paulo, São Paulo , 261 p.

Chaves, P. de T. da C. \& A. L. Vendel. 1997. Reprodução de Stellifer rastrifer (Jordan) (Teleostei, Sciaenidae) na Baía de Guaratuba, Paraná, Brasil. Revta. bras. Zool., 14 (1): 81-89. 
Chaves, P. de T. da C. 1985. O desenvolvimento ovocitário em representantes de dez famílias de teleósteos amazônicos: aspectos estruturais e considerações ecológicas. Dissertação de mestrado. Fundação Universidade do Amazonas, Instituto Nacional de Pesquisas da Amazônia, Manaus, 70 p.

Chaves, P. de T. da C. 1988. Aspectos convergentes da dinâmica ovariana nos peixes, com uma contribuição à biologia reprodutiva de 14 espécies do litoral de São Paulo. Tese de doutorado. Instituto Oceanográfico da Universidade de São Paulo, São Paulo, 123 p.

Chilton, D. E. \& R. Beamish. 1982. Age determination methods for fishes studied by the Groundfish Program at the Pacific Biological Station. Can. Sp Publ Fish. Aquat Sci., 60: 1- 102.

Dias, J. F.; E. Peres-Rios; P. de T. da C. Chaves \& C. L. del B. Rossi-Wongtschowski. 1998. Análise macroscópica dos ovários de teleósteos: problemas de classificação e recomendações de procedimentos. Rev. brasil. Biol., 58 (1): 55-69.

Dias, J. F; C. Fiadi \& L. S. H. Soares. 2002. Aspectos da dinâmica reprodutiva de Citharichthys spilopterus no saco do Mamanguá (RJ). Resumos In: Simpósio Brasileiro de Oceanografia, São Paulo, 2002. Universidade de São Paulo Instituto Oceanográfico, $46 \mathrm{p}$.

Fernandes, G. 1982. Estudo da alimentação da "corvina boca-mole", Macrodon ancylodon (Bloch \& Schneider, 1801) Teleostei, Sciaenidae, na Ilha de São Luis Maranhão. Bol. Lab. Hidrob., 4 (1): 51-64.

Figueiredo, A. G.; M. Allison \& C. A. Nitrouer. 1991. Amazon discharge: internal report for AMASSSEDS researchers. Relatório técnico. Universidade Federal Fluminense. Brasil, Rio de Janeiro, 45 p. 
Figueiredo, José L. de; A. P. dos Santos; N. Yamaguti; R. A. Bernardes \& C. L. del B. Rossi-Wongtschowski. Peixes da Zona Econômica Exclusiva da região SudesteSul do Brasil. 2002. São Paulo, EDUSP - Imprensa Oficial do Estado de São Paulo, 242 p.

Franks, J. S.; J. R. Warren \& M. V. Buchanan. 1999. Age and growth of cobia, Rachycentron canadum, from the northeastern Gulf of Mexico. Fish. Bull, 97 (3): 459-471.

Gayanilo, F. C. Jr. \& D. Pauly. 1997. FAO-ICLARM stock assessment tools. (FISAT) Reference manual. FAO computerized information series (fisheries). Roma. Iclarm, 8: $262 \mathrm{p}$.

Geyer, W. R., R. C. Beardsley, J. Candela, B. M. Castro, R. V. Legeckis, S. J. Lentz, R. Limeburner, L. B. Miranda \& J. H. Trowbridge. 1991. The physical oceanography of the Amazon outflow. Oceanography, 4: 8-14.

Góes, M. P. de A. 2001. Circulação do atlântico tropical para eventos extremos. Dissertação de mestrado. Instituto Oceanográfico da Universidade de São Paulo, São Paulo, 110 p.

GraphPad Prism. 1999. Version 3,0. GraphPad Software Incorporated.

Hibiya, T. 1982. An atlas of fish histology normal and pathological features. Tokyo. Kodansha Ltd., 147p.

http://podaac.jpl.nasa.gov. Em 28 de julho de 2003.

Isaac-Nahum, V. J. \& A. E. A. de M. Vazzoler. 1983. Biologia reprodutiva de Micropogonias furnieri (Desmarest, 1823) (Teleostei, Sciaenidae), 1. Fator de condição como indicador do período de desova. Bolm. Inst. oceanogr., São Paulo, 32 (1): 63-69. 
Isaac-Nahum, V. J. 1981. Biologia reprodutiva de Micropogonias furnieri (Desmarest, 1823) (Teleostei, Sciaenidae). Dissertação de mestrado. Instituto Oceanográfico da Universidade de São Paulo, São Paulo, 157 p.

Isaac-Nahum, V. J. 1989. Analysis of methods for the estimation of fish growth parameters, based on data from the family sciaenidae and on simulated data. Dissertation Zur Erlangung des Doktorgrades der MathematischNaturwissenschaftlichen. Fakultät der Christian-Albrechts-Universität zu Kiel, 242 p.

Jablonski, S. \& Y. Matsuura. 1985. Estimate of exploitation rates and population size of skipjack tuna off the southeastern coast of Brasil. Bolm. Inst. oceanogr., São Paulo, 33 (1): 29-38.

JICA-MPEG-IBAMA. 1998. The fishery resources study of the Amazon and Tocantins River mouth areas in the Federative Republic of Brazil. Japan. Sanyo Techno Marine, $331 \mathrm{p}$.

Juras, A. A. 1979. Estudo sobre reprodução (época, tipo de desova e fecundidade) e regime alimentar de Macrodon ancylodon (Bloch \& Schneider, 1801) capturada nas costas do Rio Grande do Sul (latitude $29^{\circ} \mathrm{S} 32^{\circ} \mathrm{S}$ ). Dissertação de mestrado. Instituto Oceanográfico da Universidade de São Paulo, São Paulo, 126 p.

King, M. 1995. Fisheries biology: assessment and management. Oxford, Fishing News Books. 342 p.

Lagler, K. F.; J. E. Bardach \& R. R. Miller. 1962. Ichthyology: the study of fishes. Wiley Toppan, Japan, 545 p.

Lara, F. J. S. 1951. A study of the life history of Macrodon ancylodon (Bloch \& Schneider), a sciaenid fish occurring on the coast of southern Brazil. Anais Acad. bras. Ciênc., 23 (3): 291-322. 
Le Cren, E. D. 1951. The length-weight relationship and seasonal cycle in gonad weight and condition in the perch (Perca fluviatilis). J. Animal Ecology, 20 (2): 201-219.

Lowe-McConnell, R. H. 1962. The fishes of the British Guiana continental shelf, Atlantic coast of South America, with notes on their natural history. Zoology, 44: $669-700$.

Lowe-McConnell, R. H. 1966. The scianid fishes of British Guiana. Bull mar. Sci., 16: $20-57$.

Lowe-McConnell, R. H. 1987. Ecological studies in tropical fish communities. Cambridge, Cambridge University Press, 382 p.

Lowe-McConnell, R. H. 1999. Estudos ecológicos de comunidades de peixes tropicais. Tradução Anna Emília A. de M. Vazzoler; Ângelo A. Agostinho \& Patrícia T. M. Cunnigham. São Paulo, EDUSP, 534 p.

Lux, F. E. 1971. Age determination of fishes (Revised). Saettle, United States Departament of Commerce-National Oceanic and Atmospheric AdministrationNational Marine Fisheries Service, 7 p.

Magro, M.; M. C. Cergole \& C. L. del B. Rossi-Wongtschowski. 2000. Síntese de conhecimentos dos principais recursos pesqueiros costeiros potencialmente explotáveis na costa Sudeste/Sul do Brasil: peixes. Avaliação do potencial sustentável de recursos vivos na zona econômica exclusiva - REVIZEE. São Paulo, MMA/CIRM, 145 p.

Manickchand-Heileman, S. \& D. A. T. Phillip. 2000. Age and growth of the yellowedge grouper, Epinephelus flavolimbatus, and the yellowmouth grouper, Mycteroperca intertitialis, off Trinidad and Tobago. Fish. Bull, 98: 290-298. 
Martins-Juras, I. A. G. 1980. Estudo sobre crescimento de Macrodon ancylodon (Bloch \& Schneider, 1801) capturada nas costas do Rio Grande do Sul (latitude $29^{\circ} \mathrm{S}$ a $32^{\circ}$ S). Dissertação de mestrado. Instituto Oceanográfico da Universidade de São Paulo, São Paulo, 182 p.

Matsuura, Y. 1981. Análise econômica da produção de sardinha na região sudeste do Brasil. Bolm Inst. oceanogr., São Paulo, 30 (1): 57-64.

Matsuura, Y. 1986. Estimativa de taxa de explotação, recrutamento e biomassa do estoque da sardinha-verdadeira, Sardinella brasiliensis, na região sudeste do Brasil. Ciên. Cult., 38 (5): 892-904.

Matsuura, Y. 2001. Oceanos: fonte de alimentos para o século 21. Ciência Hoje, 28 (168): 54-56.

Menezes, N. A. \& J. L. Figueiredo. 1980. Manual de peixes marinhos do sudeste do Brasil: Teleostei (3). São Paulo. Museu de Zoologia da Universidade de São Paulo, São Paulo, 96 p.

Minitab. 2000. Minitab Statistical Software Release 13.0. Minitab Inc.

Mio, S. 1961. Age and growth of red sea bream, Evynnis japonica Tanaka. Rec. Oceanogr. Wks Japan, spec., 5: 95-101.

MMA-IBAMA-CEPNOR-SECTAM. 2001. Relatório estatístico da pesca marítima do Estado do Pará. Relatório Técnico, SECTAM, Belém, 28 p.

Molinari, R. L. ; S. L. Garzoli; E. J. Katz; D. E. Harrison; P. L. Richadson \& G. Reverdin. 1986. A synthesis of the First GARP Global Experiment (FGGE) in the equatorial Atlantic Ocean. Progress in Oceanography, 16: 91-112.

Moraes, N. 1980. Aspectos do ciclo reprodutivo e do crescimento de Macrodon ancylodon Bloch \& Schneider, 1801, da Ilha do Mel (Baía de Paranaguá - 25³0’S 
48²3’W). Dissertação de mestrado. Universidade Federal do Paraná, Curitiba, $78 \mathrm{p}$.

Nédélec, C. 1982. Definition and classification of fishing gear categories. FAO Fisheries Technical Paper. Roma, 222: 51p.

Paiva, M. P. 1997. Recursos pesqueiros marinhos e estuarinos do Brasil. Fortaleza, Editora da Universidade Federal do Ceará (EUFC), 278 p.

Paiva, R. S. 2001. Parâmetros físicos, químicos, biomassa e produção primária do fitoplâncton na plataforma continental amazônica. Tese de doutorado. Instituto Oceanográfico da Universidade de São Paulo, São Paulo, 153 p.

Pauly, D. 1980. A selection of simple methods for the assessment of tropical fish stocks. FAO Fish Cir., 729: 54 p.

Pauly, D. 1983. Some simple methods for the assessment of tropical fish stocks. FAO Fish. tech. Pap., 234: 52 p.

Peres-Rios, E. 1995. Aspectos reprodutivos de Prionotus punctatus (Bloch, 1797) (Teleostei: Triglidae) na região costeira de Ubatuba, São Paulo, Brasil. Dissertação de mestrado. Instituto Oceanográfico da Universidade de São Paulo, São Paulo, 62 p.

Peres-Rios, E. 2001. Papel do estuário no ciclo de vida das espécies dominantes da ictiofauna do Complexo Estuarino-lagunar de Cananéia-Iguape. Tese de doutorado. Instituto Oceanográfico da Universidade de São Paulo, São Paulo, $128 \mathrm{p}$.

Pilling, G. M.; R. S. Milner; M. W. Easey; C. C. Mess; S. Rathacharen \& R. Azemia. 2000. Validation of annual growth increments in the otoliths of the lethrinid Lethrinus mahesena and the lutjanid Aprion virenscens from sites in the tropical 
Indian Ocean, with notes on the nature of increments in Pristipomoides filamentosus. Fish. Bull, 98 (3): 600-611.

Powell, A. B.; E. H. Laban; S. A. Holt \& G. J. Holt. 2000. Validation of age estimates from otoliths of larval and juvenile spotted seatrout, Cynoscion nebulosus. Fish. Bull, 98 (3): 650-654.

Ricker, W. E. 1975. Computation and interpretation of biological statistics of fish populations. Bull Fish. Res. Bd Can., 191: 382.

Rivera, G. A. \& R. S. Appeldoorn. 2000. Age and growth of dolphinfish, Coryphaena hippurus, off Puerto Rico. Fish. Bull, 98: 345-352.

Santana, J. V. 1998. Aspecto da pesca e da biologia da pescada-gó, Macrodon ancylodon (Bloch \& Schneider, 1801) da costa Norte do Brasil. Dissertação de mestrado. Universidade federal do Ceará, Fortaleza, 106 p.

Santos, S. S. 2002. Caracterização genética, taxonomia molecular e biogeografia da pescada-gó (Macrodon ancylodon - Sciaenidae) da costa atlântica da América do Sul. Dissertação de mestrado. Universidade Federal do Pará, Bragança, 103 p.

Silva, J. F. da. 1989. Dados climatológicos de Cananéia e Ubatuba (Estado de São Paulo). Bolm climatol. Inst. oceanogr., São Paulo, 6: 1-21.

Silva, J. P. da. 1996. Aspectos da biologia reprodutiva de Cathorops spixii (Agassiz, 1829) das Ilhas Pai Matos ( $\left.25^{\circ} \mathrm{N} 47^{\circ} 54^{\prime} \mathrm{W}\right)$ região estuarino-lagunar de Cananéia. Dissertação de mestrado. Instituto Oceanográfico da Universidade de São Paulo, São Paulo, 90 p.

Sinque, C. 1977. Distribuição do ictioplâncton na região lagunar de Cananéia e descrição de larvas da família Sciaenidae (Teleostei). Tese de doutorado. Instituto de Biociências da Universidade de São Paulo, São Paulo, 127 p. 
Sparre, P. \& S. C. Venema. 1997. Introdução à avaliação de mananciais de peixes tropicais. Parte 1- Manual. Roma, FAO Doc. téc. Pescas, 306-1, Rev. 2: 410 p.

Vaz-dos-Santos, A. M. 2002. Idade e crescimento da merluza, Merluccius hubbsi Marini, 1933 (Teleostei: Merluccidae) na zona econômica exclusiva entre o Cabo de São Tomé (RJ) e o Chuí (RS), Brasil. Dissertação de mestrado. Instituto Oceanográfico da Universidade de São Paulo, São Paulo, 191p.

Vazzoler, A. E. A. de M. 1963. Sobre a fecundidade e a desova da pescada-foguete. Bolm Inst. oceanogr., São Paulo, 13 (2): 33-40.

Vazzoler, A. E. A. de M. 1971. Diversificação fisiológica e morfológica de Micropogonias furnieri (Desmarest, 1823) ao sul de Cabo Frio, Brasil. Bolm Inst. oceanogr., São Paulo, 20 (2): 1-70.

Vazzoler, A. E. A. de M. 1982. Manual de métodos para estudos biológicos de populações de peixes: reprodução e crescimento. Brasília, CNPq, Programa Nacional de Zoologia, 108 p.

Vazzoler, A. E. A. de M. 1996. Biologia reprodutiva de peixes teleósteos: teoria e prática. Maringá, EDUEM, 169 p.

Weatherley, A. H. 1972. Growth and ecology of fish populations. Londres, Academic Press, 293 p.

West, G. 1990. Methods of assessing ovarian development in fishes: a review. Aust. J. mar. freshwater Res., 41: 199-222.

Wootton, R. J. 1990. Ecology of teleost fishes. London, Chapman and Hall, 404 p.

Yamaguti, N. \& E. P. dos Santos1966. Crescimento da pescada-foguete (Macrodon ancylodon): aspecto quantitativo. Bolm Inst. oceanogr., São Paulo, 15 (1): 75-78.

Yamaguti, N. 1967. Desova da pescada-foguete, Macrodon ancylodon. Bolm Inst. oceanogr., São Paulo, 16 (1): 101-106. 
Yamaguti, N. 1979. Diferenciação geográfica de Macrodon ancylodon (Bloch \& Schneider, 1801) na costa brasileira, entre as latitudes $18^{\circ} 36^{\prime} \mathrm{S}$ e $32^{\circ} 10^{\prime} \mathrm{S}$, etapa I. Bolm Inst. oceanogr., São Paulo, 28 (1): 53-118.

Zagaglia, C. R. 2003. Técnicas de sensoriamento remoto aplicadas à pesca de atuns no Atlântico Oeste Equatorial. Dissertação de mestrado. Instituto Nacional de Pesaquisas Espaciais, São José dos Campos, 165 p.

Zar, J. H. 1999. Biostatistical analysis. 4 ed. New Jersey, Prentice Hall, 663 p.

Zorro, M. C. 1999. Biologia e estrutura populacional das espécies da família Sciaenidae (Pisces: Perciformes), no estuário do rio Caeté município de Bragança, ParáBrasil. Dissertação de mestrado. Universidade Federal do Pará, Bragança, 87 p. 


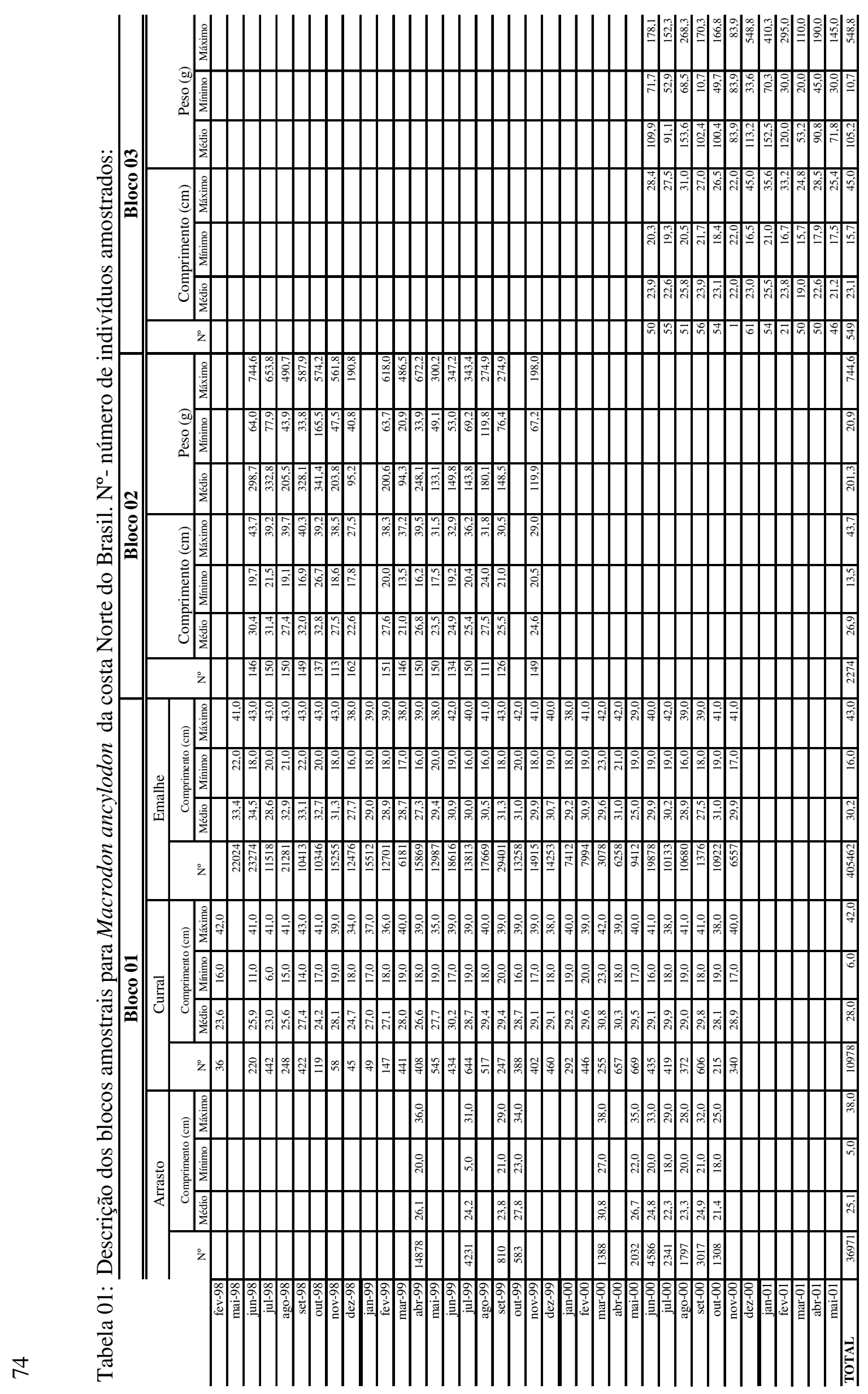




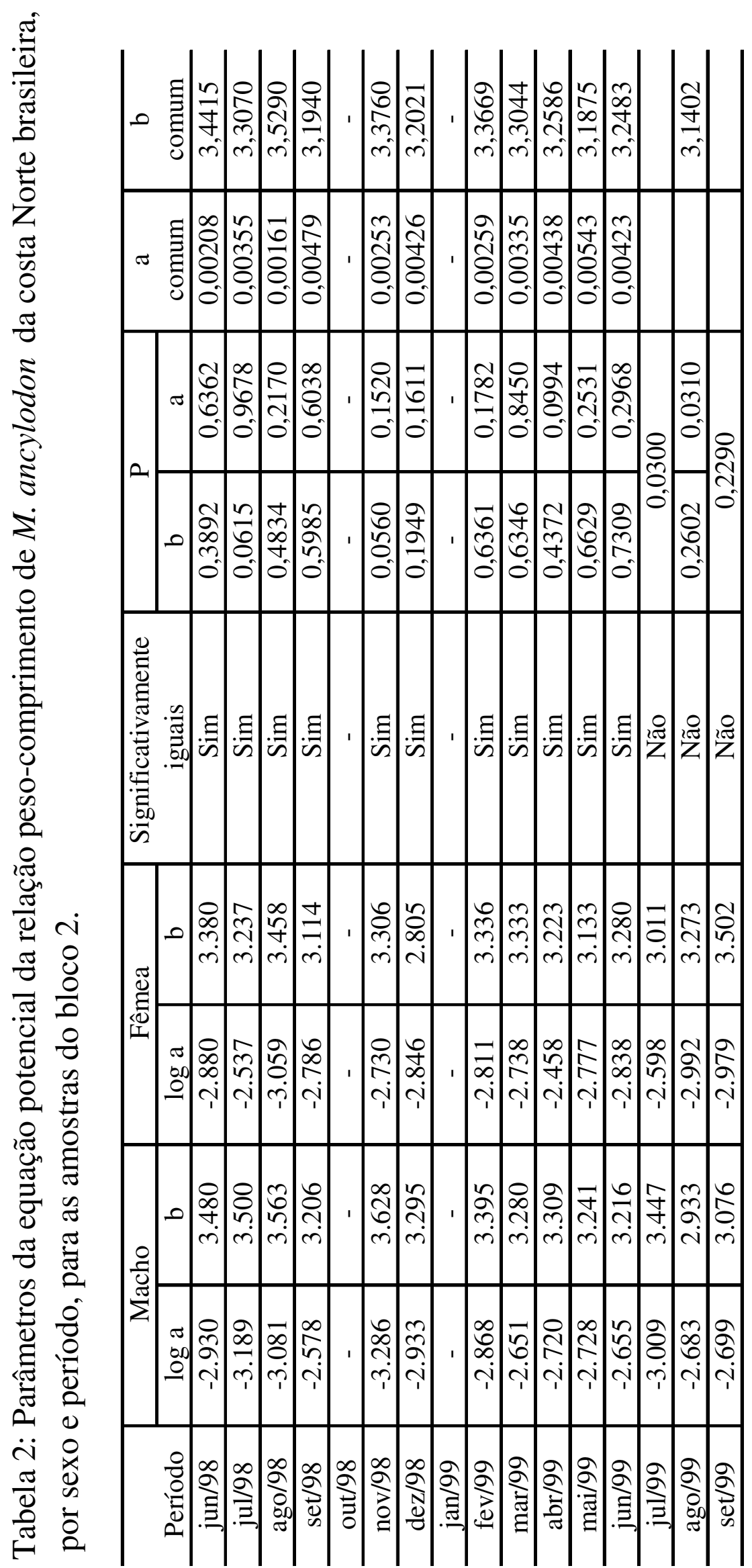


Tabela 3: Parâmetros da equação potencial da relação peso-comprimento de Macrodon ancylodon da costa Norte brasileira, por período amostrado, para as amostras do bloco 2.

\begin{tabular}{c|r|r|r}
\hline Período & a & b & $\mathrm{r}^{2}$ \\
\hline Junho/98 & 0,0026 & 3,3756 & 0,9588 \\
\hline Julho/98 & 0,0045 & 3,2376 & 0,9681 \\
\hline Agosto/98 & 0,0020 & 3,4623 & 0,9476 \\
\hline Setembro/98 & 0,0065 & 3,1088 & 0,9388 \\
\hline Outubro/98 & & & \\
\hline Novembro/98 & 0,0032 & 3,3099 & 0,9574 \\
\hline Dezembro/98 & 0,0146 & 2,8035 & 0,8284 \\
\hline Janeiro/99 & & & \\
\hline Fevereiro/99 & 0,0029 & 3,3365 & 0,9631 \\
\hline Março/99 & 0,0030 & 3,3344 & 0,9912 \\
\hline Abril/99 & 0,0048 & 3,2244 & 0,9878 \\
\hline Maio/99 & 0,0063 & 3,1352 & 0,9030 \\
\hline Junho/99 & 0,0039 & 3,2798 & 0,9171 \\
\hline Julho/99 & 0,0085 & 3,0109 & 0,8962 \\
\hline Agosto/99 & 0,0034 & 3,2730 & 0,8620 \\
\hline Setembro/99 & 0,0017 & 3,5024 & 0,9634 \\
\hline
\end{tabular}

Tabela 4: Equações das relações dos comprimentos e pesos do otólito com o comprimento e peso dos indivíduos de Macrodon ancylodon da costa Norte do Brasil. $\mathrm{L}_{\mathrm{oe}}$, comprimento do otólito esquerdo; $\mathrm{L}_{\mathrm{od}}$, comprimento do otólito direito; $\mathrm{H}_{\mathrm{oe}}$, altura do otólito esquerdo; $\mathrm{H}_{\mathrm{od}}$, altura do otólito direito; $\mathrm{W}_{\mathrm{oe}}$, peso do otólito esquerdo; $\mathrm{W}_{\mathrm{od}}$, peso do otólito direito; $\mathrm{L}_{\mathrm{t}}$, comprimento total do peixe; e $\mathrm{W}_{\mathrm{t}}$, peso total do peixe.

\begin{tabular}{l|l|l}
\hline \multicolumn{1}{c|}{ Relação } & \multicolumn{1}{|c|}{ Equação } & \multicolumn{1}{c}{ Tipo } \\
\hline \hline Loe $\mathrm{x}$ Lod & $\mathrm{y}=1,0055 \mathrm{x}-0,0505$ & reta \\
\hline Hoe $\mathrm{x}$ Hod & $\mathrm{y}=0,9704 \mathrm{x}-0,1305$ & reta \\
\hline Woe $\mathrm{x}$ Wod & $\mathrm{y}=0,9999 \mathrm{x} 0,00007$ & reta \\
\hline Loe $\mathrm{x} \mathrm{Lt}$ & $\mathrm{y}=7,8312 \ln (\mathrm{x}-30,768)$ & logarítmica \\
\hline Hoe $\mathrm{x}$ Lt & $\mathrm{y}=-0,00008 \mathrm{x}^{2}+0,0517 \mathrm{x}-2,1869$ & polinomial \\
\hline Woe $\mathrm{x}$ Wt & $\mathrm{y}=0,0000000002 \mathrm{x}^{4}-0,00000008+0,000003 \mathrm{x}^{2}+0,0014 \mathrm{x}+0,0056$ & polinomial \\
\hline Woe $\mathrm{x}$ Loe & $\mathrm{y}=0,00003 \mathrm{x}^{3,3028}$ & potencial \\
\hline Woe $\mathrm{x}$ Lt & $\mathrm{y}=-0,00000004 \mathrm{x}^{3}+0,00002 \mathrm{x}^{2}-0,0032 \mathrm{x}+0,1456$ & polinomial \\
\hline \hline
\end{tabular}




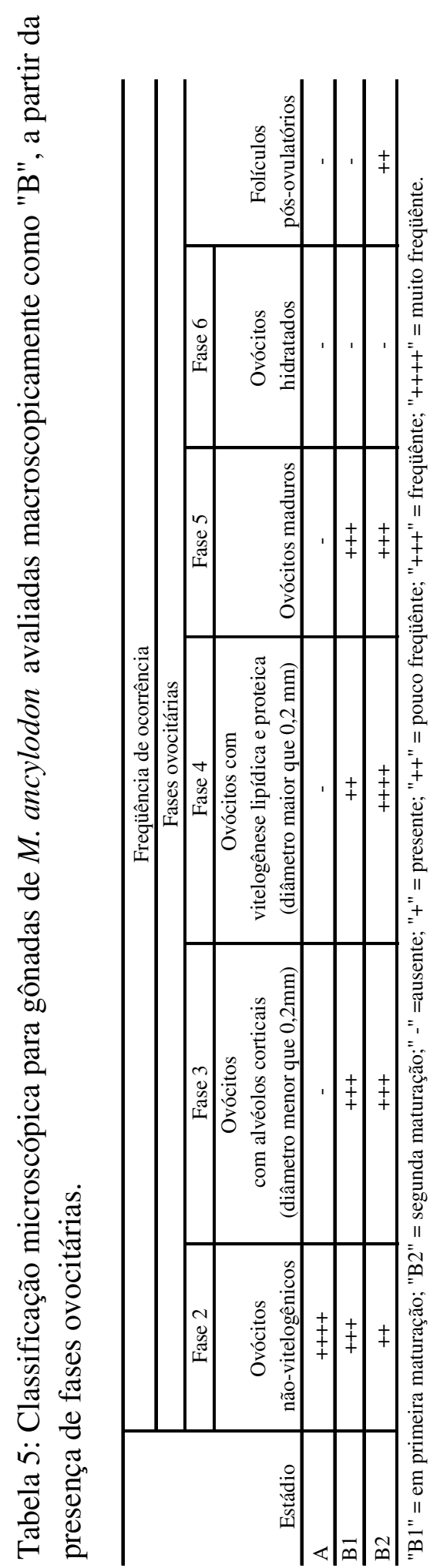

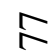


Tabela 6: Ocorrência das estruturas derivadas dos folículos ovarianos de M. ancylodon da costa Norte do Brasil por período, para gônadas avaliadas macroscopicamente como "B".

\begin{tabular}{l|c|c}
\hline \multicolumn{1}{c|}{ Período } & Folículo Pós-Ovulatório (FPO) & Folículo Atrésico (FA) \\
\hline Junho/98 & - & + \\
\hline Julho/98 & + & + \\
\hline Agosto/98 & - & - \\
\hline Setembro/98 & + & + \\
\hline Outubro/98 & & + \\
\hline Novembro/98 & + & - \\
\hline Dezembro/98 & - & + \\
\hline Janeiro/99 & & + \\
\hline Fevereiro/99 & + & + \\
\hline Março/99 & - & - \\
\hline Abril/99 & - & \\
\hline Maio/99 & - & \\
\hline
\end{tabular}

Tabela 7: Resumo de alguns dos parâmetros de crescimento para diferentes populações de Macrodon ancylodon na costa brasileira.

\begin{tabular}{|c|c|c|c|c|c|c|c|c|}
\hline \multirow[t]{2}{*}{ Autor } & \multicolumn{7}{|c|}{ Parâmetros de crescimento } & \multirow[t]{2}{*}{ Método } \\
\hline & Local & Coortes & $\mathrm{L}_{\infty}(\mathrm{cm})$ & $\mathrm{k}$ & $t_{0}$ & $\mathrm{~L}_{\text {máx }}(\mathrm{cm})$ & Idade & \\
\hline Santana, 1998 & PA & $\begin{array}{l}\text { Janeiro } \\
\text { Agosto }\end{array}$ & $\begin{array}{l}45,26 \\
45,50\end{array}$ & $\begin{array}{l}0,42 \\
0,44\end{array}$ & - & - & $\begin{array}{c}\text { 6-8 } \\
\text { anos }\end{array}$ & Indireto \\
\hline Zorro, 1999 & $\mathrm{PA}$ & $\begin{array}{l}\text { Jul-Ago } \\
\text { Out-Nov }\end{array}$ & $\begin{array}{l}42,7 \\
43,6 \\
\end{array}$ & $\begin{array}{l}0,53 \\
0,54\end{array}$ & $-0,28$ & 41,0 & $\begin{array}{c}6-7 \\
\text { anos }\end{array}$ & Indireto \\
\hline Este trabalho & PA & $\begin{array}{c}\text { Jun-Jul } \\
\text { Nov-Dez }\end{array}$ & $\begin{array}{l}46,8 \\
47,4\end{array}$ & $\begin{array}{l}0,44 \\
0,42\end{array}$ & $\begin{array}{l}-0,33 \\
-0,34\end{array}$ & 45,0 & 6 anos & Indireto \\
\hline Castro, 2000 & Sudeste & $\begin{array}{c}\text { Abril } \\
\text { Novembro }\end{array}$ & 50,0 & 0,36 & $-0,40$ & 46,5 & 7 anos & Indireto \\
\hline Bertozzi, 2002 & SP & Abril & 50,5 & 0,38 & - & 48,0 & 8 anos & Indireto \\
\hline Yamaguti \& Santos, 1966 & RS & - & $\begin{array}{l}43,6 \mathrm{~F} \\
33,0 \mathrm{M}\end{array}$ & $\begin{array}{l}0,27 \\
0,44\end{array}$ & - & 44,0 & $\begin{array}{c}+9 \\
\text { anos }\end{array}$ & Direto \\
\hline Martins-Juras, 1980 & RS & - & $\begin{array}{l}42,2 \mathrm{~F} \\
36,8 \mathrm{M}\end{array}$ & 0,47 & $\begin{array}{l}0,38 \\
0,35 \\
\end{array}$ & 42,9 & $\begin{array}{c}5-6 \\
\text { anos }\end{array}$ & Direto \\
\hline Isaac-Nahum, 1989 & RS & $\begin{array}{c}\text { Março } \\
\text { Dezembro }\end{array}$ & 47,9 & 0,42 & - & 45,0 & 11 anos & Indireto \\
\hline
\end{tabular}




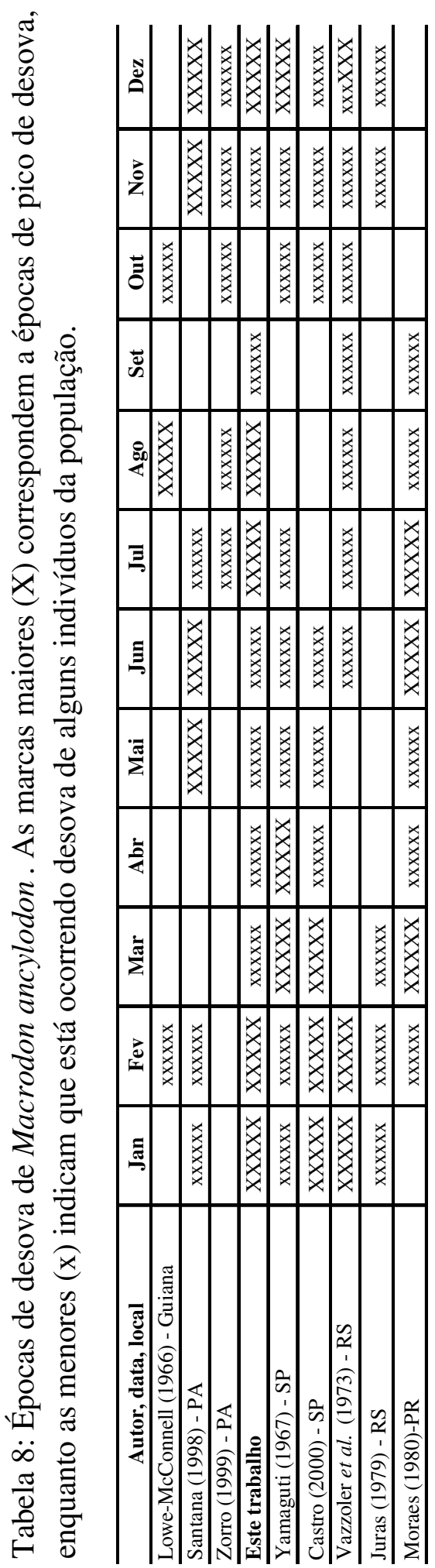


Tabela 9: Descrição de alguns parâmetros reprodutivos para diferentes populações de $M$. ancylodon para a costa brasileira.

\begin{tabular}{|c|c|c|c|c|}
\hline \multirow[b]{2}{*}{ Autor, data } & \multicolumn{2}{|c|}{$\mathrm{L}_{50}(\mathrm{~cm})$} & \multicolumn{2}{|c|}{ Proporções sexuais } \\
\hline & $\mathrm{F}$ & $\mathrm{M}$ & $\mathrm{F}$ & $\mathrm{M}$ \\
\hline Lowe-McConnell (1966) - Guiana & \multicolumn{2}{|c|}{$20,0-23,0$} & 47,40 & 52,60 \\
\hline Santana (1998) - PA & 18,6 & - & 60,41 & 39,59 \\
\hline Zorro (1999) - PA & \multicolumn{2}{|c|}{21,5} & - & - \\
\hline Este trabalho & 25,08 & - & 45,55 & 54,45 \\
\hline Lara (1951) - SP & \multicolumn{2}{|c|}{30,0} & - & - \\
\hline Vazzoler (1962) - SP & \multicolumn{2}{|c|}{26,0} & - & - \\
\hline Yamaguti (1967) - SP & \multicolumn{2}{|c|}{25,0} & 48,00 & 52,00 \\
\hline Castro (2000) - SP & 29,12 & 27,28 & 44,00 & 56,00 \\
\hline Moraes (1980)-PR & 22,18 & - & 55,83 & 44,17 \\
\hline Vazzoler et al. (1973) - RS & \multicolumn{2}{|c|}{18,8} & - & - \\
\hline Juras (1979) - RS & 27,4 & 21,5 & 48,70 & 51,30 \\
\hline
\end{tabular}




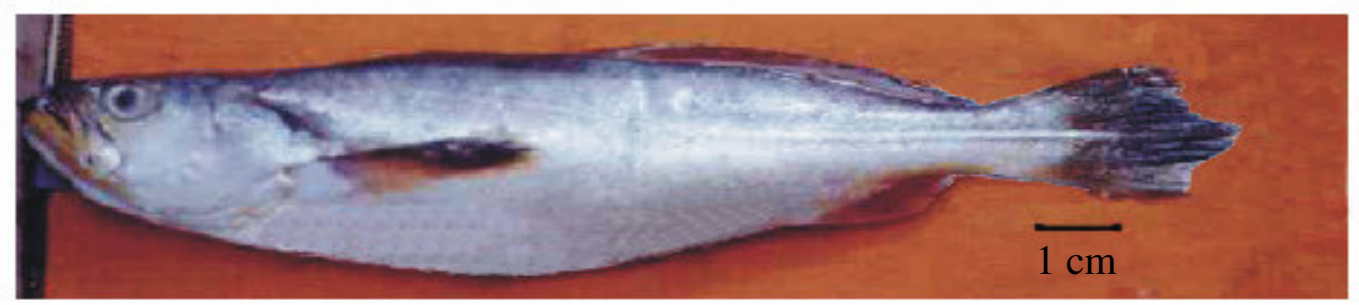

Figura 1: Macrodon ancylodon (Bloch \& Schneider, 1801) da costa Norte do Brasil. 


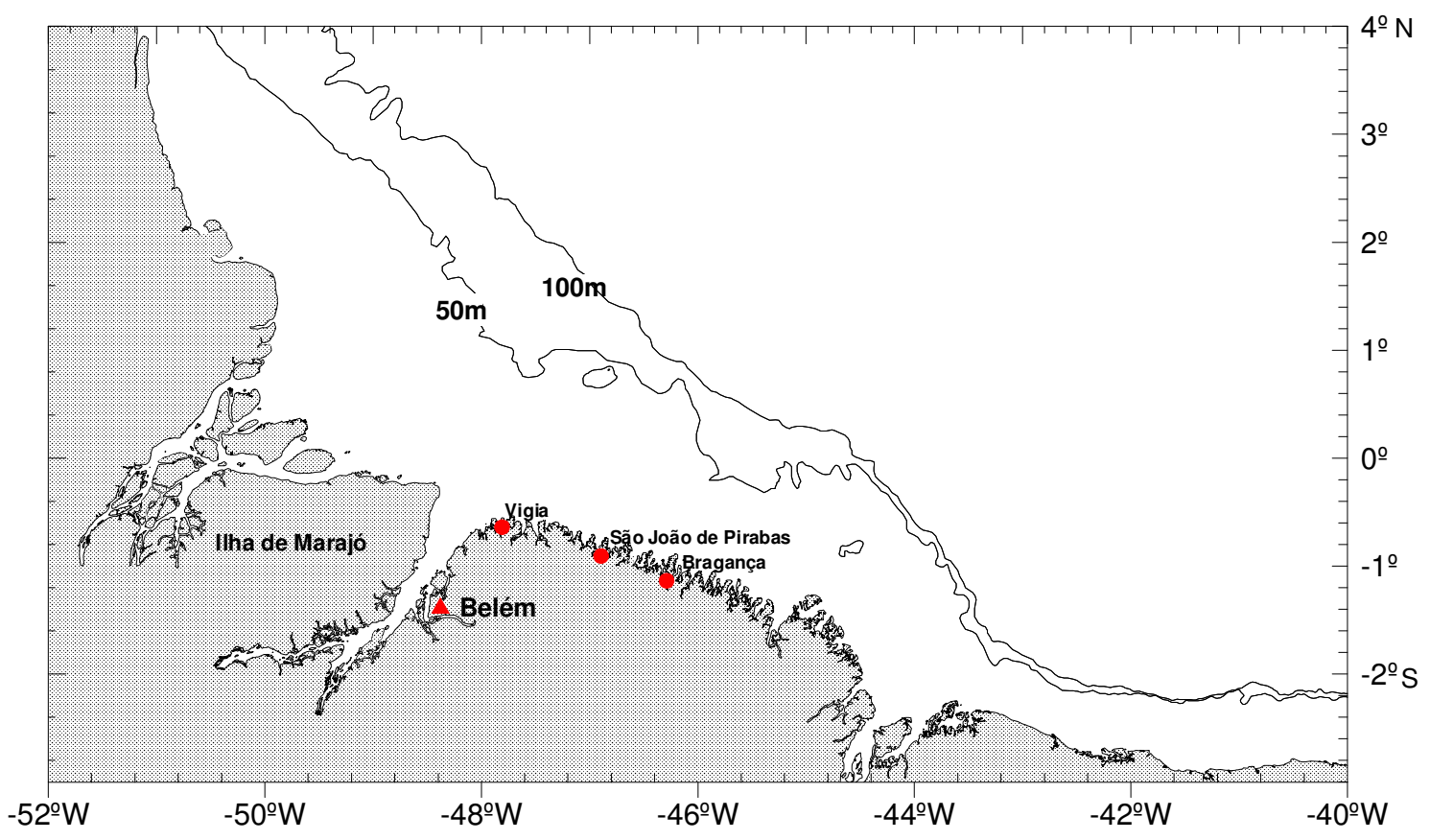

Figura 2:Mapa da área de estudo (costa Norte do Brasil), com a indicação dos locais de desembarques pesqueiros onde foram realizadas as amostragens para este trabalho.

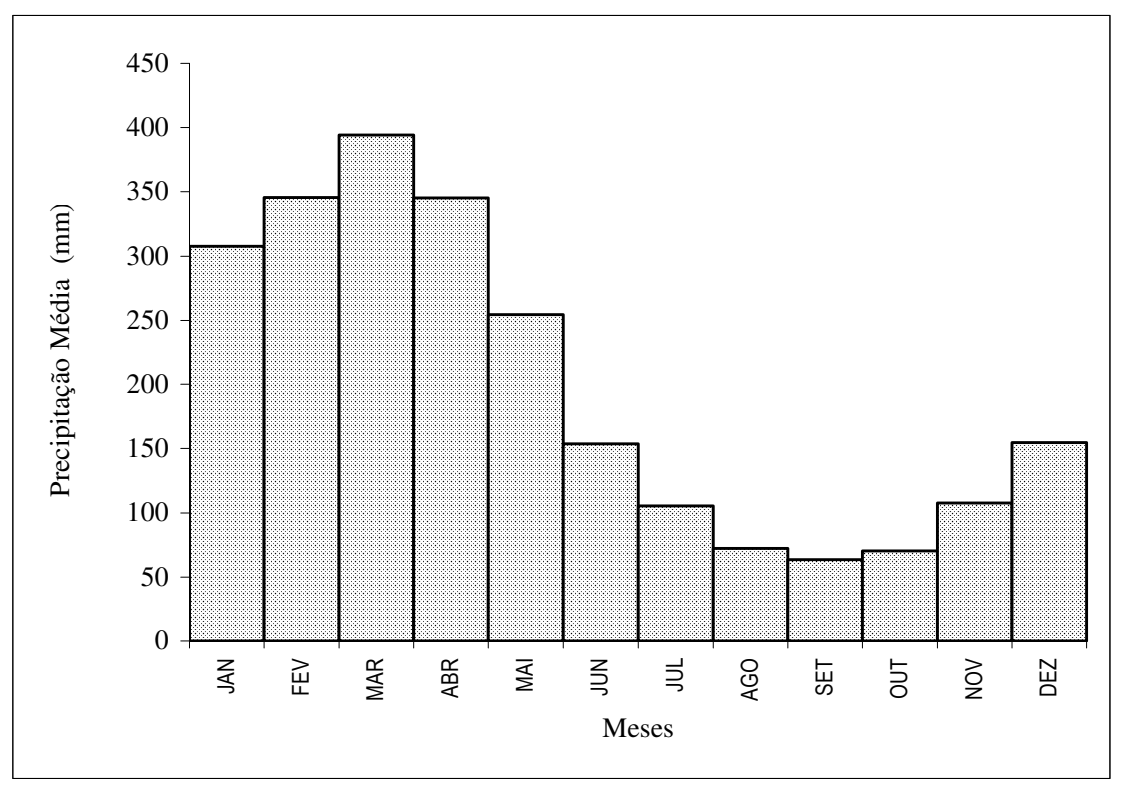

Figura 3: Média mensal da precipitação de chuvas no período de 1966 a 2001, nas estações localizadas próximas às desembocaduras dos rios Amazonas e Tocantins. Fonte: INMET. 
A)

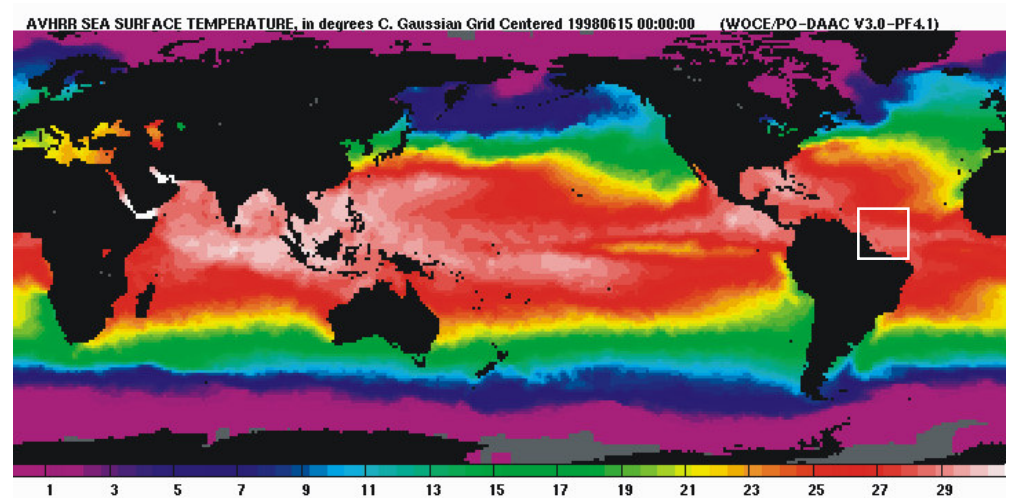

B)

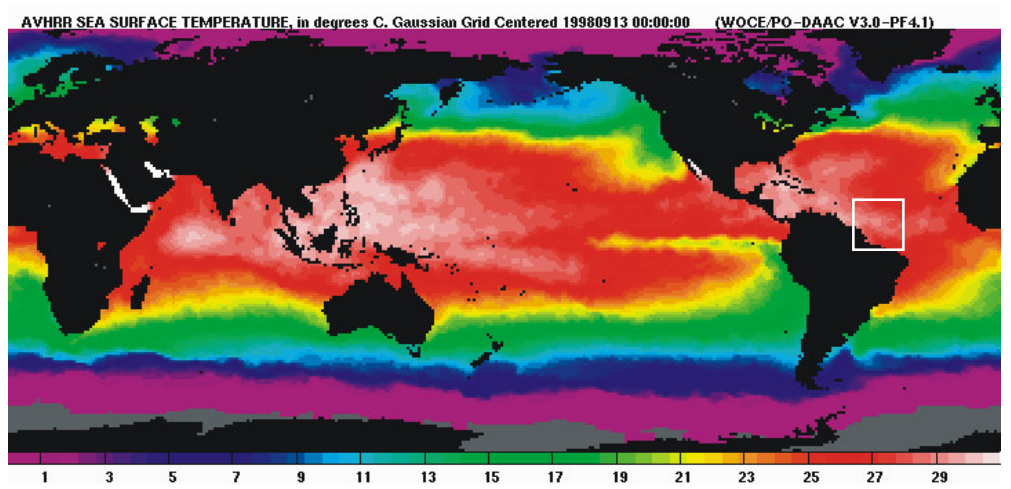

C)

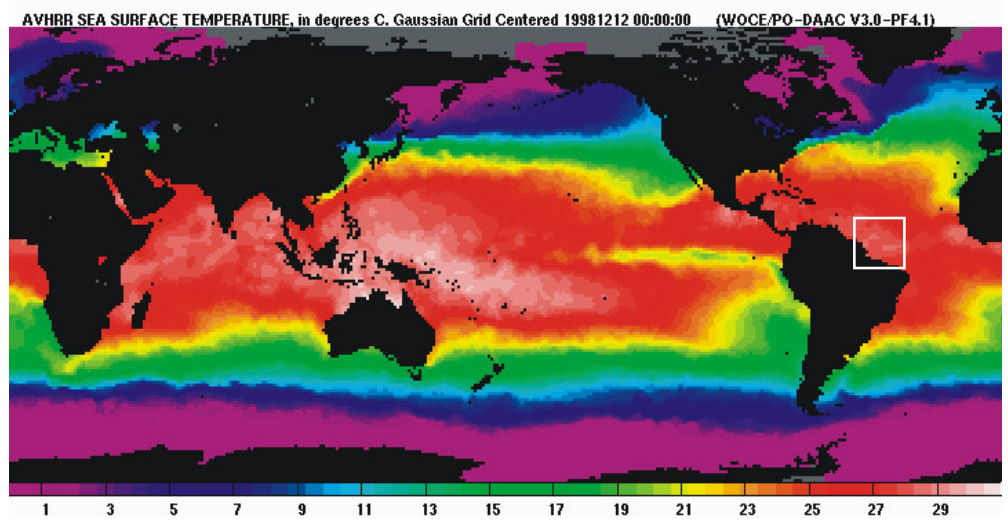

D)

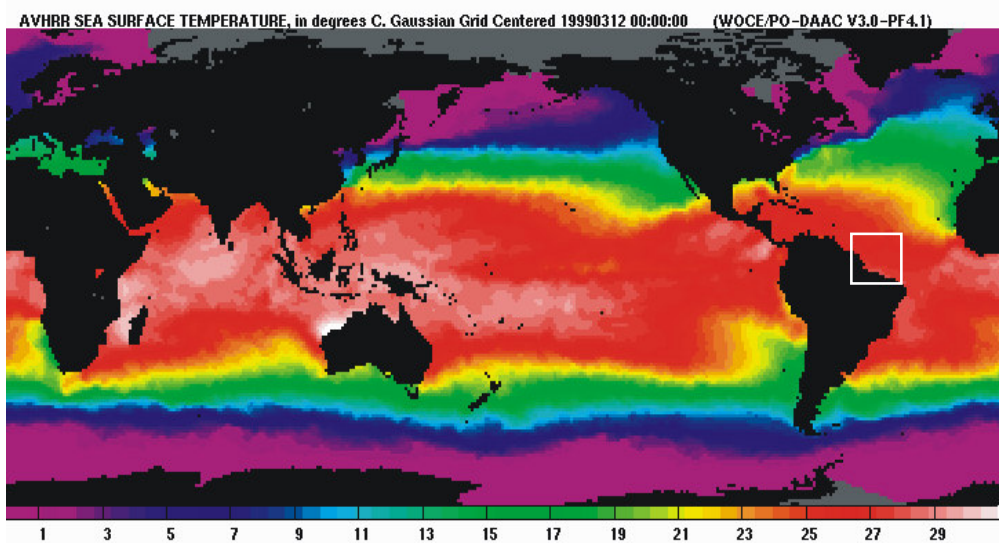

Figura 4: Temperatura da superfície do mar (TSM) referente a: A) junho de 1998; B) setembro de 1998; C) dezembro de 1999 e. Dados fornecidos pelo PODAAC/JPL. 

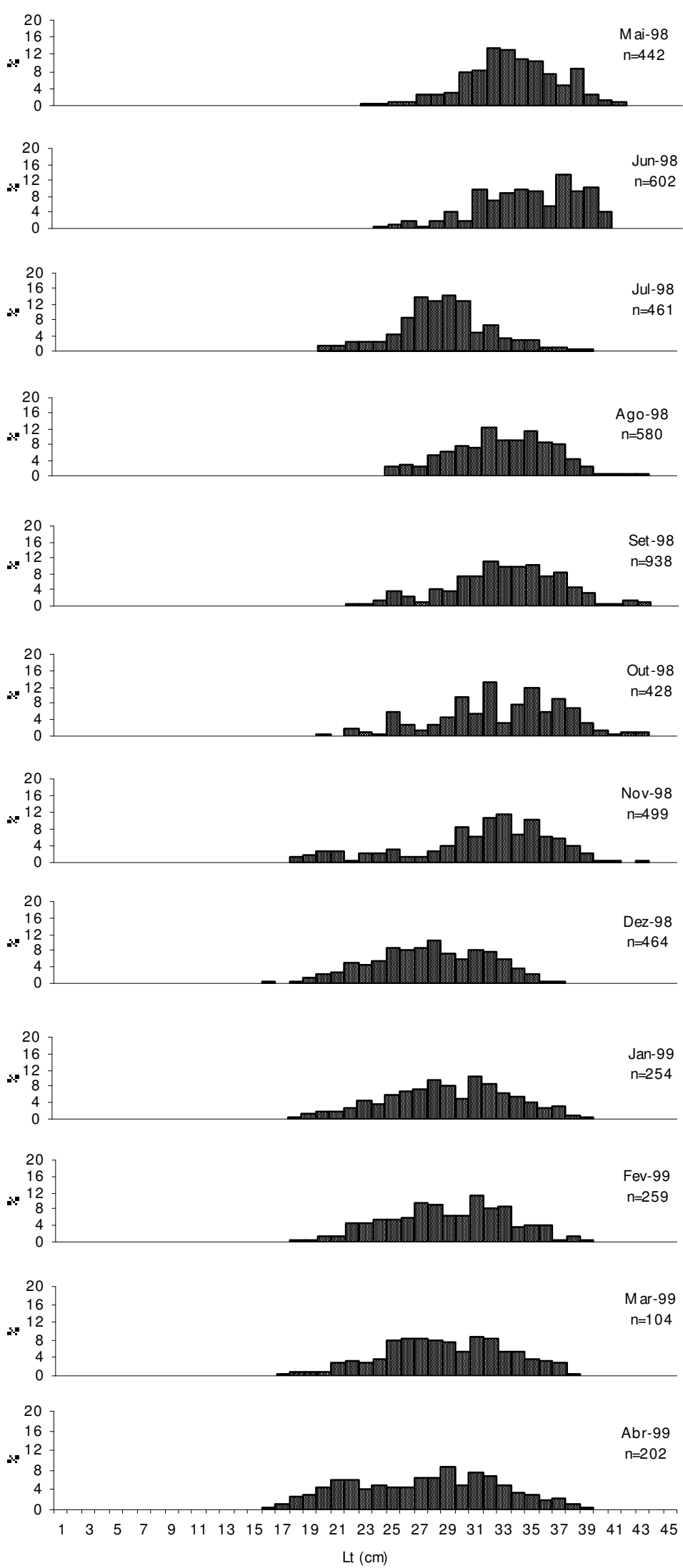

Figura 5: Distribuição da freqüência de classes de comprimento total $(\mathrm{cm})$ para indivíduos de $M$. ancylodon da costa Norte do Brasil provenientes da atividade artesanal (emalhe) do bloco amostral 1. Continua. 

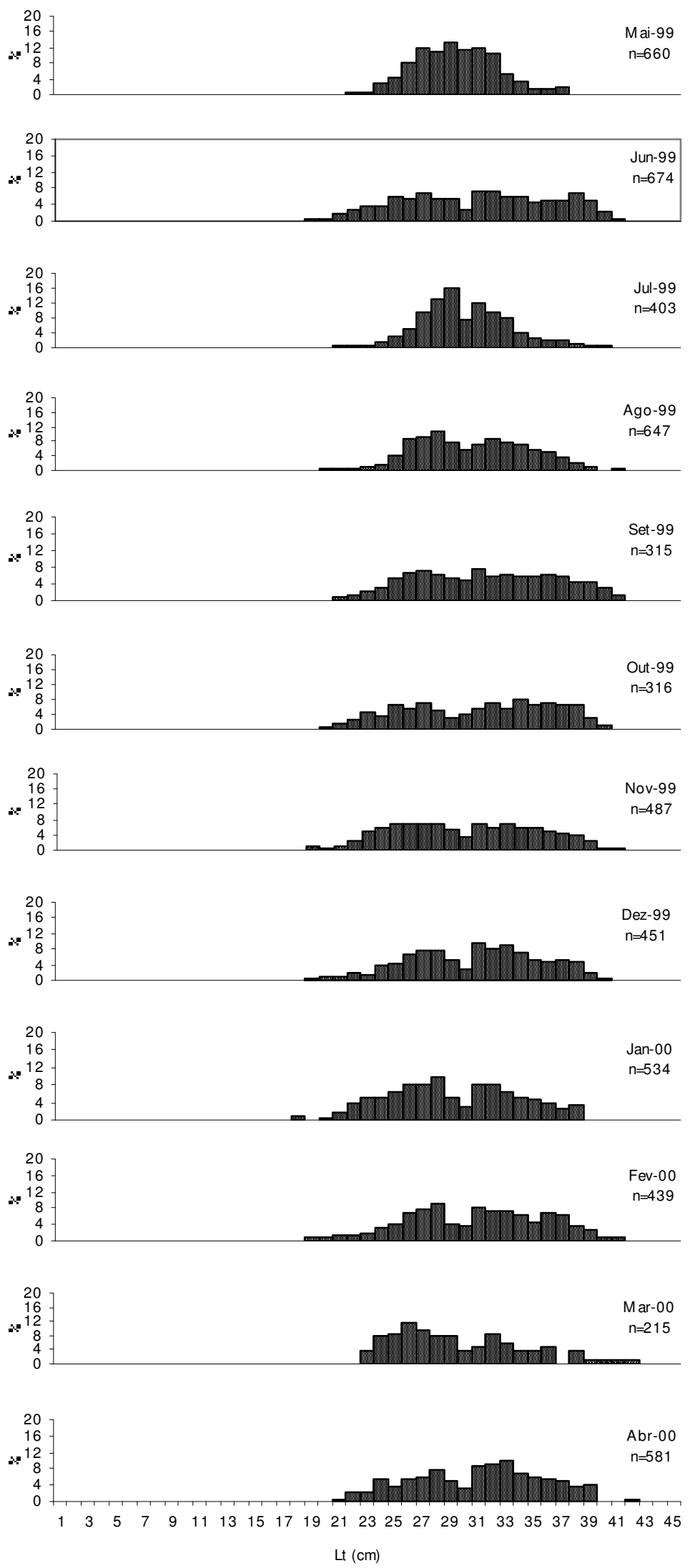

Figura 5: Continua. 

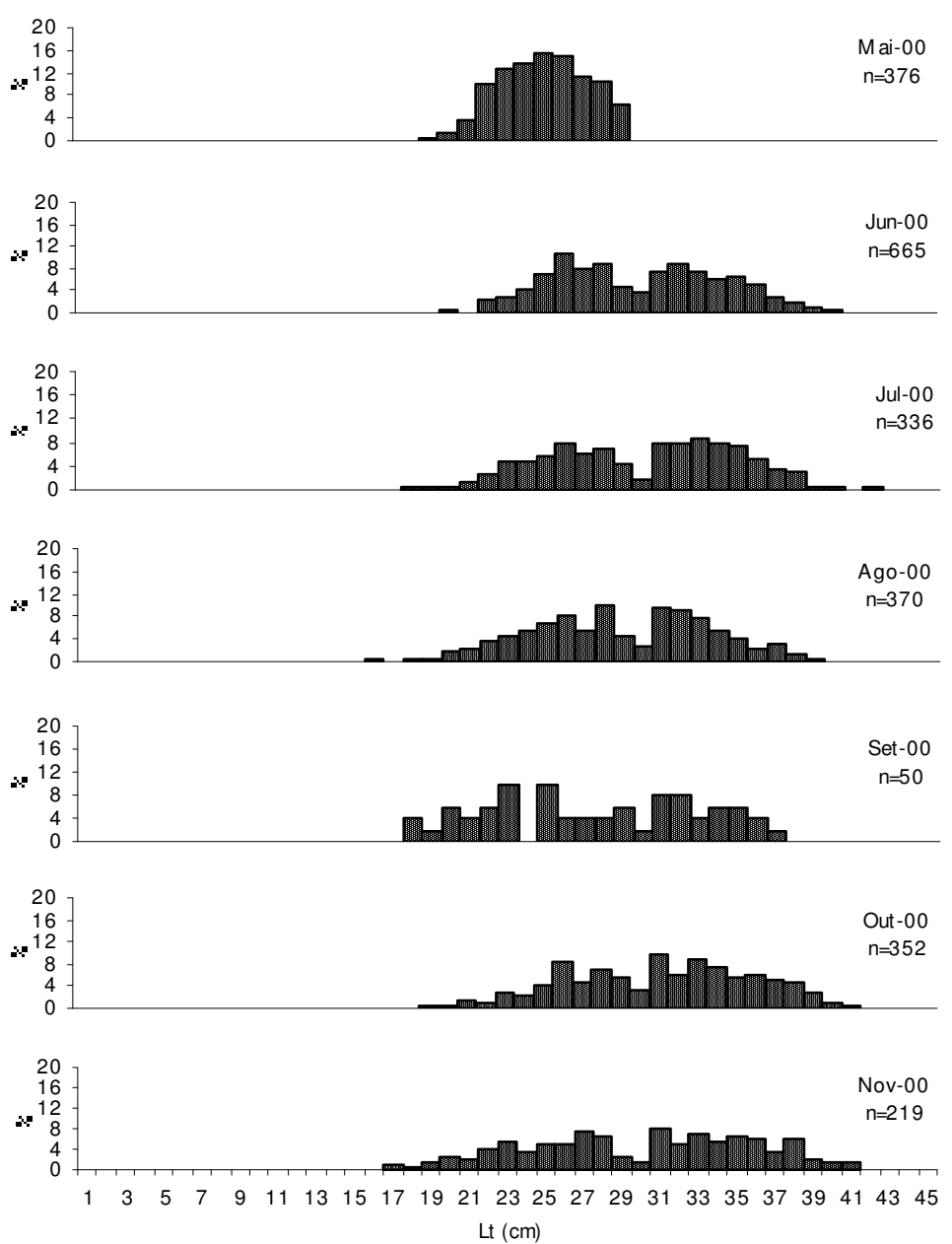

Figura 5: Fim. 

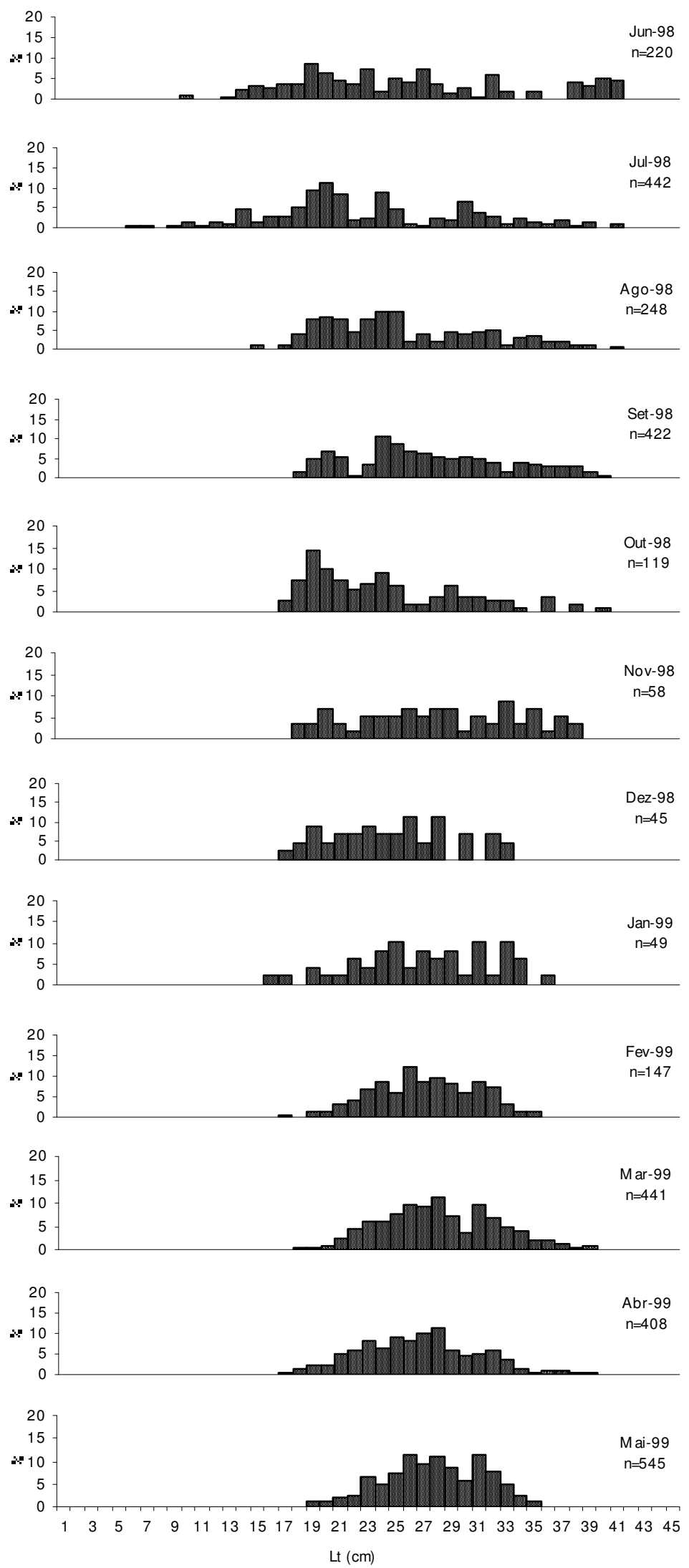

Figura 6: Distribuição de freqüência de classes de comprimento total $(\mathrm{cm})$ para indivíduos de M.ancylodon da costa Norte do Brasil provenientes da atividade artesanal (curral - cerco fixo) do bloco amostral 1.Continua. 

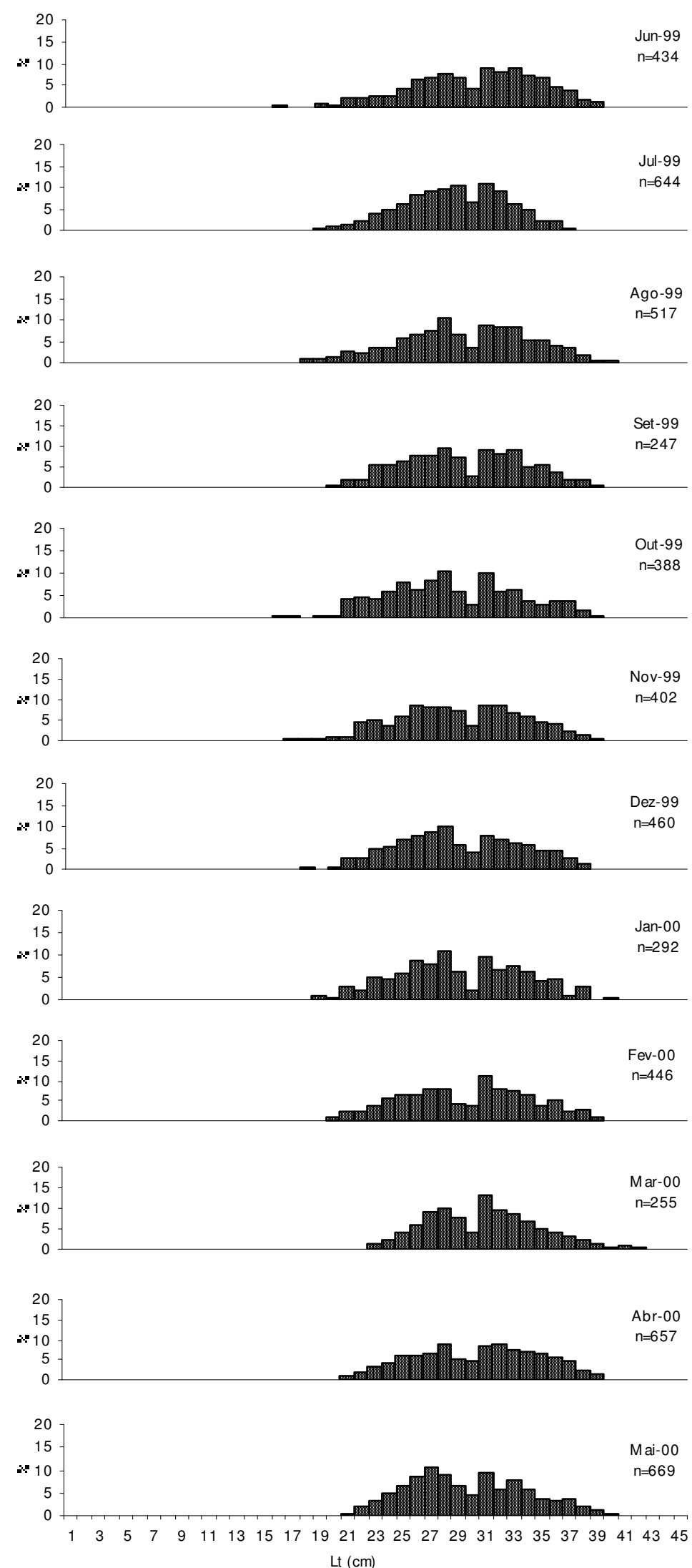

Figura 6: Continua. 

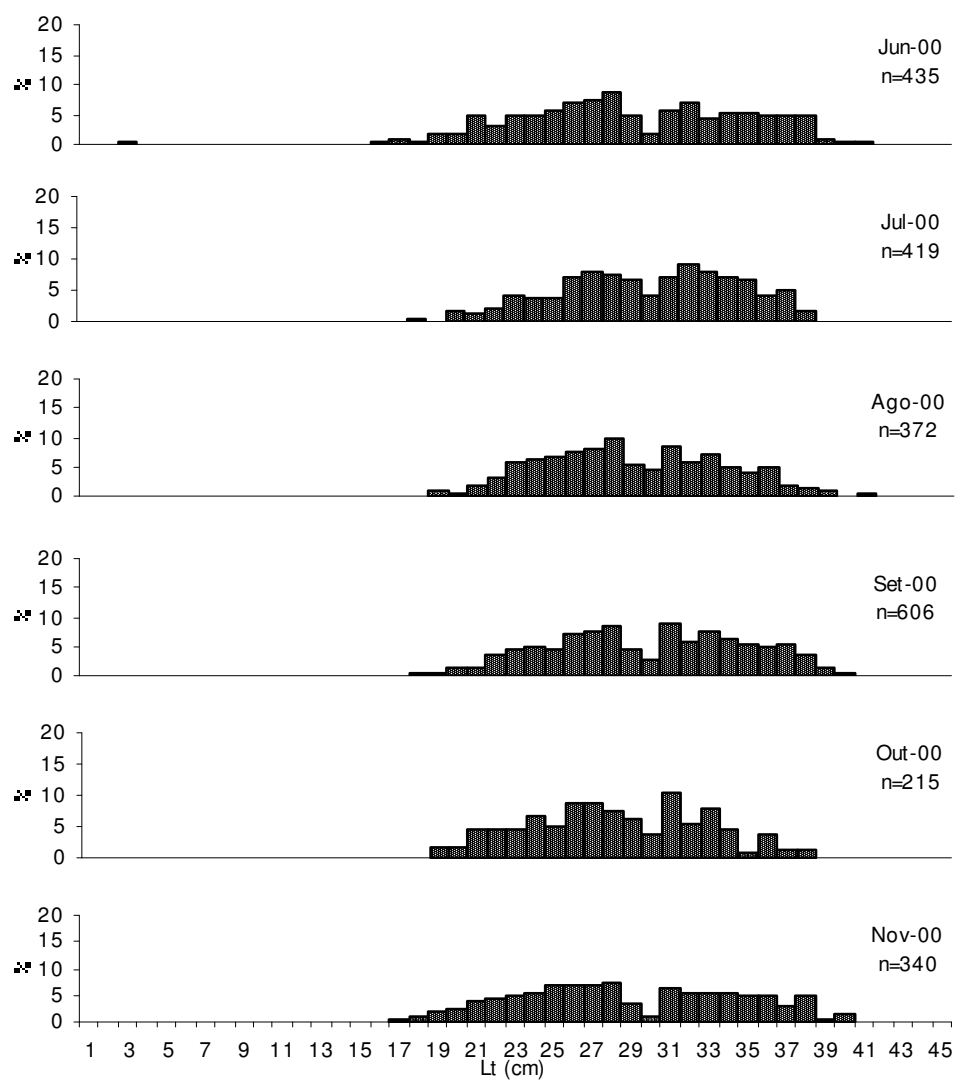

Figura 6: Fim. 


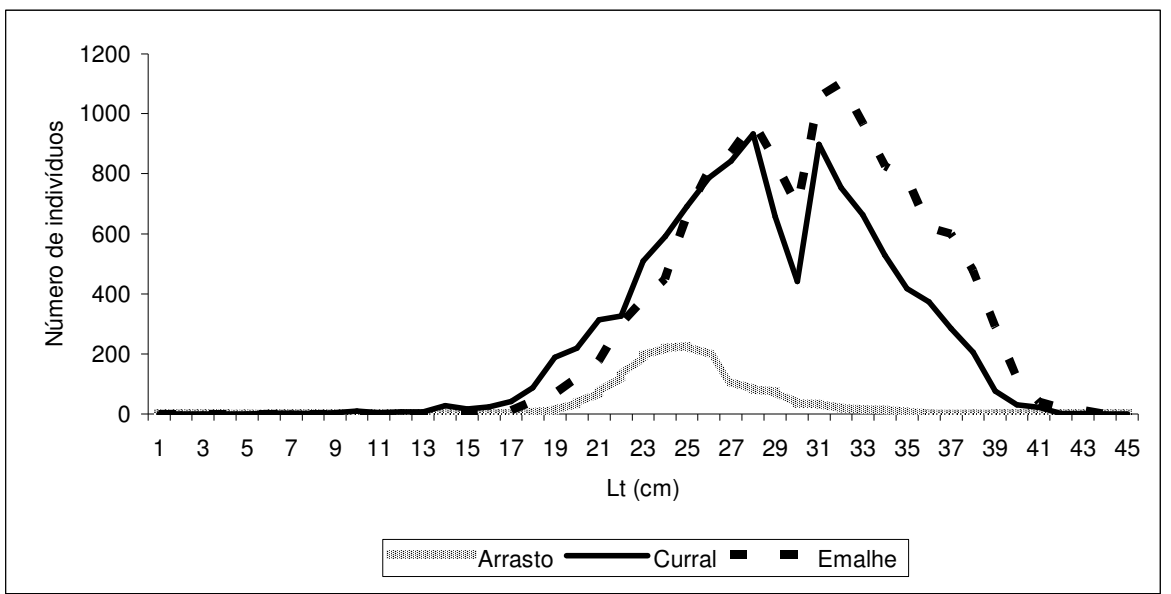

Figura 7: Descrição das capturas em número de índivídos por classe de comprimento e por arte de pesca das amostras do bloco 1, para M. ancylodon da costa Norte brasileira. 

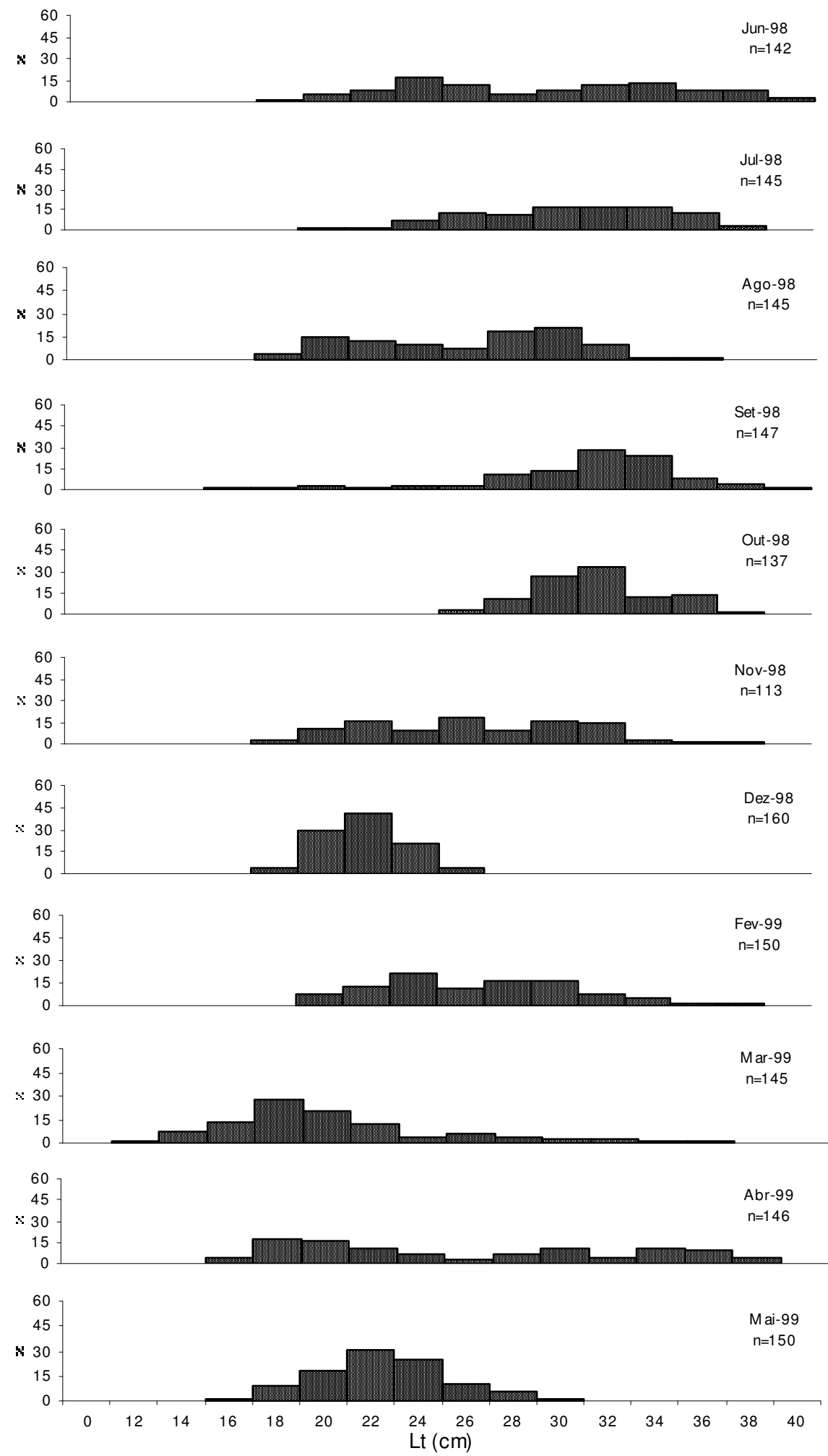

Figura 8: Distribuição de freqüência de classes de comprimento (Lt) para indivíduos de M. ancylodon da costa Norte do Brasil provenientes das amostras do bloco 2 . 

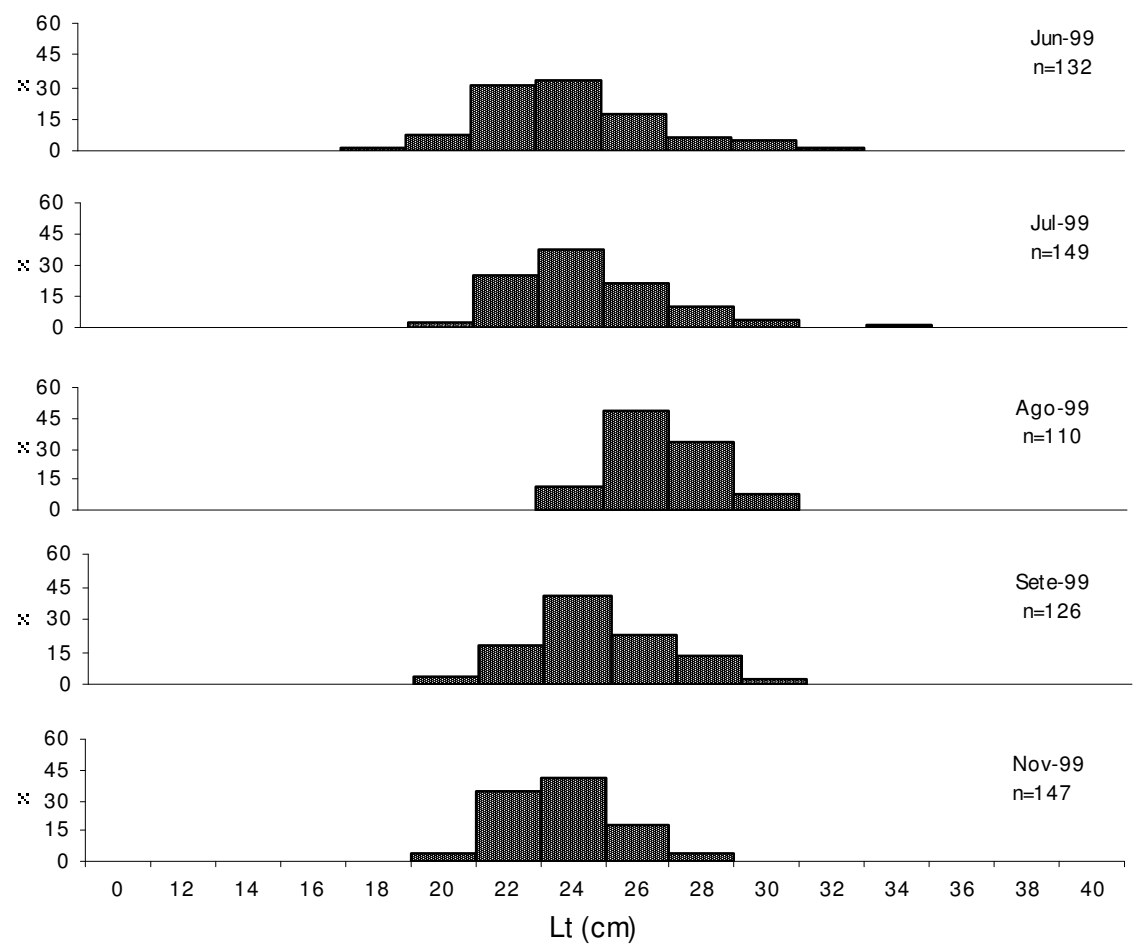

Figura 8: Fim. 

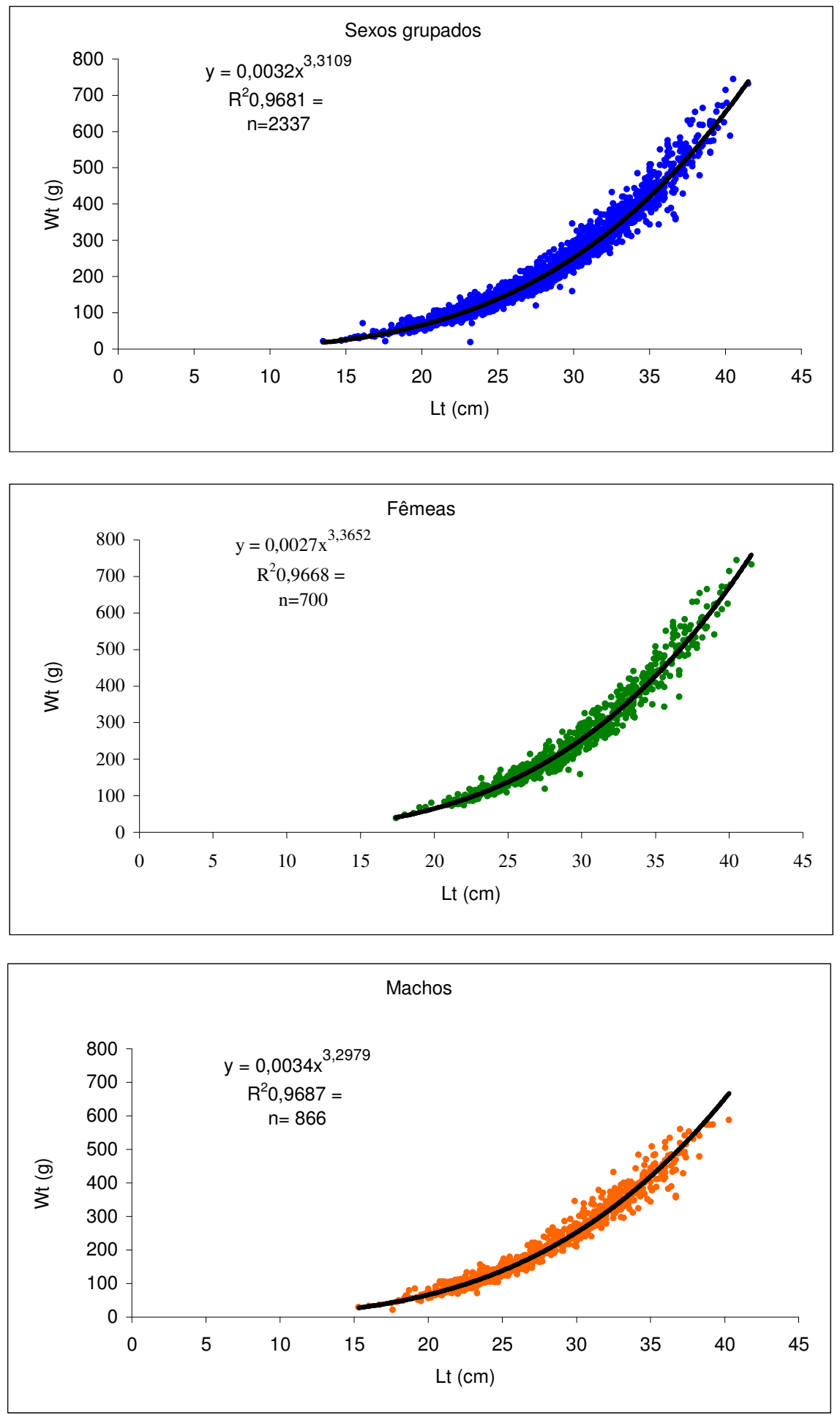

Figura 9: Relação peso-comprimento de Macrodon ancylodon para as amostras do bloco 2. 

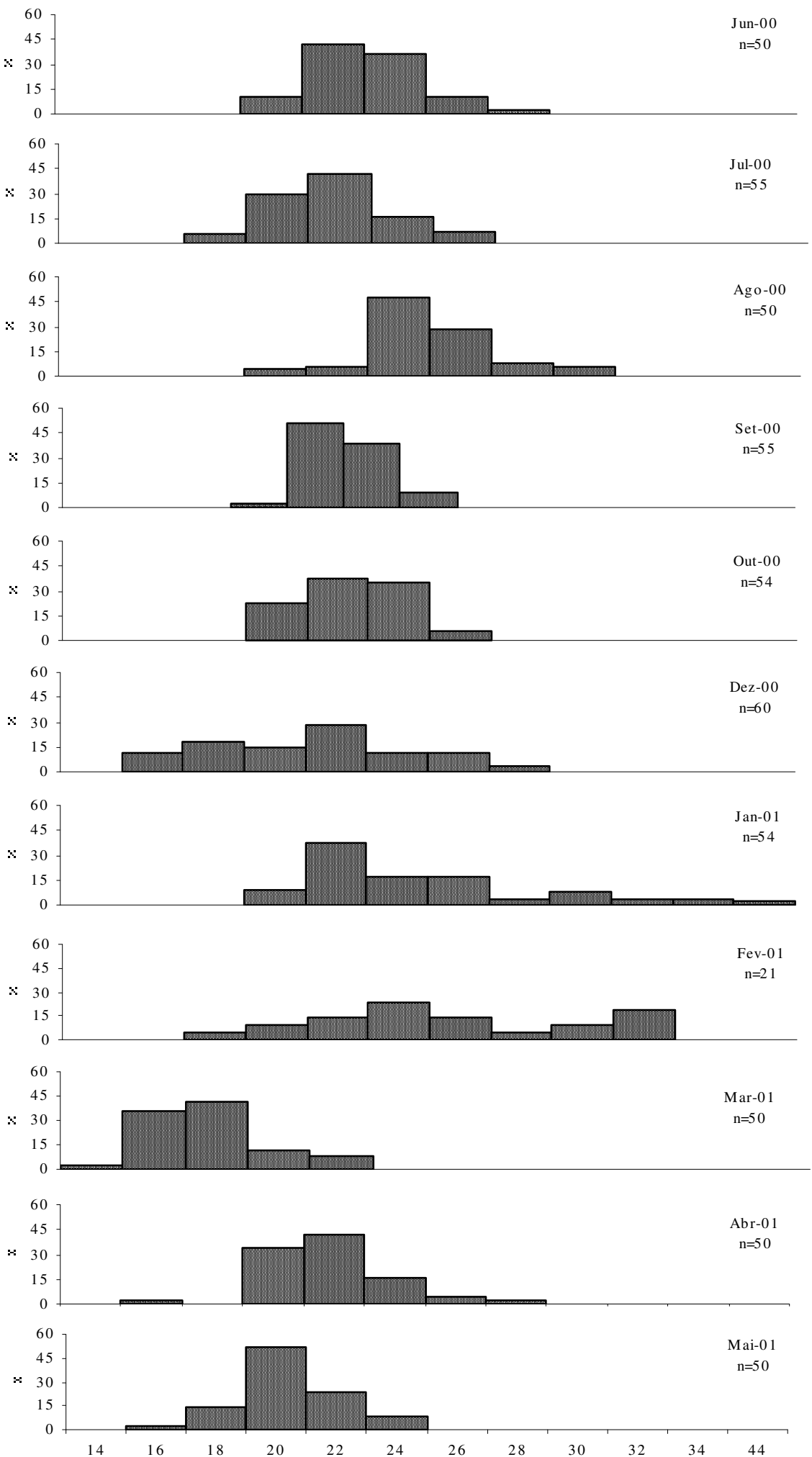

Figura 10:

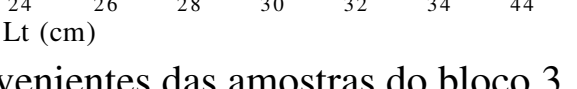

los de M.ancylodon da costa Norte do Brasil provenientes das amostras do bloco 3. 


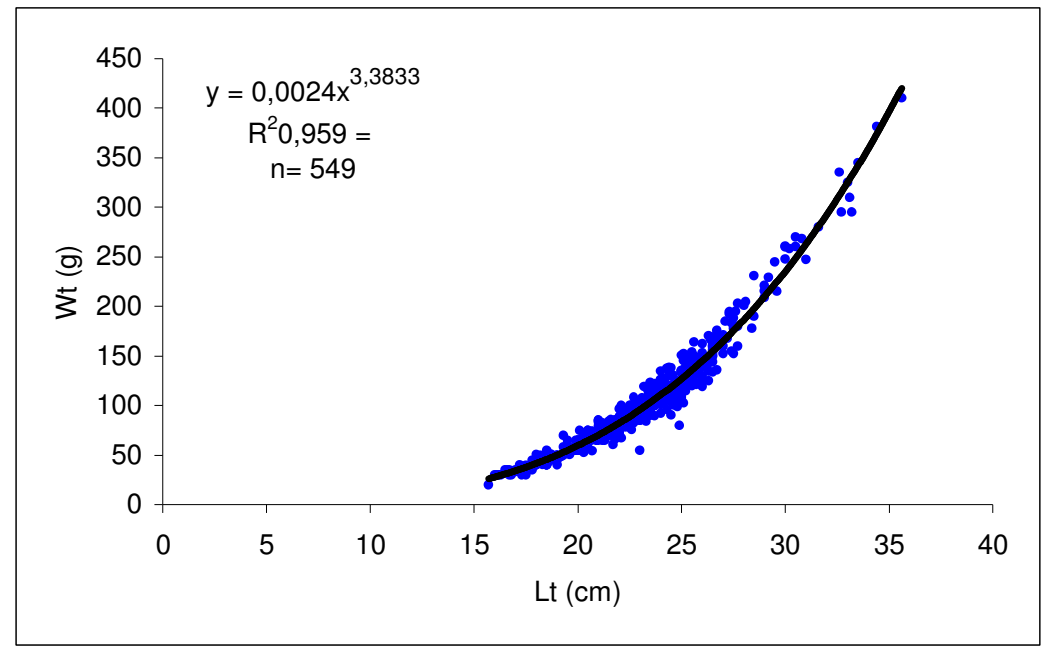

Figura 11: Relação peso-comprimento para sexos grupados de Macrodon ancylodon da costa Norte do Brasil para as amostras do bloco 3. 


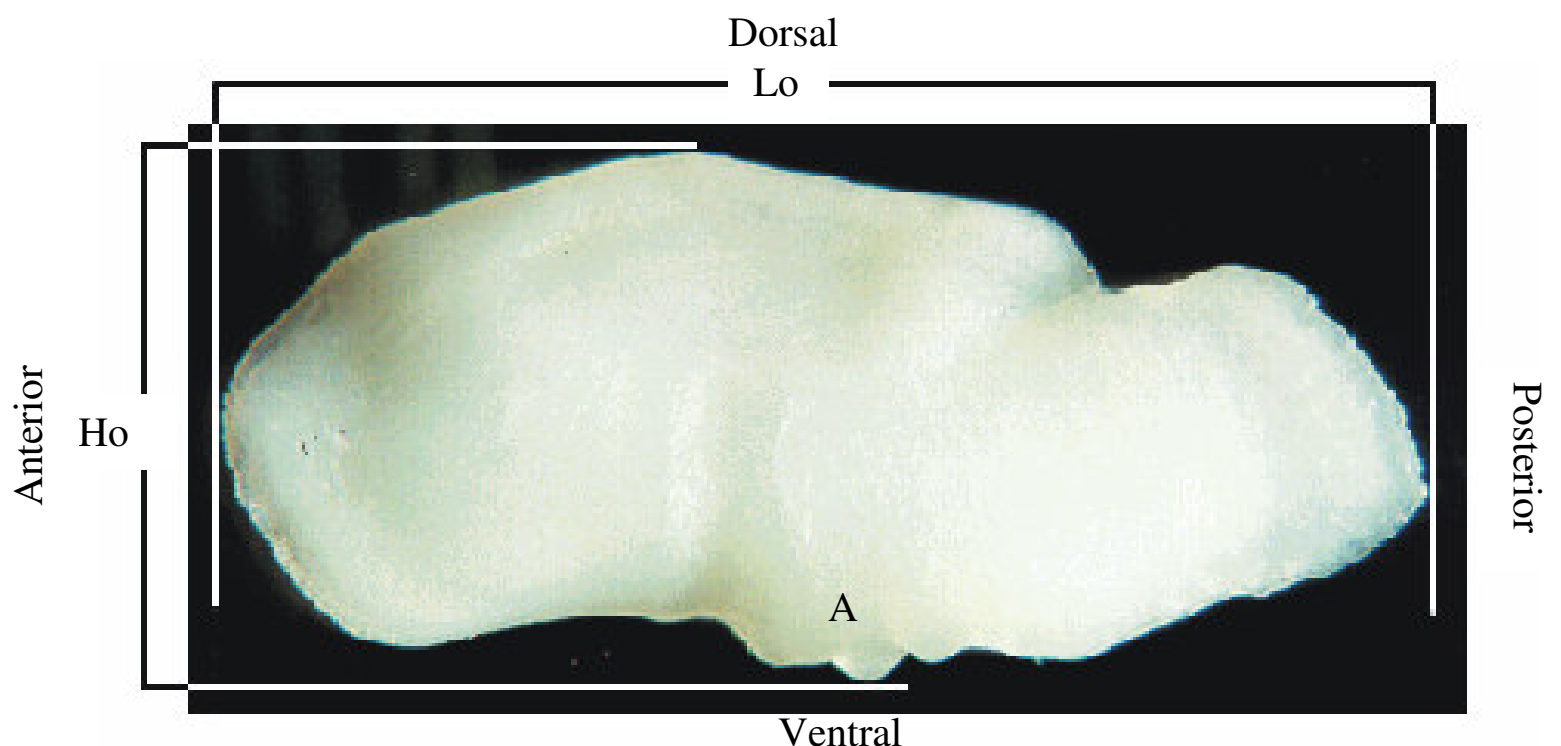

Figura 12: Otólito sagita esquerdo inteiro de Macrodon ancylodon (Bloch \& Schineider, 1801) da costa Norte do Brasil. Lo = comprimento total do otólito $(\sim 12,25 \mathrm{~mm})$, Ho $=$ altura do otólito $(\sim 5,00 \mathrm{~mm})$ e $\mathrm{A}=$ denticulações . 

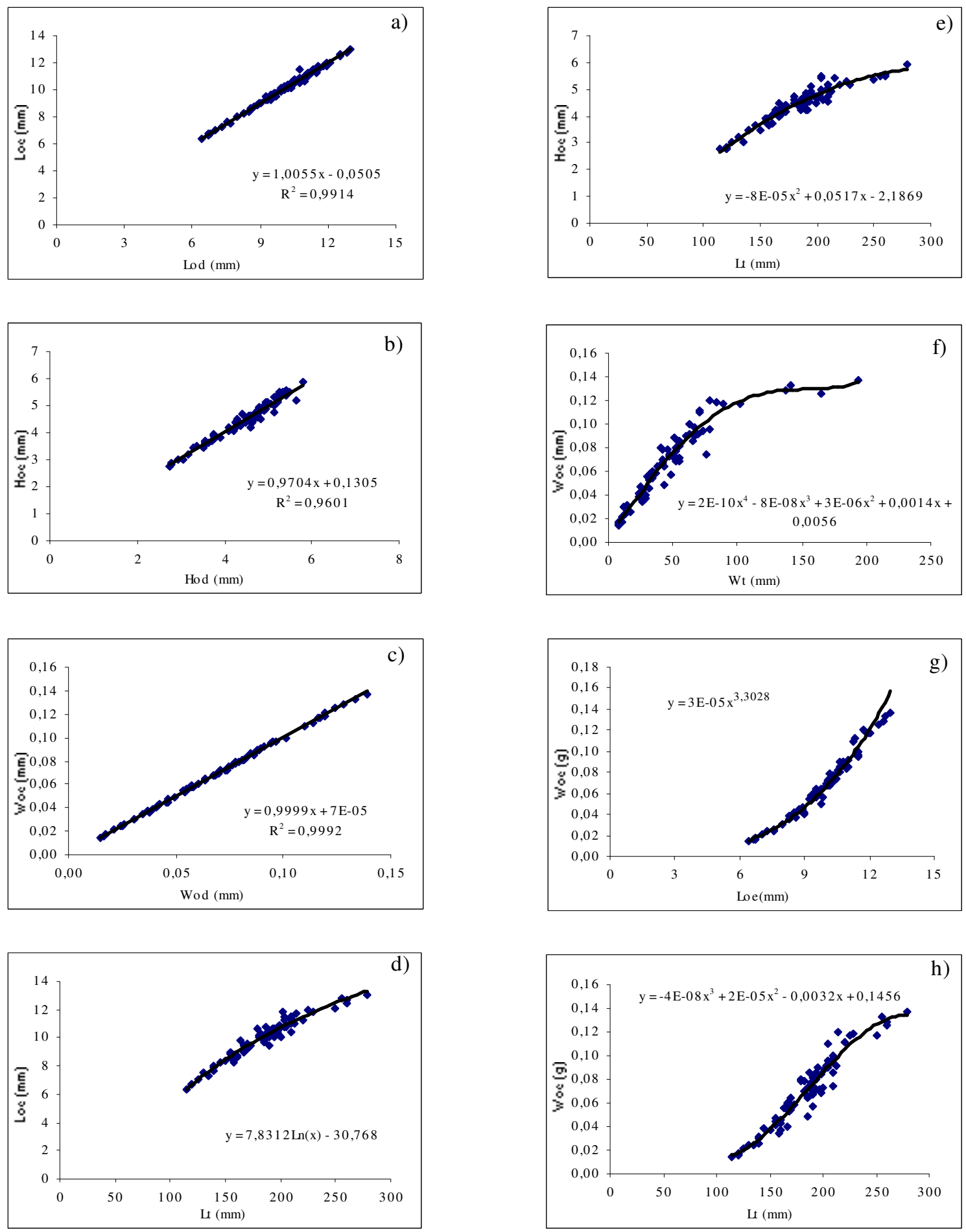

Figura 13: Equações matemáticas que descrevem o crescimento em peso e comprimento de Macrodon ancylodon da costa Norte do Brasil. Loe - comprimento do otólito esquerdo; Lod - comprimento do otólito direito; Hoe - altura do otólito esquerdo; Hod altura do otólito direito; Woe - peso do otólito esquerdo; Wod - peso do otólito direito; $\mathrm{Lt}$ - comprimento total do peixe; $\mathrm{Wt}$ - peso total do peixe. 

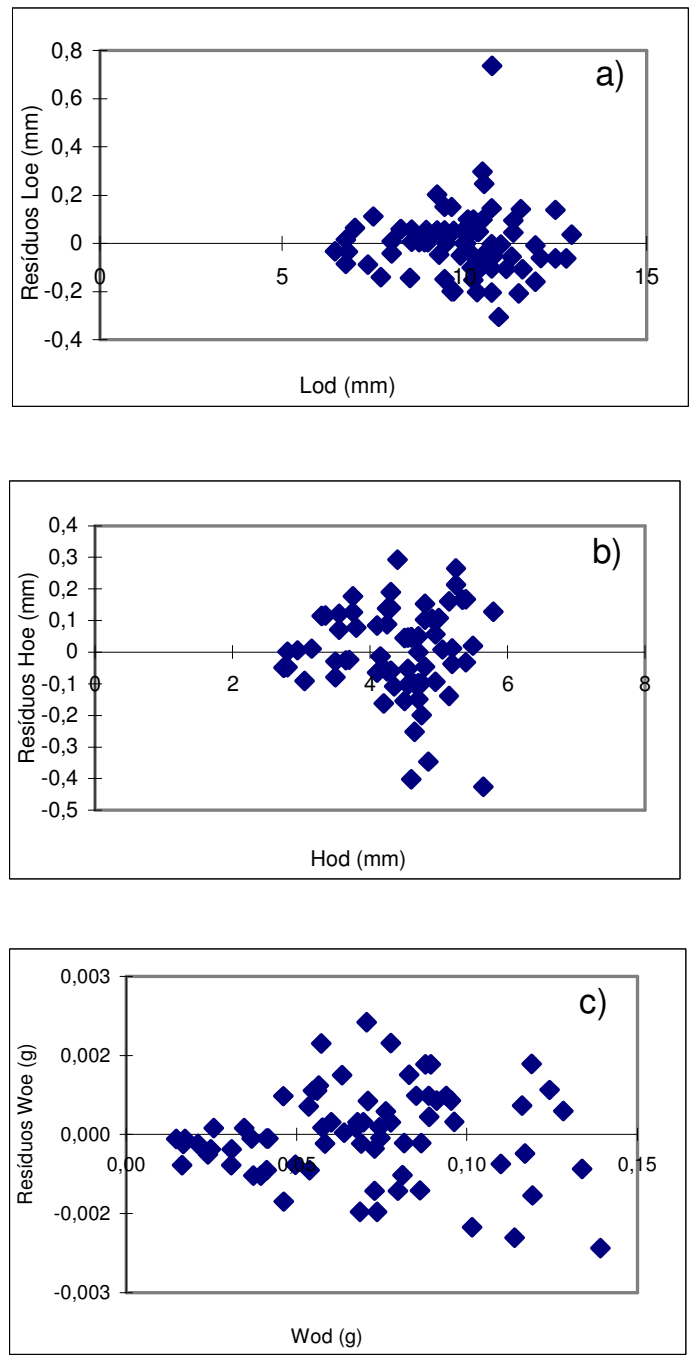

Figura 14: Gráficos dos resíduos da regressão linear das medidas dos otólitos de M. ancylodon da costa Norte do Brasil. 

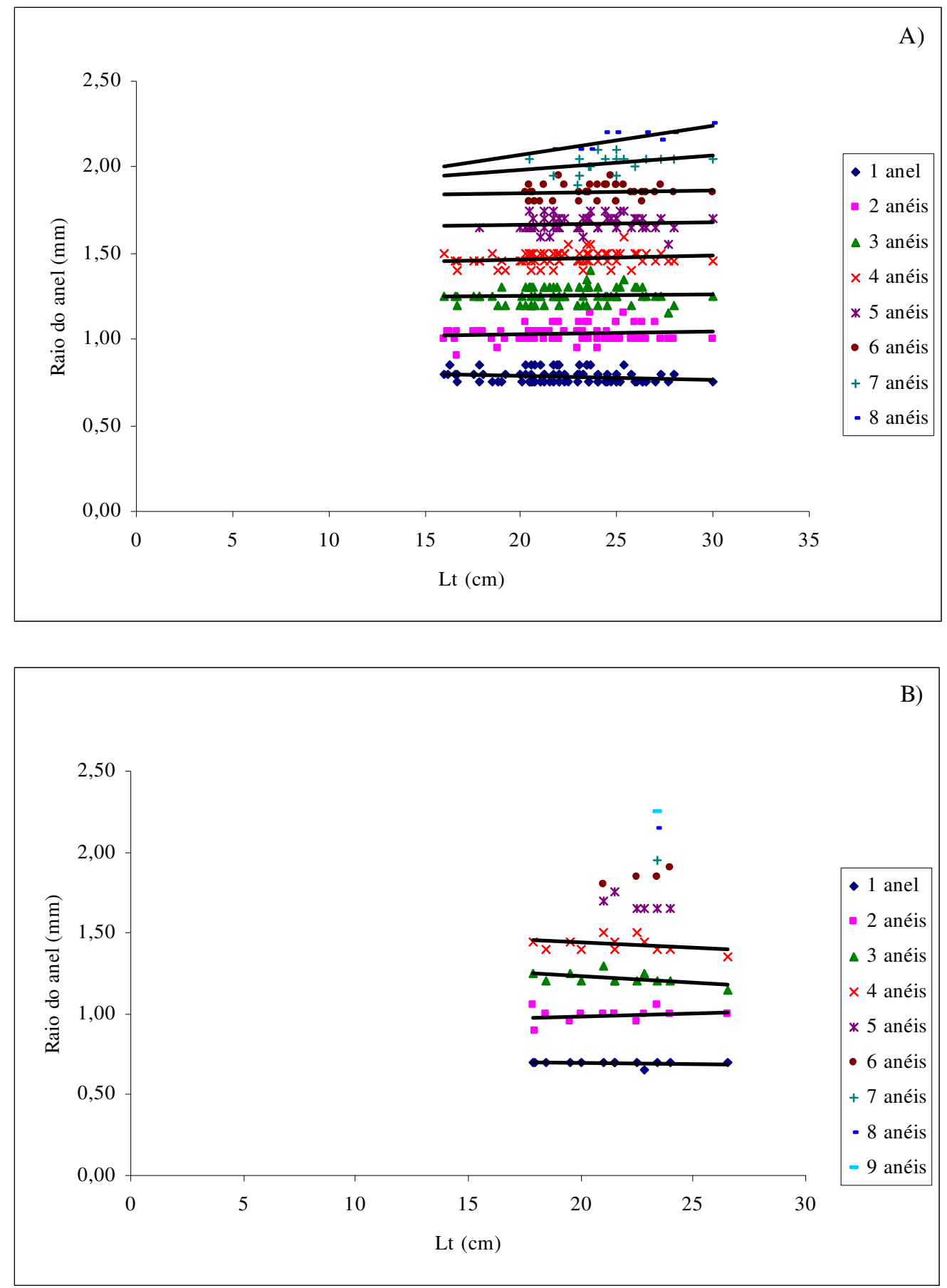

Figura 15: A) Diagrama de dispersão dos dados de comprimento total e os valores de anéis em secções de otólitos para indivíduos com o primeiro raio na amplitude de 0,75 $0,85 \mathrm{~mm}$ em relação ao núcleo. B) Diagrama de dispersão dos dados de comprimento total e os valores dos raios de anéis em secções de otólitos para indivíduos com o primeiro raio na amplitude de $0,65-0,70 \mathrm{~mm}$ em relação ao núcleo. 

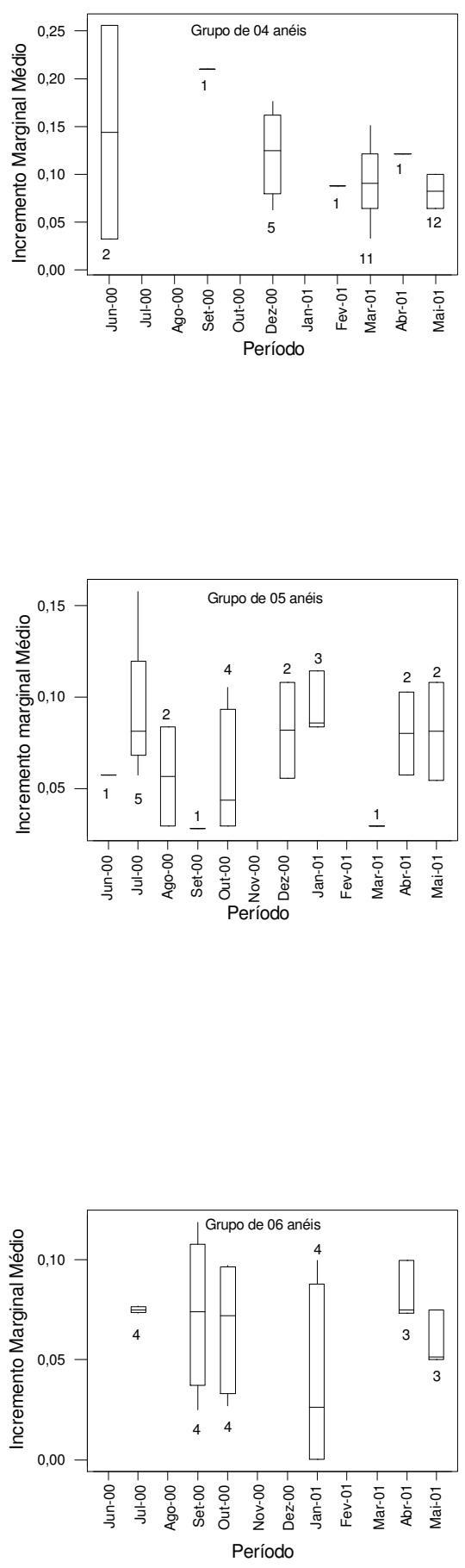

Figura 16: Incremento marginal médio dos otólitos de Macrodon ancylodon da costa Norte do Brasil, por grupo de anéis e por período de ocorrência. Os números representam o número de otólitos analisados. 


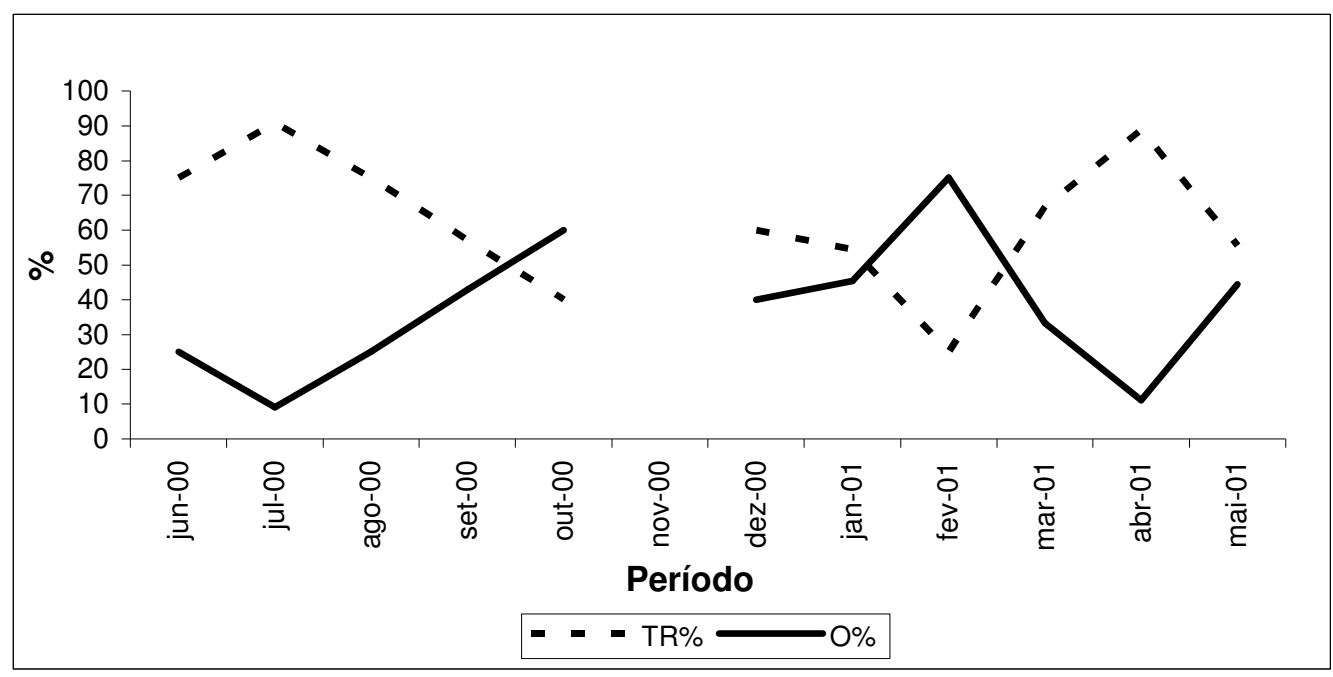

Figura 17: Porcentagem do tipo de bordo por período amostrado para Macrodon ancylodon da costa Norte do Brasil. TR - translúcido; O - opaco. 

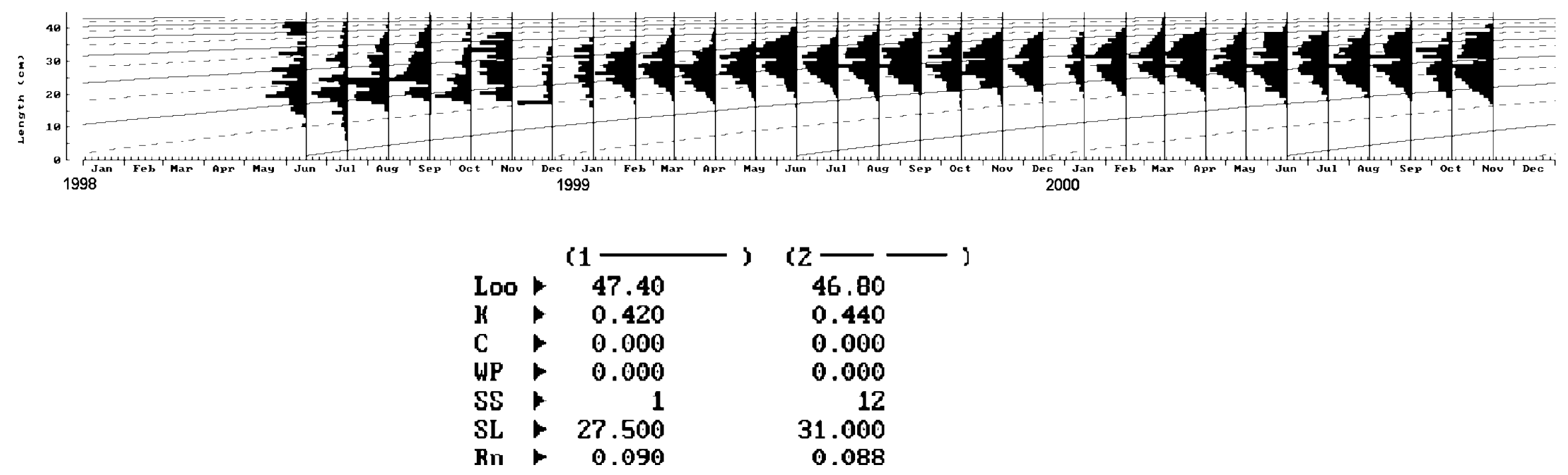

Figura 18: Curvas de crescimento das coortes calculadas através do sistema ELEFAN I (pacote computacional FISAT) para Macrodon ancylodon da costa Norte do Brasil. 


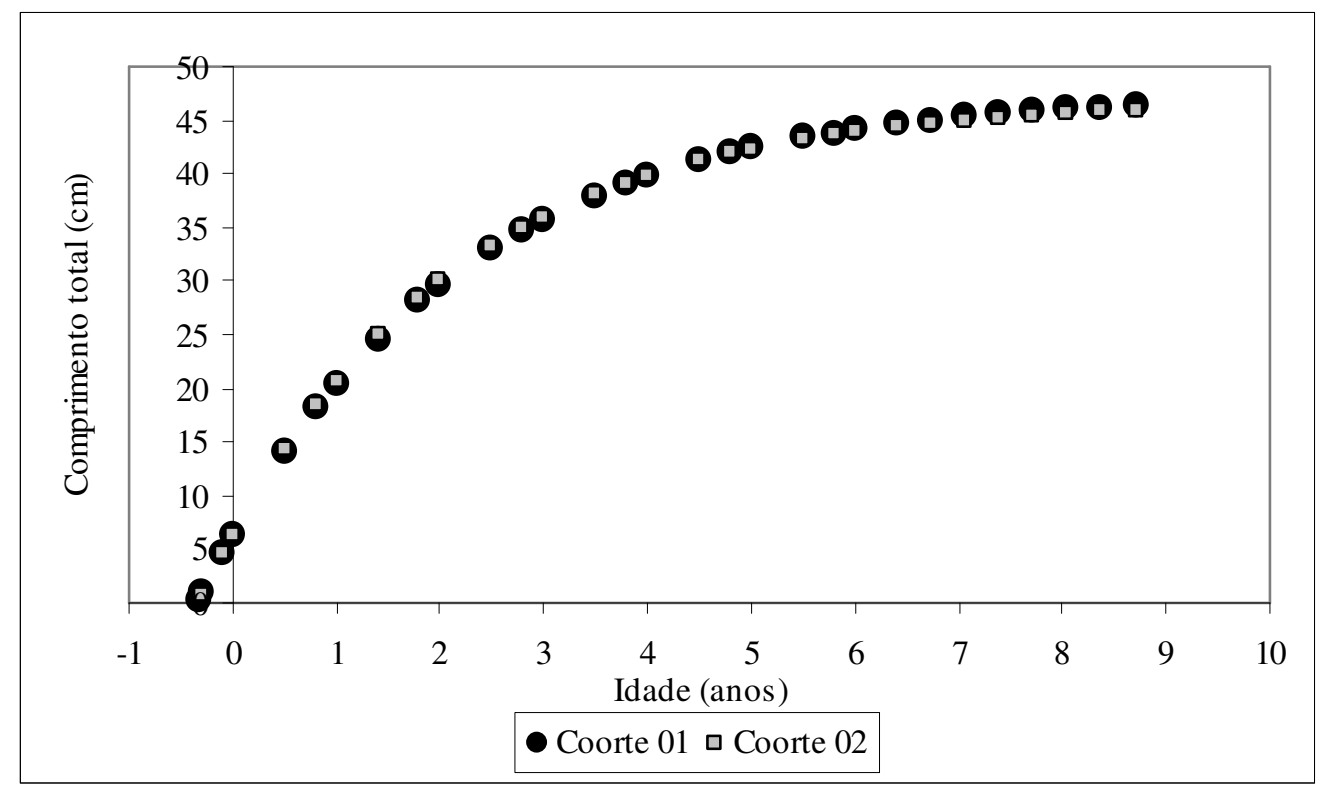

Figura 19: Ajuste da equação de crescimento de von Bertalanffy para Macrodon ancylodon na costa Norte do Brasil a partir dos dados estimados pelo método indireto para sexos grupados. Coorte 01 - junho e coorte 02 - dezembro. 


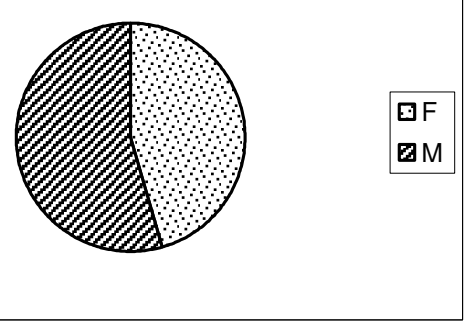

Figura 20: Proporção sexual de M. ancylodon da costa Norte do Brasil no período de 1998 a 1999.

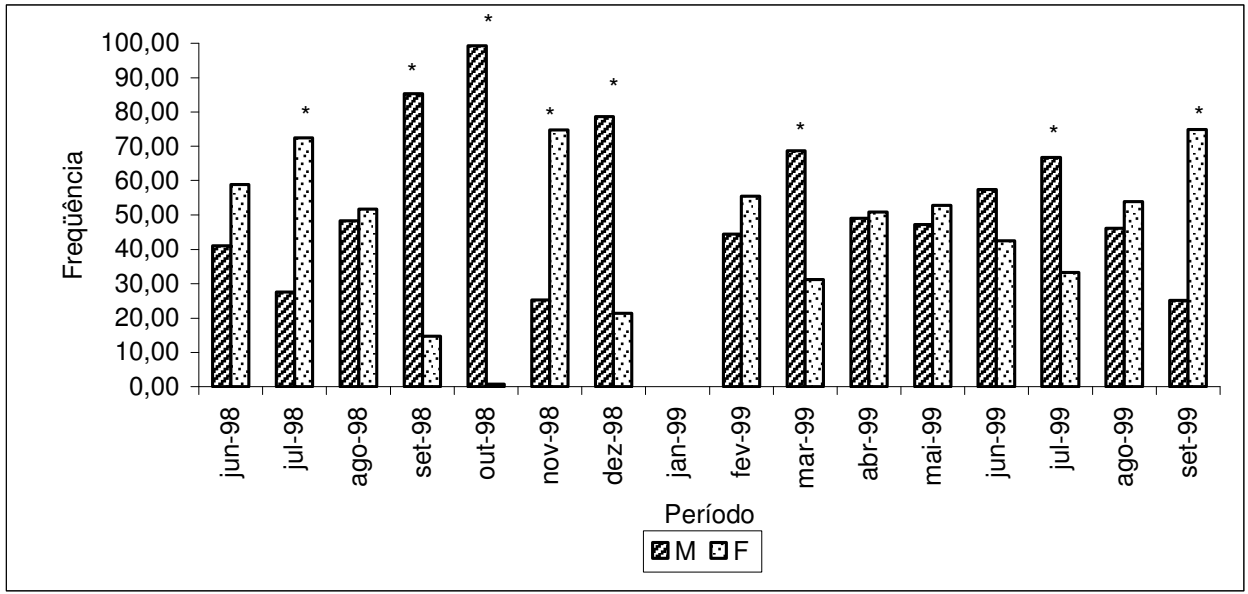

Figura 21: Proporção sexual mensal de $M$. ancylodon da costa Norte do Brasil para o período de 1998 a 1999. * significamente diferente ao nível de 5\%.

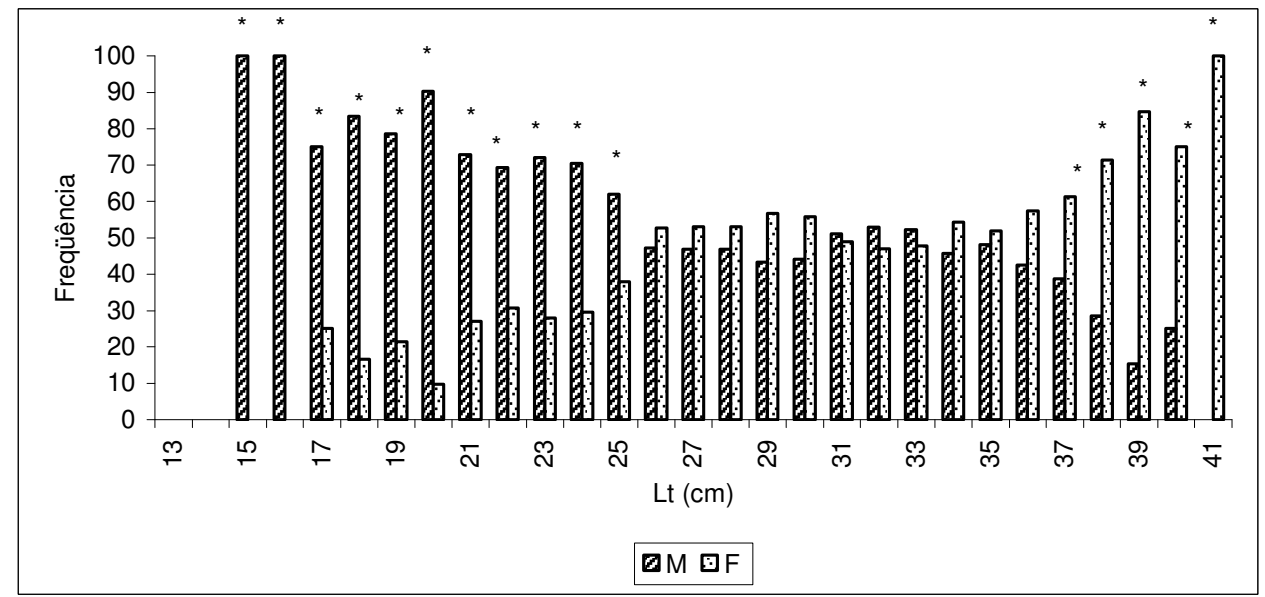

Figura 22: Proporção sexual de M. ancylodon da costa Norte do Brasil por classe de comprimento para o período de 1998-1999. * significamente diferente ao nível de 5\%. 


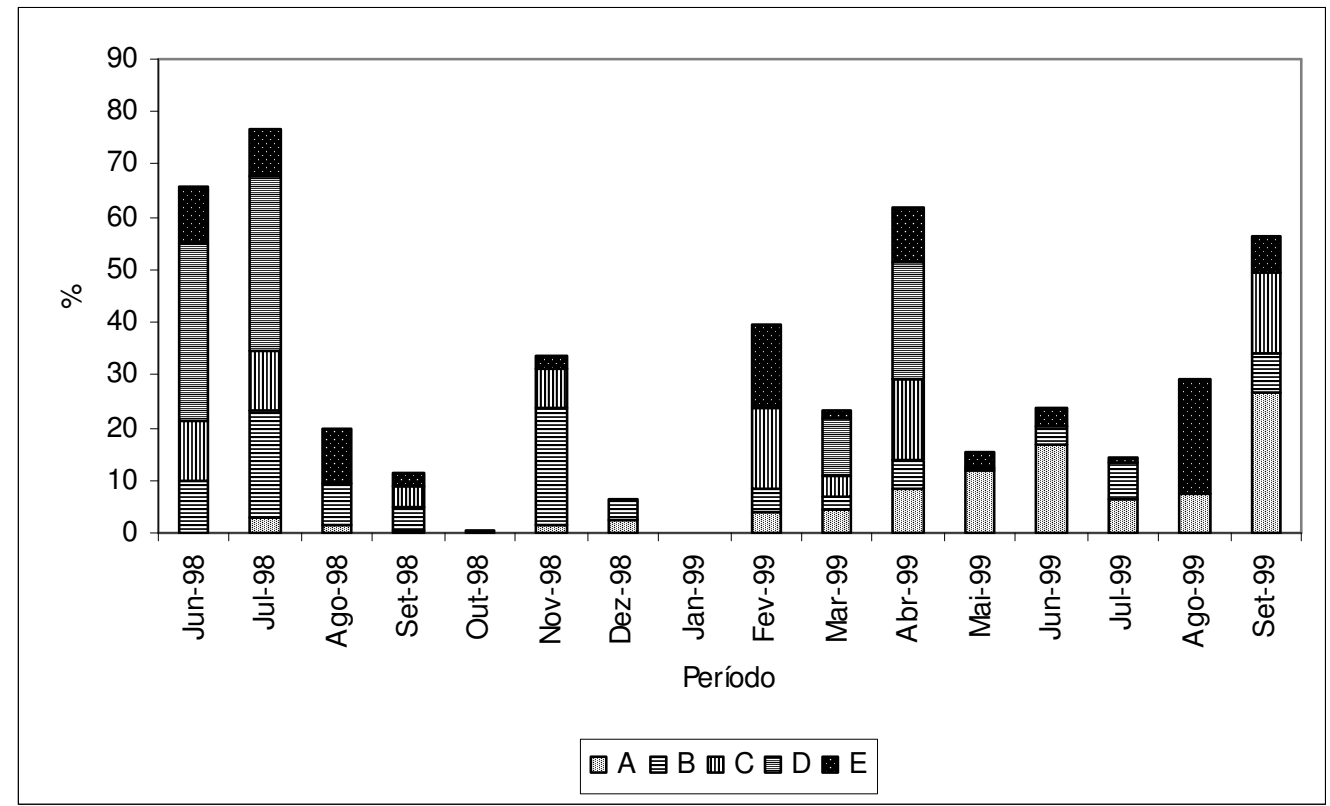

Figura 23: Freqüência de ocorrência dos estádios de maturidade para fêmeas de $M$. ancylodon da costa Norte do Brasil, para o período de 1998 a 1999.

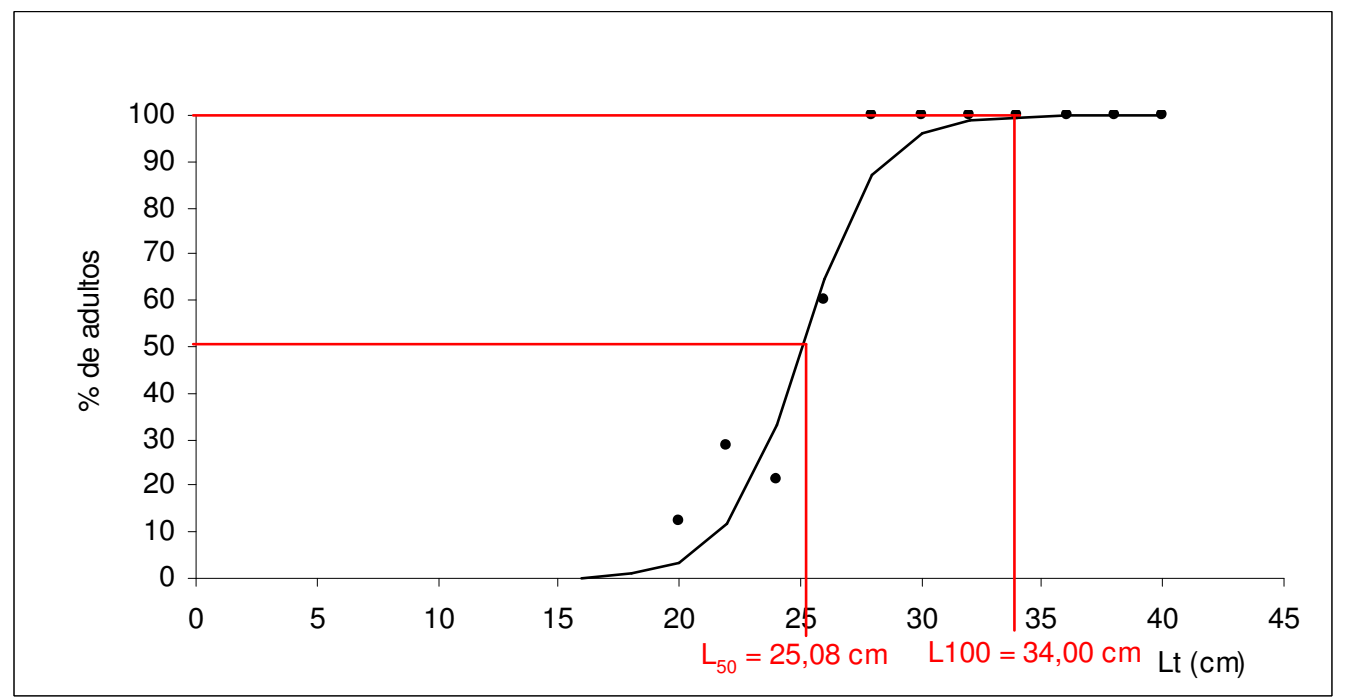

Figura 24: Distribuição da frequiência relativa de fêmeas adultas da espécie Macrodon ancylodon da costa Norte do Brasil segundo comprimento total. A curva sigmóide representa o ajuste do modelo logístico para estimativa de $\mathrm{L}_{50}$ e $\mathrm{L}_{100}$. 


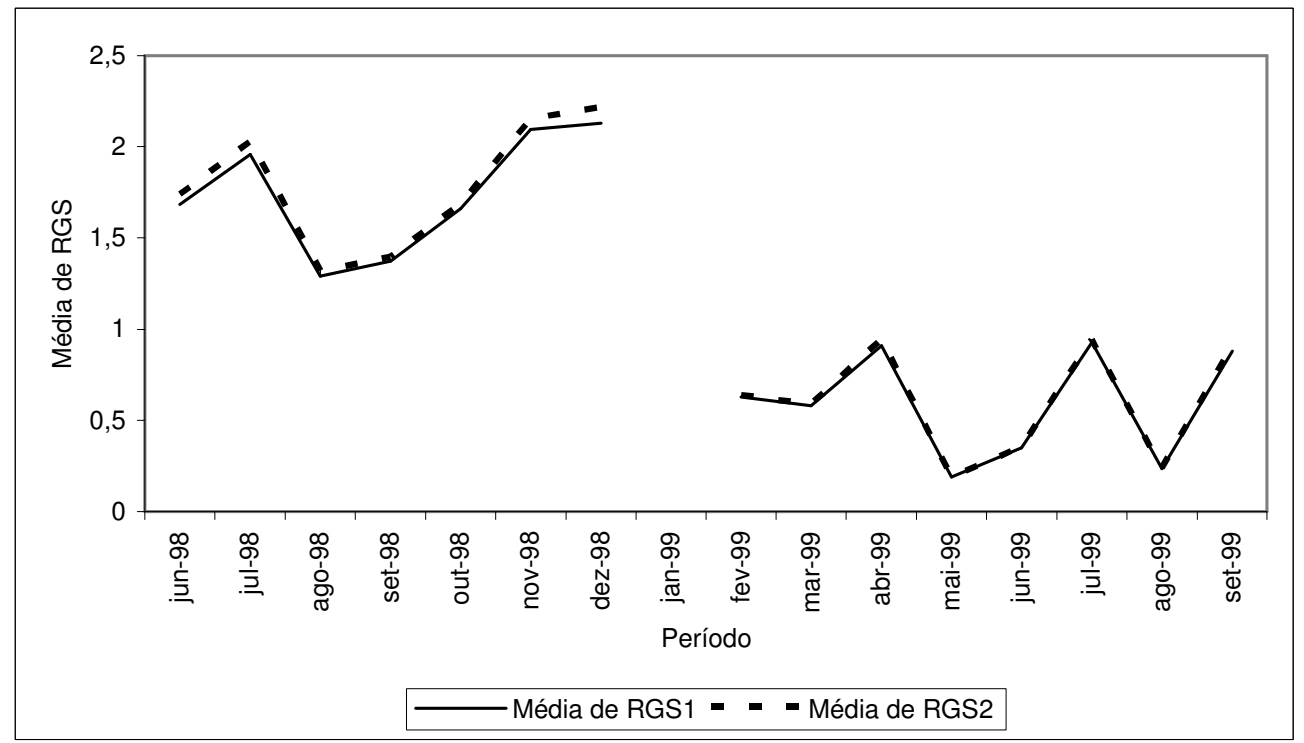

Figura 25: Variação temporal da relação gonadossomática das fêmeas de Macrodon ancylodon da costa Norte do Brasil.

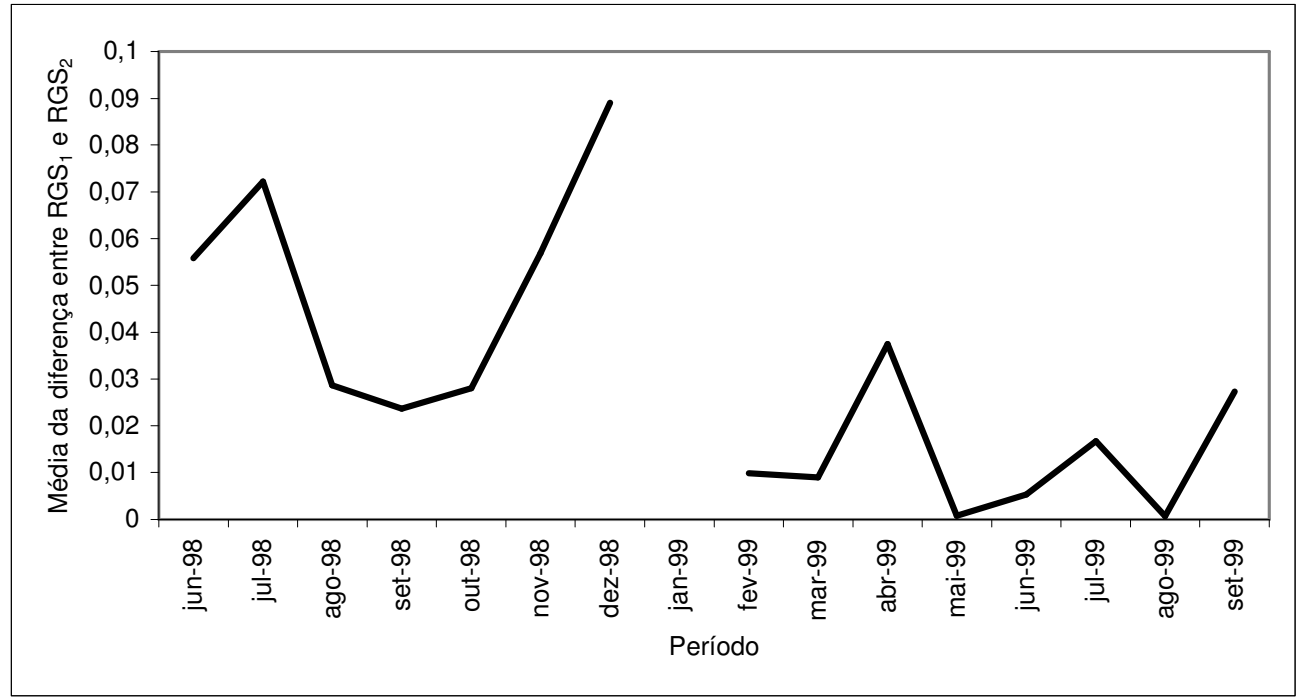

Figura 26: Variação temporal da diferença entre as relações gonadossomáticas RGS1 e $\mathrm{RGS}_{2}$ para fêmeas de Macrodon ancylodon da costa Norte do Brasil. 


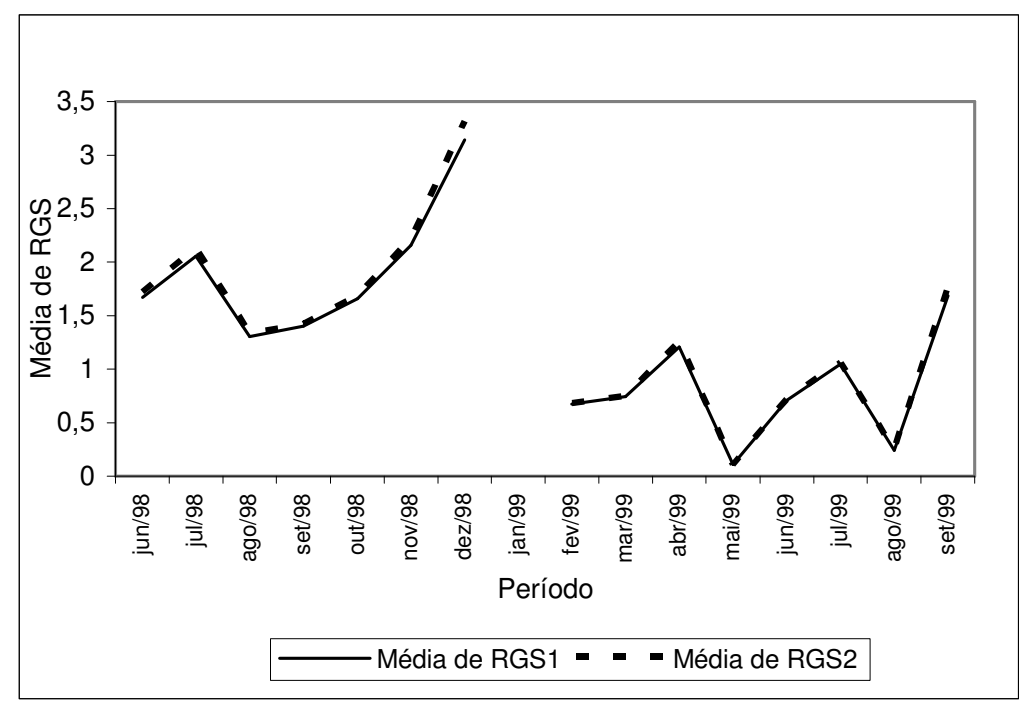

Figura 27: Variação temporal da relação gonadossomática das fêmeas de Macrodon ancylodon da costa Norte do Brasil utilizando os valores dos indivíduos maiores que o comprimento médio de início de primeira maturação gonadal.

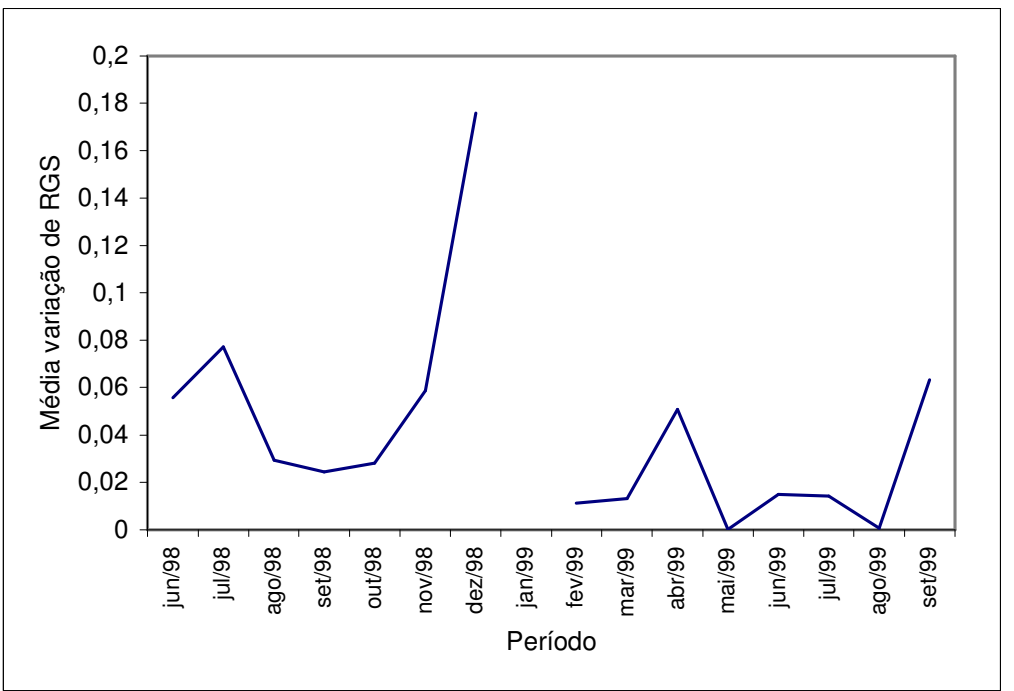

Figura 28: Variação temporal da diferença entre as relação gonadossomática das fêmeas de Macrodon ancylodon da costa Norte do Brasil, utilizando os valores dos indivíduos maiores que o comprimento médio de início de primeira maturação gonadal. 


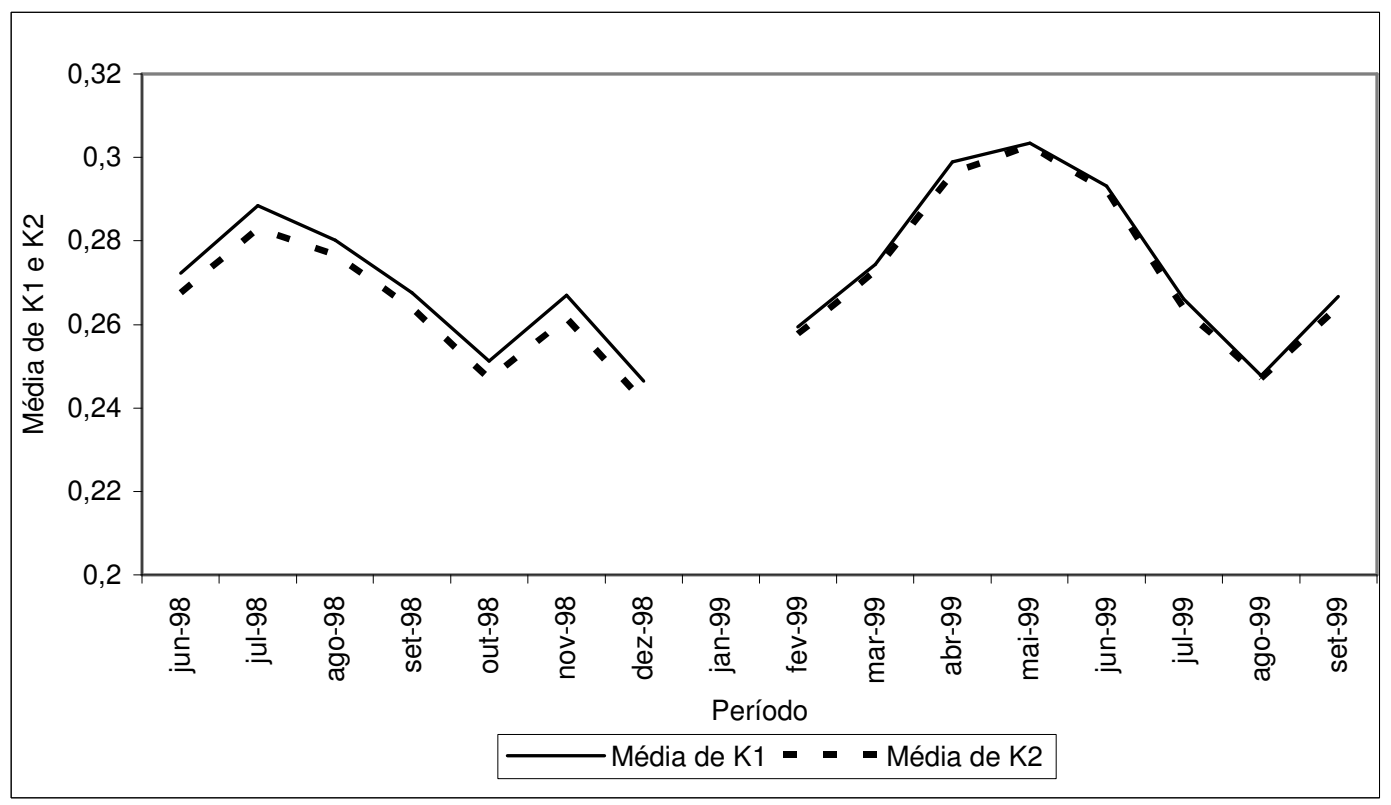

Figura 29: Variação temporal do fator de condição das fêmeas de Macrodon ancylodon da costa Norte do Brasil.

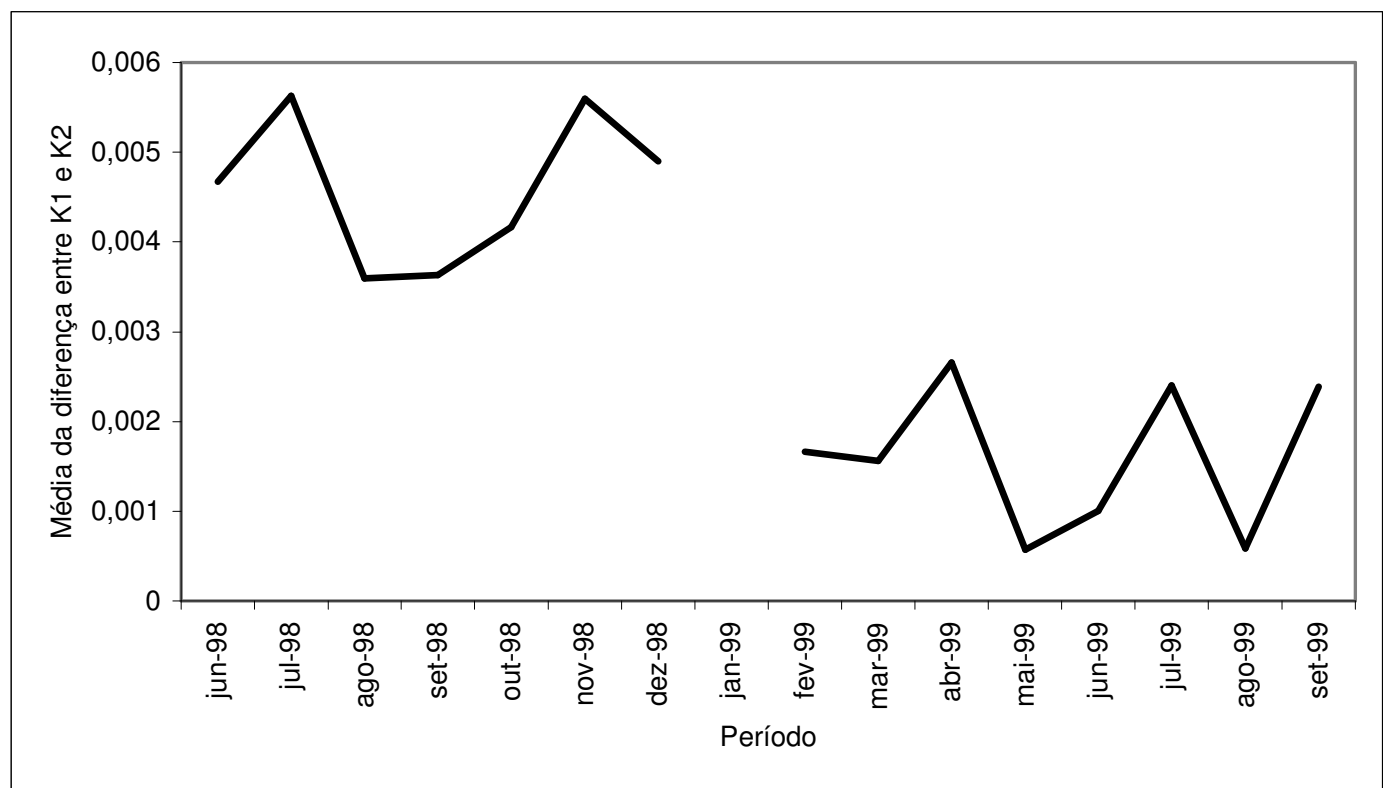

Figura 30: Variação temporal da diferença entre os valores do fator de condição para fêmeas de Macrodon ancylodon da costa Norte do Brasil. 

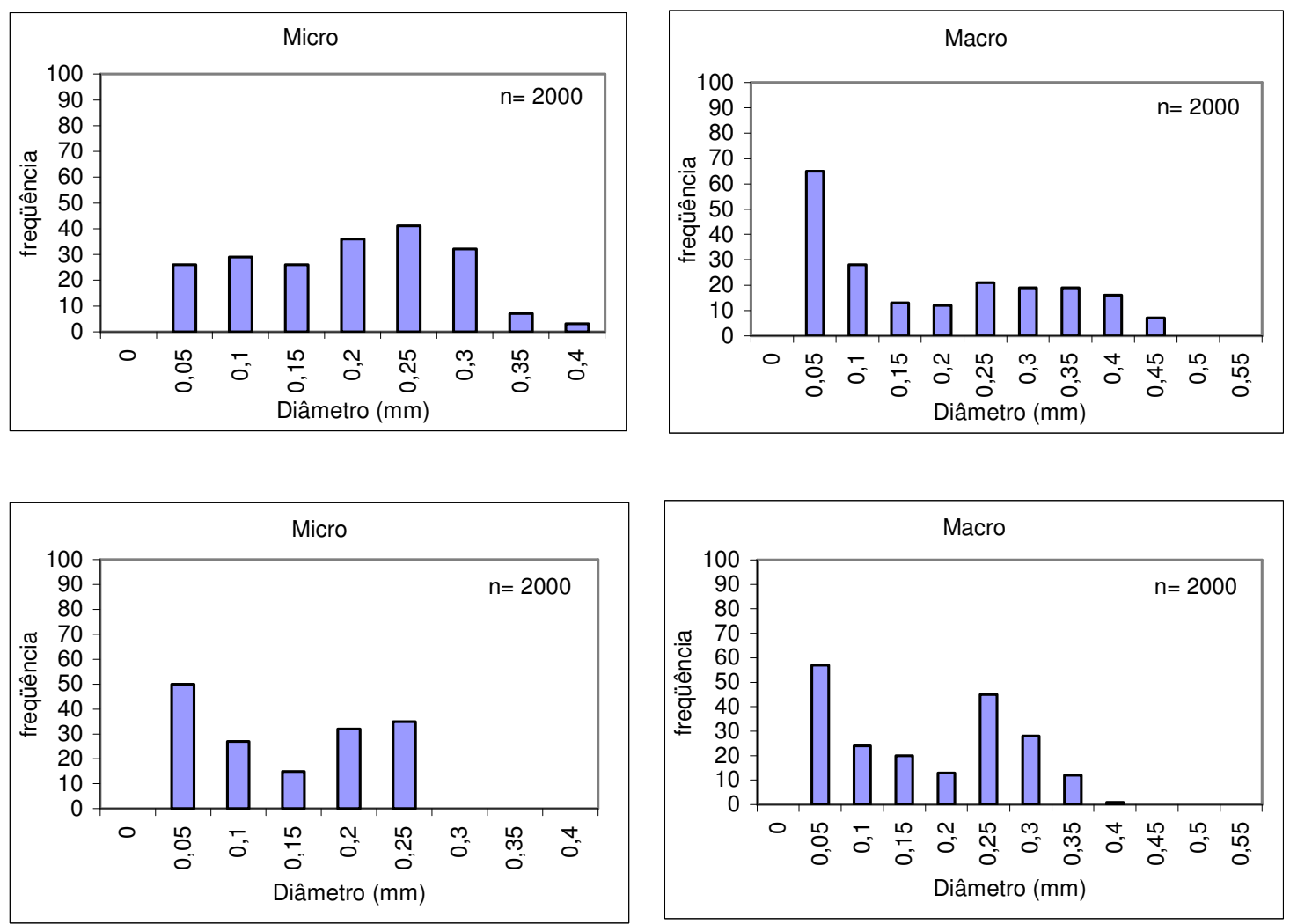

Figura 31: Distribuição do diâmetro dos ovócitos da M. ancylodon da costa Norte do Brasil. tomados a partir da leitura em preparações permanentes sob estereomicroscópio (micro) e de ovócitos dissociados sob estereomicroscópio (macro). 


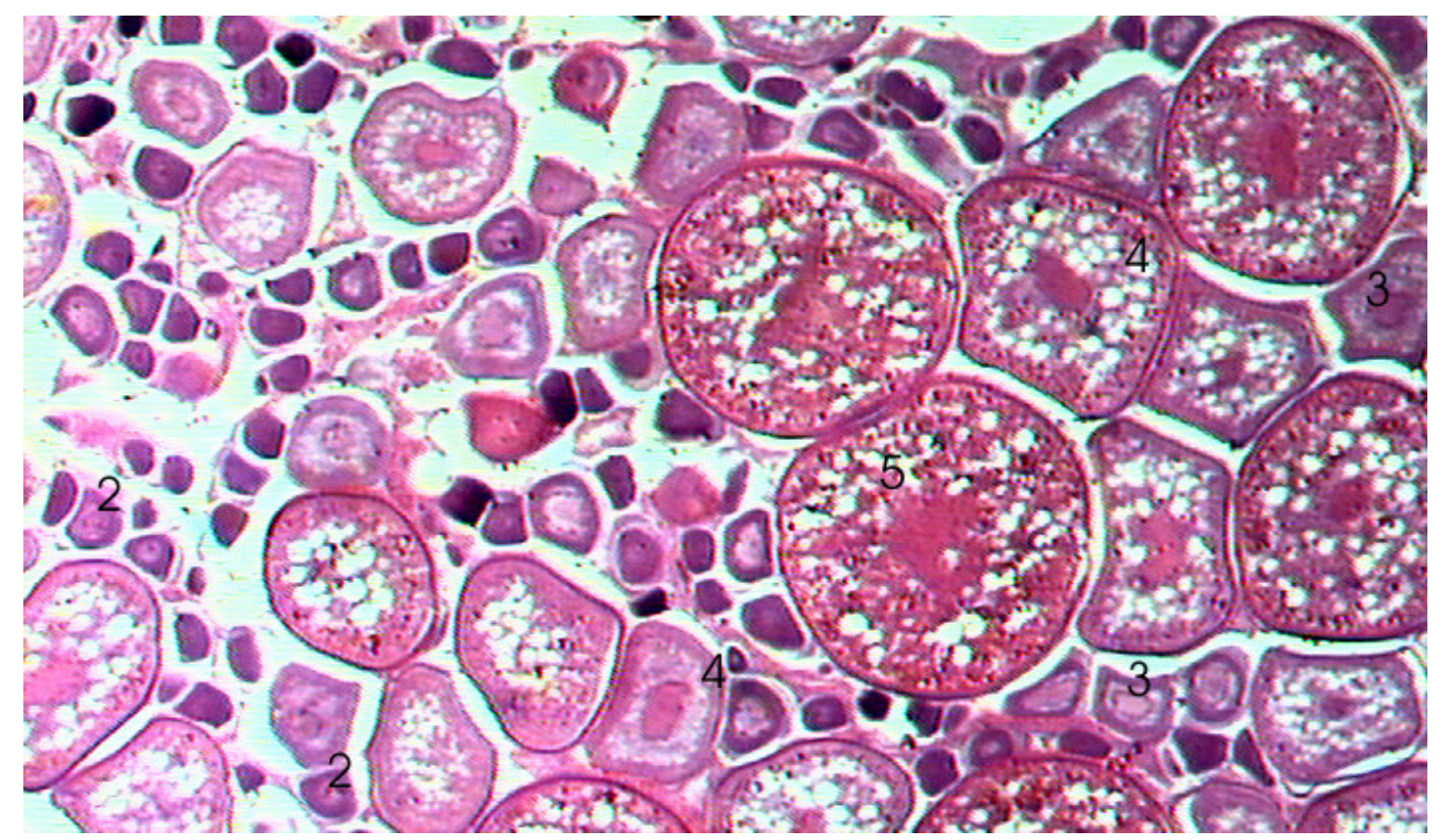

Figura 32: Corte de ovário B1 de Macrodon ancylodon da costa do Brasil, onde se observam ovócitos nas fases 2, 3, 4 e 5, com ausência de folícuolos pós-ovulatórios e folículos atrésicos. Aumento 4x.

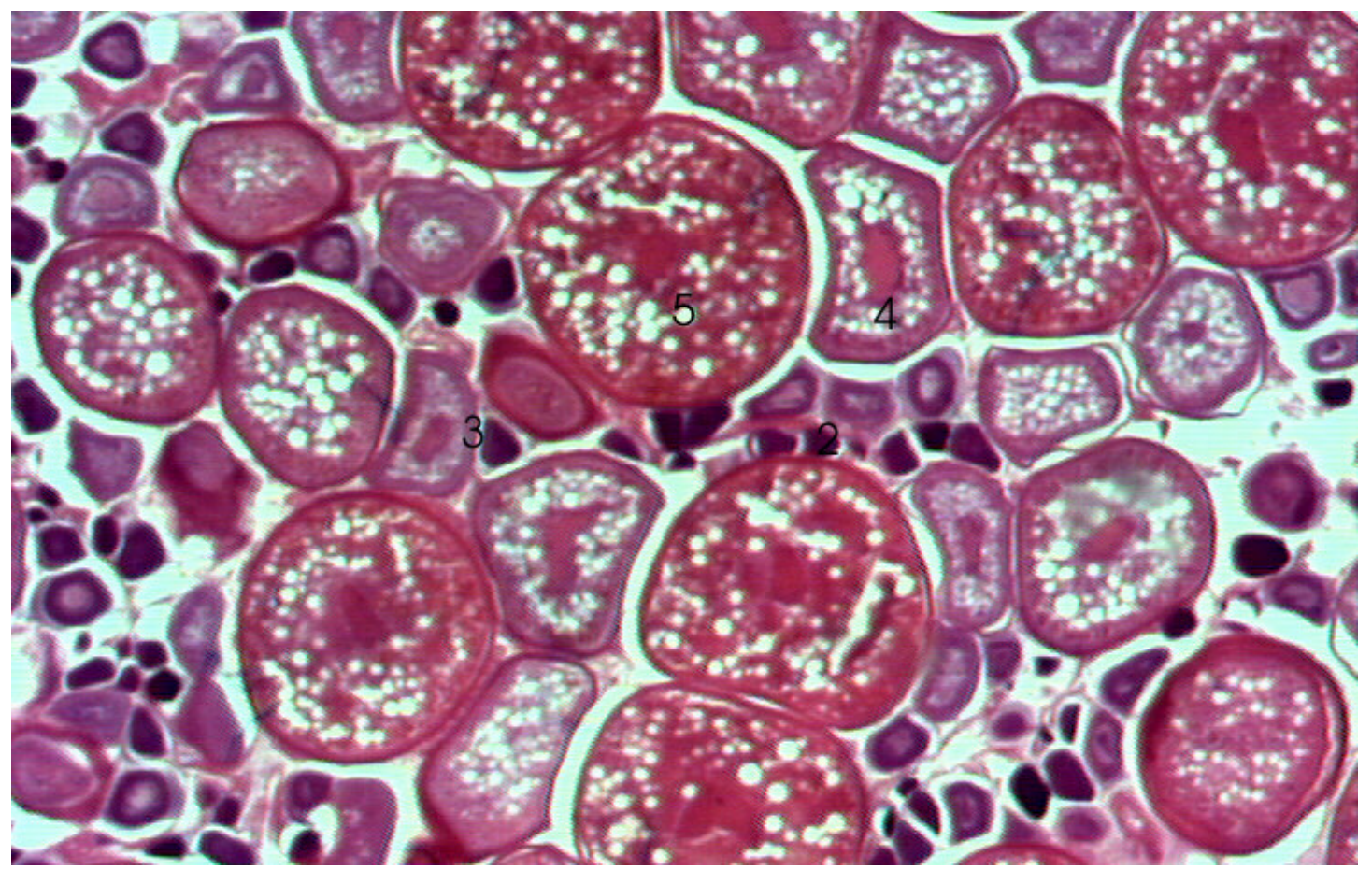

Figura 33: Corte de ovário B1 de Macrodon ancylodon da costa do Brasil, onde se observam ovócitos nas fases 2, 3, 4 e 5, com ausência de folícuolos pós-ovulatórios e folículos atrésicos. Aumento 4x. 
111

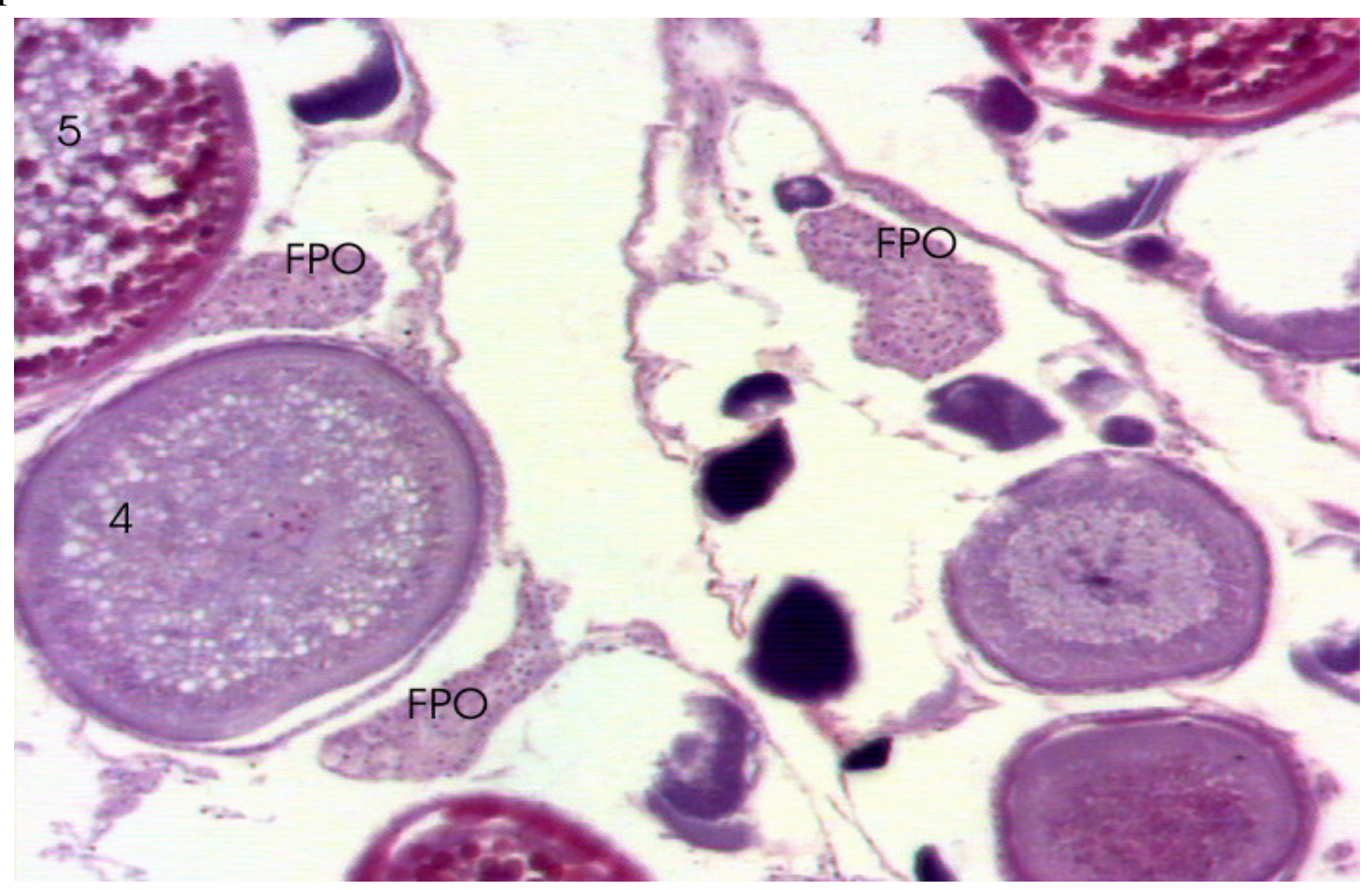

Figura 34: Corte de ovário $\mathrm{B}_{\mathrm{n}}$ de Macrodon ancylodon da costa Norte do Brasil, onde se observam folículos pós-ovulatórios e folículo atrésico. Aumento 10x.

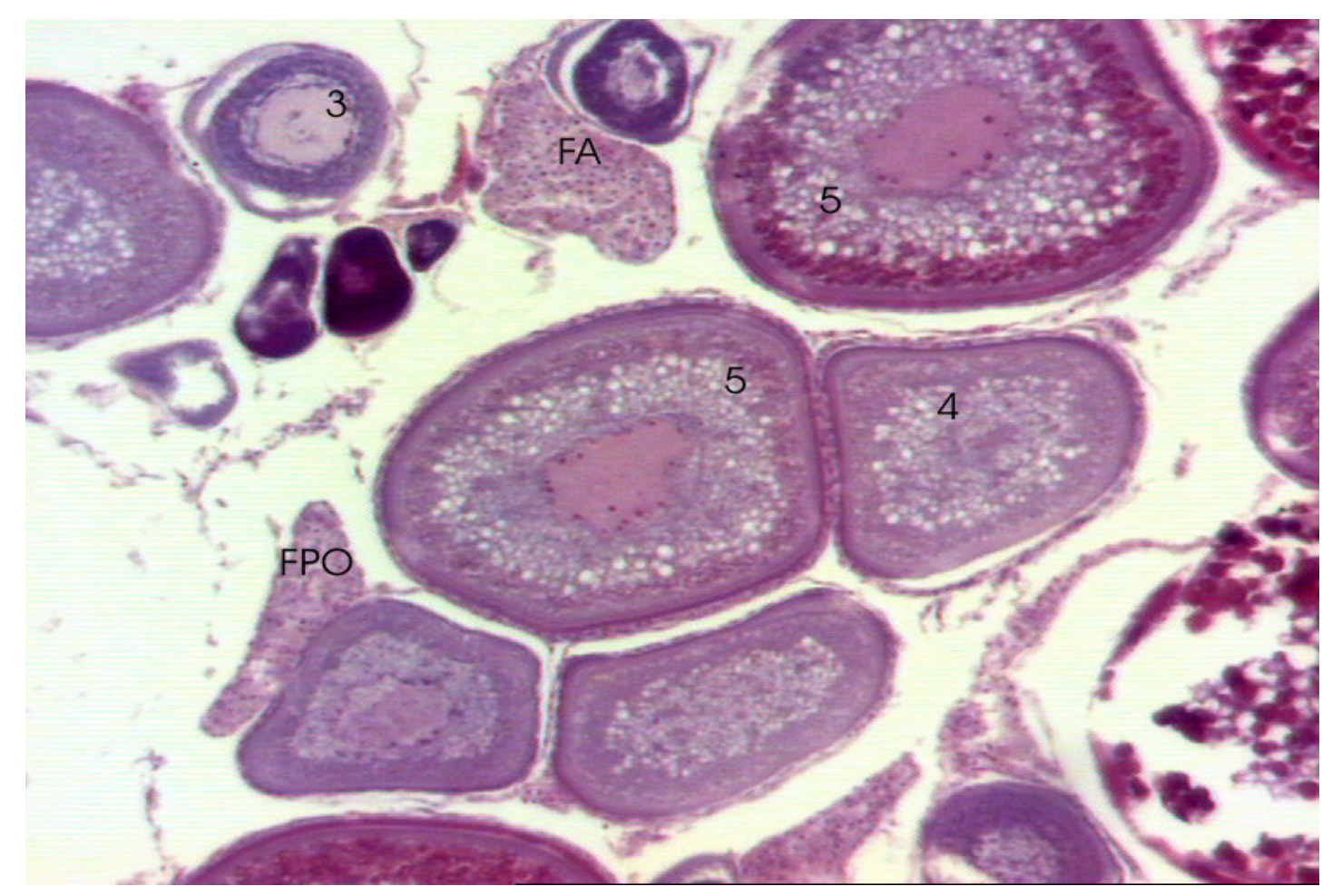

Figura 35: Corte de ovário $\mathrm{B}_{\mathrm{n}}$ de Macrodon ancylodon da costa Norte do Brasil, onde se observam folículos pós-ovulatórios e folículo atrésico. Aumento 10x. 


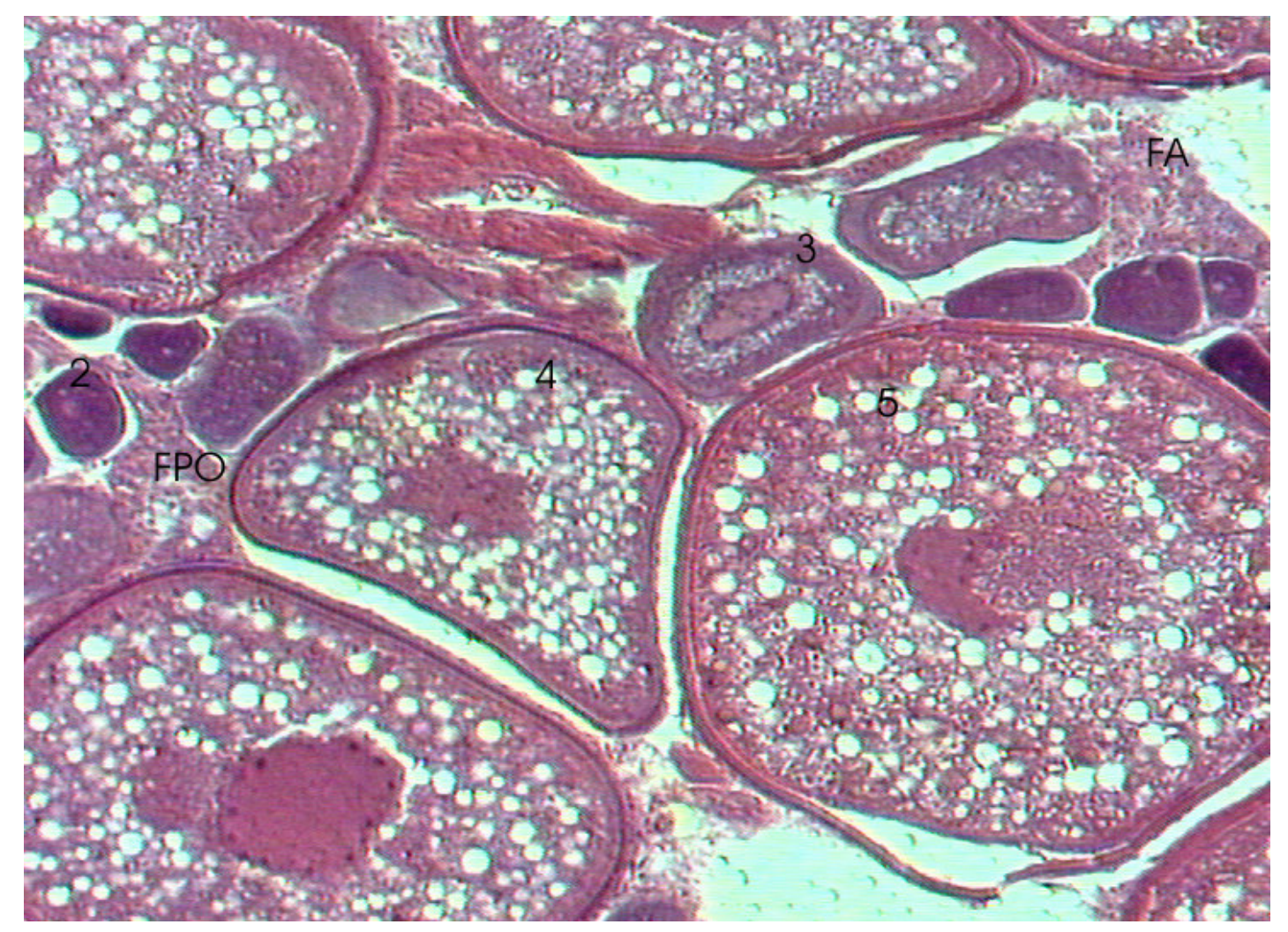

Figura 36: Corte de ovário $\mathrm{B}_{\mathrm{n}}$ de Macrodon ancylodon da costa Norte do Brasil, onde se observam folículos pós-ovulatórios e folículo atrésico. Aumento 10x. 